Natália Pillar da Silva

Extremos de Vento Sobre o Oeste do Oceano Atlântico Sul: Análise Direcional das Ocorrências 
Natália Pillar da Silva

\title{
Extremos de Vento Sobre o Oeste do Oceano Atlântico Sul: Análise Direcional das Ocorrências
}

\author{
Orientador: \\ Prof. Dr. Ricardo de Camargo \\ Universidade De São PaUlo \\ Instituto de Astronomia, Geofísica e CiênCias Atmosféricas \\ "VERSÃo CORRIGIDA. O ORIGINAL ENCONTRA-SE DISPONÍVEL NA UNIDADE."
}

São Paulo 


\section{AGRADECIMENTOS}

Meus sinceros agradecimentos a todos que contribuíram para o desenvolvimento desse trabalho: A minha família, especialmente minha mãe, Marília. Muito obrigada. Principalmente pela paciência!

Ao meu orientador Dr. Ricardo de Camargo, por toda a orientação acadêmica e pessoal, pelo apoio e por manter sempre a minha motivação elevada para o desenvolvimento do trabalho.

A todos os professores e funcionários do Departamento de Ciências Atmosféricas pelo suporte e grande contribuição.

Aos meu nobres colegas (feras) pela amizade, carinho, parceria e risadas durante esses anos de mestrado.

A CAPES pelo auxílio financeiro nos meses de desenvolvimento.

E a todos que, de uma forma ou de outra, às vezes mesmo sem saber me ajudaram a alcançar esse objetivo. 


\section{Sumário}

$\begin{array}{ll}\text { Lista de Figuras } & \text { p. } 5\end{array}$

$\begin{array}{ll}\text { Lista de Tabelas } & \text { p. } 7\end{array}$

$\begin{array}{ll}\text { Resumo } & \text { p. } 8\end{array}$

$\begin{array}{ll}\text { Abstract } & \text { p. } 9\end{array}$

1 Introdução $\quad$ p. 10

1.1 Análise de Extremos . . . . . . . . . . . . . . . . . p. 12

1.2 Revisão Bibliográfica - Aplicações em Meteorologia e Oceanografia . . . . . p. 14

1.3 Caracterização Meteorológica da Área de Estudo . . . . . . . . . . . . . . p. 18

2 Material e Métodos $\quad$ p. 22

2.1 Conjuntos de Dados . . . . . . . . . . . . . . . . . . . p. 22

2.1.1 Dados de Reanálise NCEP/NCAR I . . . . . . . . . . . . . . p. 22

2.1.2 Simulação com o Modelo BRAMS . . . . . . . . . . . p. 23

2.2 Método Peaks Over Threshold - POT ～. . . . . . . . . . . . . . . . . . p. 27

2.2.1 Descrição Geral e Critérios de Independência . . . . . . . . . . . p. 27

2.2 .2 Teoria Básica . . . . . . . . . . . . . . . p. 28

2.2.3 Determinação do Limiar . . . . . . . . . . . . . . . . . p. 30

2.2.4 Cálculo dos Valores Extremos de Retorno . . . . . . . . . . . p. 31

2.2.5 Critério de Estabilidade . . . . . . . . . . . . . p. 33

2.2.6 Separação Direcional das Séries . . . . . . . . . . . . p. 33

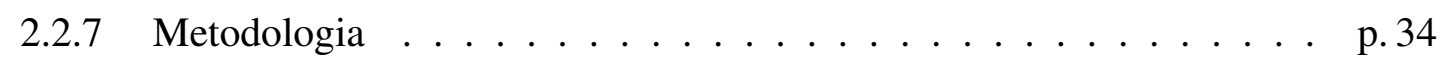

3 Resultados e Discussão $\quad$ p. 35

3.1 Limiares . . . . . . . . . . . . . . . . . . p. 35

3.2 Região Tropical . . . . . . . . . . . . . . . . . . p. 36

3.3 Região Sudeste/Sul . . . . . . . . . . . . . . . . . . p. . . . . . . . .

3.4 Comparação Qualitativa com Análise Feita a Partir de Dados Coletados . . . p. 64 
4 Conclusões

p. 66

4.0.1 Sugestões Para Trabalho Futuros . . . . . . . . . . . . . . . . . . . p. 69

Referências Bibliográficas

p. 71 


\section{Lista de Figuras}

1.1 Extremos de retorno para 100 anos, extraído de Caires e Sterl (2005). . . . p. 16

1.2 Extremos de retorno para 100 anos, extraído de Vinoth e Young (2011). . . . p. 17

1.3 Mapa de distribuição anual da frequência de ocorrência de ciclones América do Sul. Extraído de Gan e Rao (1991) . . . . . . . . . . . . . . . . p. 20

1.4 Densidade de ciclogêneses, menos intensos (acima) e mais intensos (abaixo). Extraído de Reboita (2008). . . . . . . . . . . . . . . . . . p. 21

2.1 Grades utilizadas para o downscaling atmosférico. . . . . . . . . . . p. 25

2.2 Exemplo hipotético de uma série de eventos iid. Extraído de Embrechts et al.

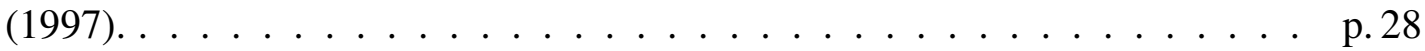

2.3 Formas da função de distribuição de uma GPD, extraído de Embrechts et al. (1997). O eixo x apresenta os valores para o limiar (u) e o eixo y a função de distribuição cumulativa. . . . . . . . . . . . . . . . p. 30

2.4 Esquematização de uma curva para valores extremos de retorno e seus intervalos de confiança . . . . . . . . . . . . . . . p. 33

2.5 Diagrama de representação da separação direcional dos dados de intensidade do vento. . . . . . . . . . . . . . . . . . . . p. 34

3.1 Limiares $u$ (percentil de 95\% das séries completas) calculados para os conjuntos NCEP e BRAMS. . . . . . . . . . . . . . . . p. 36

3.2 Quantidade de eventos acima do limiar $\left(N_{u}\right)$ para ventos de leste. Região Tropical. . . . . . . . . . . . . . . . . . p. 37

3.3 Valores extremos de retorno para ventos de leste. Região Tropical. . . . . . . p. 38

3.4 Quantidade de eventos acima do limiar $\left(N_{u}\right)$ para ventos de nordeste. Região Tropical. . . . . . . . . . . . . . . . . . p. . . . . . . . . .

3.5 Valores extremos de retorno para ventos de nordeste. Região Tropical. . . . . p. p.

3.6 Quantidade de eventos acima do limiar $\left(N_{u}\right)$ para ventos de sudeste. Região Tropical. . . . . . . . . . . . . . . . . . p. 42

3.7 Valores extremos de retorno para ventos de sudeste. Região Tropical. . . . . . p. p. 44

3.8 Quantidade de eventos acima do limiar $\left(N_{u}\right)$ para ventos de norte. Região Sudeste/Sul. . . . . . . . . . . . . . . . . . p. 45

3.9 Valores extremos de retorno para ventos de norte. Região Sudeste/Sul. . . . . p. p. 47 
3.10 Quantidade de eventos acima do limiar $\left(N_{u}\right)$ para ventos de nordeste. Região Sudeste/Sul . . . . . . . . . . . . . . . . . . . . . . p. 48

3.11 Valores extremos de retorno para ventos de nordeste. Região Sudeste/Sul. . . p.50

3.12 Quantidade de eventos acima do limiar $\left(N_{u}\right)$ para ventos de leste. Região Sudeste/Sul. . . . . . . . . . . . . . . . . . p. 51

3.13 Valores extremos de retorno para ventos de leste. Região Sudeste/Sul. . . . . p.52

3.14 Quantidade de eventos acima do limiar $\left(N_{u}\right)$ para ventos de sudeste. Região Sudeste/Sul . . . . . . . . . . . . . . . . . p.53

3.15 Valores extremos de retorno para ventos de sudeste. Região Sudeste/Sul. . . . p.54

3.16 Quantidade de eventos acima do limiar $\left(N_{u}\right)$ para ventos de sul. Região Sudeste/Sul. . . . . . . . . . . . . . . . . . p. 55

3.17 Valores extremos de retorno para ventos de sul. Região Sudeste/Sul. . . . . . p.57

3.18 Quantidade de eventos acima do limiar $\left(N_{u}\right)$ para ventos de sudoeste. Região Sudeste/Sul. . . . . . . . . . . . . . . . . . . . p. 58

3.19 Valores extremos de retorno para ventos de sudoeste. Região Sudeste/Sul. . p.59

3.20 Quantidade de eventos acima do limiar $\left(N_{u}\right)$ para ventos de oeste. Região Sudeste/Sul. . . . . . . . . . . . . . . . . . . p. 60

3.21 Valores extremos de retorno para ventos de oeste. . . . . . . . . . p. 61

3.22 Quantidade de eventos acima do limiar $\left(N_{u}\right)$ para ventos de noroeste. Região Sudeste/Sul. . . . . . . . . . . . . . . . . p. 62

3.23 Valores extremos de retorno para ventos de noroeste. Região Sudeste/Sul. . p.63

4.1 Valores extremos de retorno para 100 anos calculados por Vinoth e Young (2011). Adaptado para foco sobre o Oceano Atlântico Sul. . . . . . . . . . p. 69 


\section{Lista de Tabelas}

2.1 Características dimensionais das grades da simulação utilizada . . . . . . . p. 25

2.2 Critérios de independência utilizados em trabalhos anteriores . . . . . . . . p 28

2.3 Estimadores utilizados em trabalhos anteriores . . . . . . . . . . . p. 29

3.1 Valores extremos para 50 anos de retorno para ventos de diferentes quadrantes na Bacia de Campos/RJ. Valores METOCEAN DATA extraídos de CENPES/PDP/MC-PETROBRAS (2005) e $x_{r}$ máximo aproximado na região da Bacia de Campos para NCEP e BRAMS . . . . . . . . . . p. 64 


\section{Resumo}

Tendo em vista o crescente investimento em atividades economicamente importantes nas zonas costeiras, tal como a produção petrolífera brasileira e o crescimento na atividade portuária e esforço de pesca, a compreensão adequada dos fenômenos oceanográficos e meteorológicos sobre tais zonas é de grande valia para as operações desses setores.

Os ventos representam um importante parâmetro para análise nesse sentido, sendo a principal fonte de energia para a geração de ondas de gravidade nos oceanos, e determinantes na caracterização de condições severas tempo. Uma série de estudos foram desenvolvidos nos últimos anos envolvendo a análise do comportamento dos extremos de ondas sobre a região do Oceano Atlântico Sul, de acordo com o crescimento da demanda por tais informações pelo setor industrial. No entanto, há poucos registros de estudos que caracterizem os extremos de intensidade de vento sobre essa região. E, em nenhum desses trabalhos, a separação direcional do vento extremo e seus fenômenos causadores foram levados em consideração.

Dessa forma, o presente trabalho visa atender diretamente a necessidade por trabalhos nesse sentido para a região do Oceano Atlântico Sul, buscando oferecer uma análise dos campos de ventos extremos direcionalmente segregados, através de dados do projeto de reanálise NCEP/NCAR Reanalysis I e de resultados de uma simulação numérica com o modelo BRAMS.

A tais conjuntos de dados foi aplicada a metodologia de análise de extremos Peaks Over Threshold (POT), que trata do ajuste dos excessos acima de um limiar estabelecido a uma distribuição conhecida, a Distribuição Generalizada de Pareto ( Generalized Pareto Distribution GPD). E, a partir disso, construir mapas com os valores extremos de retorno para longos períodos. Tais parâmetros são muito importantes na predição de eventos extremos e no refinamento de simulações de longo período.

Os extremos relacionados aos fenômenos em larga escala, dados pelos campos do NCEP, em conjunto com o maior detalhamento em mesoescala, dado pelo BRAMS, refletiram diretamente no comportamento dos valores extremos de retorno. Para todas as direções do vento analisadas, observaram-se feições mais refinadas dos extremos de retorno para os resultados com a simulação do BRAMS, principalmente nas zonas costeiras. Essas feições, principalmente àquelas ao sul e sudeste do Oceano Atlântico Sul, tiveram seus valores potencializados em zonas já conhecidas na bibliografia pela grande incidência de eventos altamente energéticos. 


\section{Abstract}

Given the growing investment in important economic activities in coastal areas, such as oil and gas exploitation, harbor activities and increasing fishing effort, the proper understanding of oceanographic and meteorological phenomena over such areas has great value to the operations of such sectors.

The winds are an important parameter for analysis in this context, being the main source of energy for gravity waves generation in the ocean, and determining the characterization of severe weather conditions. A number of studies have been developed in recent years involving the behavior of extreme waves over the South Atlantic Ocean region, given the growing demand for such information by industrial sectors. However, there are few records of studies that characterize the extremes of wind speed fields over this region. And, in none of these works, the direction of the extreme wind and meteorological phenomenon associated were considered.

Thus, this paper aims to address directly the need for work in this context for the South Atlantic Ocean region, seeking to offer an analysis of extreme wind fields directionally separated, through data from the NCEP/NCAR Reanalysis 1 and results from a numerical simulation with BRAMS.

The Peaks Over Threshold (POT), which deals with the adjustment of the excesses above a threshold to the Generalized Pareto Distribution (GPD), was applied to both datasets. And from that, maps with the extreme return values have been developed for long return periods. These parameters are very important in predicting extreme events and refinement of long-period simulations.

Extreme winds related to the large scale phenomena, represented by NCEP fields, in conjunction with the greater mesoscale detail, given by the BRAMS simulation, directly reflected in the behavior of extreme return values. For all wind directions analyzed, there were more refined features of the extremes return levels given by the BRAMS simulation, especially in coastal areas. These features, notably those in the south and southeast of the South Atlantic Ocean, values were strengthened in areas already known in the literature for the high incidence of energetic events. 


\section{$1 \quad$ Introdução}

Além de contar com uma grande ocupação humana, a ampla zona costeira e domínio marítimo do Brasil agregam intensas atividades em diversos setores economicamente importantes que prosperam através da exploração de seus múltiplos recursos. Pode-se enumerar práticas ligadas à indústria portuária, pesqueira, turismo e transporte de passageiros, cultivo de animais marinhos para fins comerciais, etc. E, mais recentemente, vem crescendo o investimento na construção de fazendas eólicas e plataformas para exploração de petróleo e gás nas zonas costeiras e mar aberto. Tais setores industriais, particularmente, investem massivamente na pesquisa das condições meteorológicas e oceanográficas das zonas em que se encontram, uma vez que suas estruturas estão sujeitas às condições severas de tempo e ao intenso regime de ondas gerado em situações de alta energia. Condições com ventos de alta intensidade, principais geradores de grandes ondulações, podem acarretar em danos consideráveis, consequentemente, grandes prejuízos econômicos. Sendo assim, a devida caracterização e qualidade na previsão de eventos extremos são imprescindíveis na manutenção das atividades dessas indústrias e vem crescendo o investimento em pesquisas associadas à caracterização de eventos extremos na região costeira do Brasil.

Uma série de trabalhos vem abordando o estudo de eventos altamente energéticos na zona costeira do Brasil através do cálculo de valores extremos de retorno para longos períodos, tais como Silva (2008), Campos (2009) e Oliveira et al. (2010). Muitos deles tratam do cálculo desses valores para altura de ondas em zonas favoráveis a implementação de plataformas para exploração de petróleo e gás natural. Além disso, alguns trabalhos tratam do estudo dos extremos de séries individuais de intensidade do vento na região sudeste sul do Oceano Atlântico Sul. Nenhum desses trabalhos, no entanto, trata da aplicação de métodos específicos para a obtenção de um 
mapeamento espacial detalhado da distribuição de extremos de retorno de intensidade do vento a região oceânica do Atlântico Sul. Além disso, todas as abordagens consideram apenas a intensidade do vento sem nenhuma distinção direcional, o que dificulta a identificação do mecanismo meteorológico envolvido na geração desse evento extremo. Moriarty e Templeton (1983) sugerem que a separação direcional de dados de intensidade do vento para a aplicação dos métodos pode oferecer resultados de grande valia para o aprimoramento de estruturas localizadas nas zonas costeiras. Os autores também ressaltam os cuidados no processo de distinção direcional para a aplicação de métodos estatísticos, apontando que a falta de critério na separação desses extremos pode superestimar os resultados da análise, tendo em vista que mais de um valor extremo pode estar associado ao mesmo fenômeno meteorológico geradore. Tal situação pode ser satisfeita através de adoção de rigorosos critérios para a garantia de independência entre eventos extremos escolhidos para a análise que levem em conta os diferentes quadrantes.

Tendo em vista a necessidade por estudos detalhando-se tais condições nas zonas costeiras e oceânicas da porção oeste do Oceano Atlântico Sul, o presente tem por objetivo principal oferecer uma análise de extremos da intensidade do vento sobre o oeste do Oceano Atlântico Sul, levando-se em conta seus diferentes quadrantes, através da aplicação de uma metodologia estatística de estudo de extremos, a Peaks Over Threshold, em séries de intensidade do vento do projeto de reanálise $N C E P / N C A R$ Reanalysis 1 e em resultados de uma simulação numérica com o modelo BRAMS, cujas condições iniciais e de fronteira foram dadas pela reanálise 1 do NCEP. Mais especificamente, esse trabalho busca:

- Oferecer uma distribuição espacial dos valores extremos de intensidade do vento direcionalmente segregados nas zonas costeiras e oceânicas do Atlântico Sul em sua porção oeste;

- Mapear os valores extremos para diferentes períodos de retorno, levando-se em conta sua distinção direcional;

- Buscar o vínculo entre o fenômeno gerador de ventos extremos com seu valor extremo de retorno direcionalmente segregado;

- Analisar o impacto do aumento na resolução oferecido pela simulação do BRAMS na 
representação dos eventos extremos com relação à reanálise do NCEP.

Nas seções seguintes, será apresentada uma revisão bibliográfica de trabalhos anteriores referentes a descrição técnica e aplicações da metodologia a ser aplicada no presente trabalho. E, no capítulo seguinte, serão tratados maiores detalhes acerca dos conjuntos de dados utilizados e da aplicação do método sobre os mesmos.

\subsection{Análise de Extremos}

A principal área da probabilidade que lida com o estudo do comportamento de extremos é a Teoria dos Valores Extremos (TVE). Ramo desenvolvido pelos esforços de Fisher e Tippett (1928), cujo trabalho demonstrou que dada uma população de dados com uma distribuição comum, os máximos (ou mínimos) de amostras retiradas dessa população possuem três formas distintas de uma família de distribuições, denominada Generalized Extreme Value Distribution (GEV). Gumbel (1958), a partir de séries temporais de vazão, ajustou o máximo de amostras anuais a distribuição Fisher-Tippet (uma das formas de GEV), para descrever seus extremos. Tais trabalhos constituíram a base da TVE clássica (PALUTIKOF et al., 1999; MENDES, 2004).

Focar a análise nas caudas das séries e em suas distribuições foi determinante para o desenvolvimento de diversas técnicas para avaliar o comportamento inerente dos extremos em séries temporais. E ajustar tais valores extremos à distribuições conhecidas é de grande valia para fins de extrapolação e estimação de valores extremos futuros.

Palutikof et al. (1999) ofereceram uma detalhada revisão dos principais métodos de análise das distribuições de extremos em séries de intensidade do vento. Em seu trabalho, enumeram critérios para a utilização de cada um dos principais deles. São eles:

\section{Método das Máximas Anuais}

Descrito em Gumbel (1958), trata do ajuste dos valores máximos anuais a uma das formas da GEV. Possui como principal desvantagem a necessidade de séries temporais longas (Palutikof et al. (1999) sugerem, no mínimo, 20 anos de dados) para aplicação do método de maneira 
consistente. No entanto, como sua abordagem matemática é mais simples, pois não conta com muitos parâmetros a serem determinados pelo usuário, seu cálculo é mais rápido.

\section{Método das Tempestades Independentes}

Tal método, denominado Method of Independent Storms (MIS), desenvolvido por Cook (1982), trata da separação de eventos altamente energéticos das séries originais através de processos de filtragem. Depois disso, os valores máximos de cada tempestade são utilizados para o ajuste a uma das formas da GEV. Através disso, garante-se um maior número de dados disponíveis para análise a partir de séries temporais mais curtas. Porém, o processo de filtragem para a seleção dos eventos pode excluir valores elevados do parâmetro analisado que poderiam contar como um extremo. Além disso, seu cálculo exige maior interatividade com o usuário, responsável pela configuração dos parâmetros do filtro a ser utilizado. Isso confere a técnica, maior complexidade no cálculo.

\section{Método dos Picos Acima do Limiar}

Essa técnica, denominada Peaks Over Threshold (POT), foi desenvolvida recentemente para problemas de estimação de risco na área de hidrologia. Seu desenvolvimento ganhou grande aceitação com os trabalhos de Simiu e Heckert (1996), Abild et al. (1992), Hosking e Wallis (1987), que apresentaram uma nova distribuição, denominada Generalized Pareto Distribution (GPD), como ajustável aos excessos de picos independentes acima de um dado limiar em uma série temporal. Com isso, uma quantidade maior de extremos pode ser utilizada para a análise dada uma série temporal mais curta. No entanto, a metodologia exige, além do cálculo dos parâmetros necessários para o ajuste, a escolha de um limiar adequado. Sendo assim, é exigida uma maior participação e cautela do usuário no decorrer dos cálculos, uma vez que a escolha de um limiar inadequado pode comprometer o ajuste dos excessos a GPD e, consequentemente, invalidar a extrapolação posterior para a obtenção de valores extremos de retorno.

Esse último foi o método escolhido para aplicação no presente trabalho e será detalhado mais adiante. 


\subsection{Revisão Bibliográfica - Aplicações em Meteorologia e Oce- anografia}

A análise de extremos na área de oceanografia e meteorologia vem sendo utilizada frequentemente para um maior detalhamento do comportamento de eventos altamente energéticos e suas consequências nas condições de vento e ondas. A aplicação do método POT em pesquisas na área vem crescendo, particularmente, devido à escassez de dados sobre os oceanos e zonas costeiras.

São vários os trabalhos que tratam da descrição técnica da metodologia POT. Dentre eles, destacam-se os esforços de Embrechts et al. (1997), Leadbetter (1991), Mendes (2004).

\section{Estudos em Extremos de Ondas}

Essa técnica foi aplicada por Ferreira e Soares (1998) em dados de altura de onda na vizinhança de Figueira da Foz, Portugal. Seus resultados indicaram séries com exponencialidade intrínseca (dado que uma das formas da GPD é exponencial) aos seus extremos. Tal resultado é bastante importante, tendo em vista que o conhecimento do comportamento de um grupo de extremos pode servir de avaliador da representação dos mesmos por simulações numéricas na mesma região. Dois anos depois, Ferreira e Guedes Soares (2000) publicaram um trabalho confirmando a escolha da POT, dentre as demais técnicas da TVE, como o melhor método de estudo dos extremos de altura de onda. Os autores ainda desaconselharam a utilização de ajustes diretos das séries completas à distribuições conhecidas.

Especificamente para a região da América do Sul, Silva (2008) aplicou a POT em dados de altura de onda coletados pela PETROBRÁS, entre os anos de 1991-1995, buscando uma melhor compreensão do comportamento das ondulações ligadas à situações de bom tempo na região da Bacia de Campos. Tais condições são descritas por Parente (1999) como situações com predomínio de ventos dos quadrantes norte e nordeste e persistência de um centro de alta pressão sobre a região. Já Campos (2009), fazendo uso da mesma metodologia e do mesmo conjunto de dados, caracterizou os extremos de onda ligados a diferentes sistemas meteorológicos. Em seu trabalho, calculou os extremos de retorno para condições ligadas a presença de anticiclones e 
ciclones na região, sendo os extremos menores para o primeiro com relação ao segundo sistema.

\section{Estudos em Extremos de Intensidade do Vento}

Também foram executados trabalhos de aplicação da POT em séries individuais de intensidade do vento, com destaque para o trabalho de Brabson e Palutikof (2000), que estudaram detalhadamente a eficácia da POT no estudo de séries temporais de rajadas e máximas diárias de intensidade do vento através de medições no norte da Escócia. O artigo trata com grande cautela os processos de escolha do limiar, dos métodos para os cálculos dos estimadores necessários para a aplicação da POT e dos critérios para a garantia de independência entre os picos exigida pelo método.

Oliveira et al. (2010) aplicaram a metodologia em algumas séries do projeto de reanálise $N C E P$ DOE Reanalysis 2 do National Centers for Environmental Prediction (NCEP). Nesse artigo, as séries escolhidas para análise encontram-se nas proximidades da costa sul/sudeste brasileira. Foi verificada uma inconsistência dos resultados de extremos de retorno para períodos mais longos do que 10 - 15 anos, com divergência dos intervalos de confiança.

\section{Estudos em Extremos de Onda e Intensidade do Vento}

Para análises globais de extremos de onda e vento, destacam-se os trabalhos de Caires e Sterl (2005) e Vinoth e Young (2011). No primeiro desses trabalhos, foi aplicada a POT e em seguida estimados os extremos de retorno para 100 anos em dados de altura de onda e intensidade do vento, em todo o globo, a partir do conjunto de reanálise ERA-40 do European Centre for Medium-Range Weather Forecasts (ECMWF). Esse trabalho apresenta o primeiro esforço de generalização do método para séries distribuídas no espaço, em detrimento de análises das séries individuais. Para tal, os autores optaram por uma fixação do limiar no percentil de 95\% das séries temporais completas. Um valor fixo para o limiar garante a generalização do método para aplicação em todas as séries distribuídas no espaço. O processo de generalização poderia comprometer os resultados uma vez que a técnica é sensível ao limiar. Porém, foram verificados resultados satisfatórios, com alto índice de exponencialidade confirmada em muitas das séries. Porém, dada a baixa resolução do conjunto, uma série de fenômenos de mesoescala não foram 
resolvidos e os autores indicam uma possível subestimação dos resultados, tanto para os dados de altura de onda como para os de intensidade do vento. O mapa de distribuição dos extremos de retorno para 100 anos obtidos nesse trabalho encontram-se na figura 1.1.

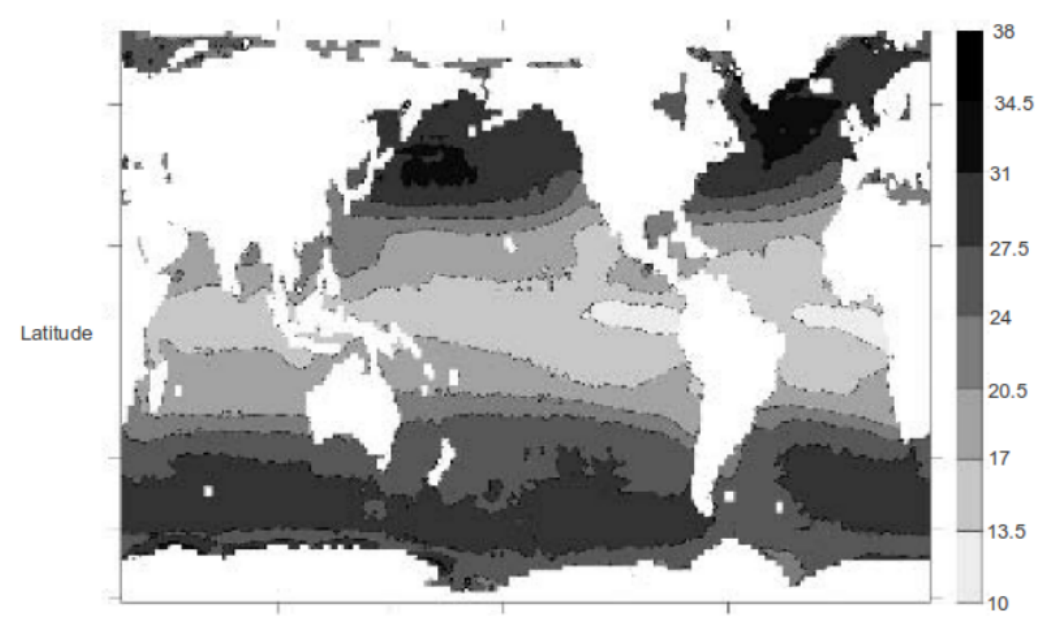

Longitude

Figura 1.1: Extremos de retorno para 100 anos, extraído de Caires e Sterl (2005).

Vinoth e Young (2011) utilizaram a mesma abordagem para a estimação de extremos de retorno de 100 anos a partir de dados de altura de ondas e intensidade do vento medidos por altímetros. Os autores verificaram uma alta sensibilidade do método POT à resolução do conjunto de dados, quando a análise é feita espacialmente. Os resultados obtidos em séries com resolução mais baixa podem apresentar menor confiabilidade e subestimação. Nesse caso, o limiar foi fixado em $90 \%$. Os extremos de retorno estimados nesse trabalho são bem mais intensos com relação aos encontrados por Caires e Sterl (2005), fator que pode estar ligado à resolução espacial distinta entre os dois conjuntos e, consequentemente, variações nos fenômenos resolvidos em cada um dos casos. O mapa de distribuição de extremos de retorno para 100 anos calculados nesse trabalho encontra-se na figura 1.2. 


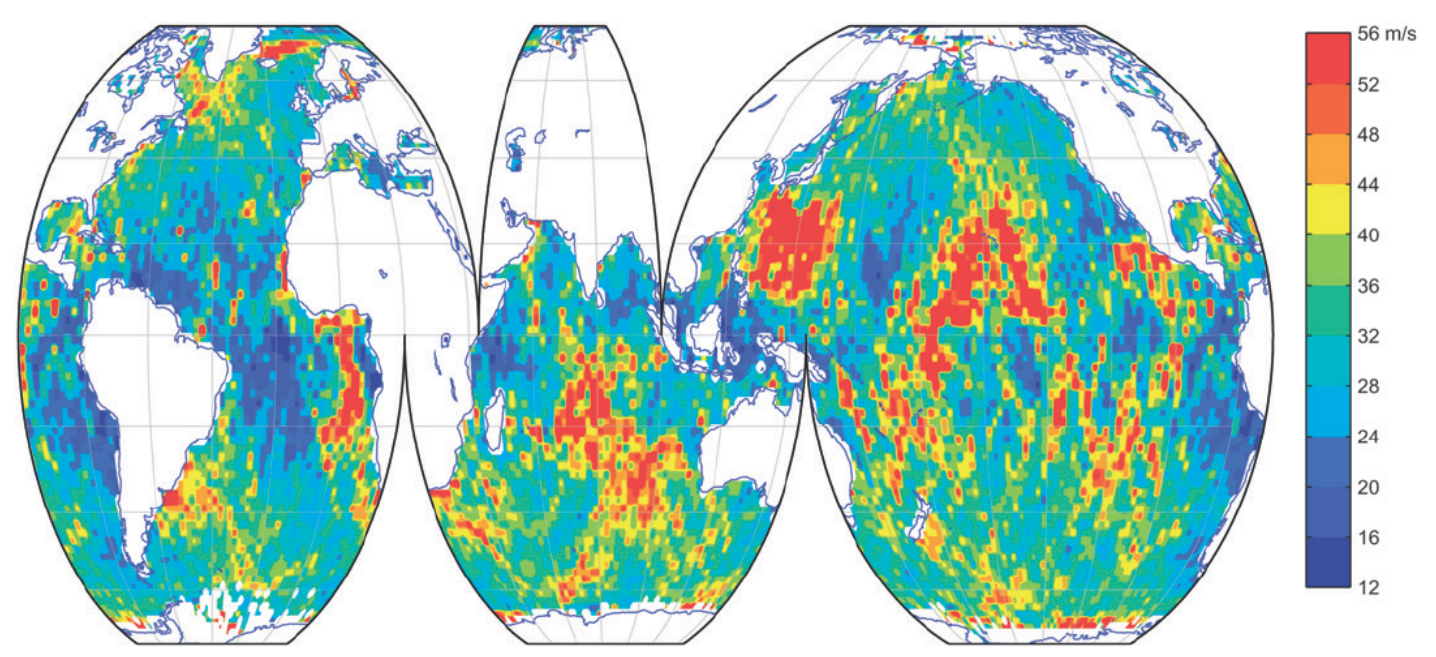

Figura 1.2: Extremos de retorno para 100 anos, extraído de Vinoth e Young (2011).

Em uma abordagem mais regional destaca-se um relatório técnico da empresa PETROBRAS, que descreve detalhadamente parâmetros meteorológicos e oceânicos sobre a região da Bacia de Campos, Rio de Janeiro. Esse documento oferece valores extremos de retorno de intensidade do vento para diferentes direções e altura de ondas, obtidos por medições diretas na região. Tal esforço buscou fundamentar uma referência de dados, o METOCEAN DATA, para a concepção de estruturas offshore e sistemas de produção na região (CENPES/PDP/MC-PETROBRAS, 2005). Trata-se da única referência para análise direcional dos valores extremos de retorno de vento separados direcionalmente.

\section{Contradições na Utilização do Método}

A eficácia da aplicação do método POT na investigação de extremos da intensidade do vento foi questionada no trabalho de Harris (2005). Nesse artigo, o autor utilizou uma série de dados com uma distribuição conhecida e buscou ajustar os excessos acima de um dado limiar à GPD. No entanto, a qualidade do ajuste não foi verificada. Em contrapartida, Simiu (2007) levantou uma série de questões não tratadas por Harris (2005) em seu trabalho, dentre elas a duração muito curta da série utilizada. Esse é um fator que pode ser determinante na falha do método, uma vez que a amostra dos excessos acima do limiar determinado pode não ser representativa dos extremos de uma série.

Tais trabalhos levantaram a questão dos cuidados que devem ser tomados pelo usuário na apli- 
cação do método. Os principais deles são, certamente, o critério utilizado para garantia de independência entre os picos escolhidos e a escolha de um limiar adequado. A sensibilidade dos resultados do método à escolha do limiar já foi foco de estudos como os de Brabson e Palutikof (2000) para dados de intensidade do vento e Neelemani (2009) para altura de ondas.

\subsection{Caracterização Meteorológica da Área de Estudo}

A área de estudo a ser abordada contempla o li toral e zona oceânica adjacente de todas as regiões do Brasil, com um domínio contido entre $65^{\circ} \mathrm{W}$ e $15^{\circ} \mathrm{W}$ de longitude e $40^{\circ} \mathrm{S}$ e $5^{\circ} \mathrm{N}$. A variabilidade no comportamento do campo de ventos sobre essas regiões pode ser entendida em termos da circulação geral da atmosfera, dada pela atuação das células convectivas de Hadley-Walker e dos sistemas frontais. Tendo em vista que a grande variação de fenômenos com capacidade de geração de extremos para cada quadrante do vento a ser analisado, a exposição dos resultados será espacialmente dividida entre uma região tropical (entre $20^{\circ} \mathrm{S}$ e $5^{\circ} \mathrm{N}$ de latitude) e uma região ao sul (entre $40^{\circ} \mathrm{S}$ e $\left.20^{\circ} \mathrm{S}\right)$.

Nos trópicos, os ventos são predominantemente de leste e guiados pelas variações nos posicionamentos da Alta Subtropical do Atlântico Sul (ASAS) e da Zona de Convergência Intertropical (ZCIT). A região de convergência dos ventos alíseos constitui a ZCIT, que é responsável pelo predomínio dos ventos dos quadrantes nordeste, leste e sudeste na região costeira norte/nordeste do Brasil. A ASAS é o sistema de que com maior amplitude espacial, possui um diâmetro de aproximadamente $2000 \mathrm{~km}$ e constitui-se a partir do ramo descendente da célula de Hadley nas proximidades de $30^{\circ} \mathrm{S}$. Trata-se de uma feição semi-permanente que responsabiliza-se pelos ventos predominantes dos quadrantes norte e nordeste na região costeira de grande parte do sudeste do Brasil. A aproximação de anticiclones extratropicais (ou altas de retaguarda) posteriormente à passagem de frentes frias pode intensificar os ventos de nordeste e constituir um extremo para os ventos dessa direção, além de influenciar na altura do nível do mar na região sudeste do Brasil. A posição desses sistemas varia de acordo com a excursão meridional da ZCIT em regime sazonal, sendo direcionada para norte (sul) nos meses de inverno austral (boreal). 
Outros fenômenos podem contribuir para a a variabilidade nos campos de extremos de retorno. As ondas de leste (MACHADO et al., 2009), ou distúrbios ondulatórios de leste, podem contribuir na variabilidade dos extremos na região oceânica próxima ao equador. Essas ondulações, que se propagam do oeste da costa Africana até o Atlântico Tropical, com atividade máxima durante o inverno austral, podem perturbar o campo de ventos em baixos níveis e gerar pulsos de ventos extremos de leste. Além disso, a circulação de brisa (ATKINSON, 1981), gerada primariamente pelo aquecimento diferencial entre continente e oceano, podem ser responsáveis por alguns eventos geradores de condições extremas. Esse aquecimento diferenciado entre continente e oceano, gera gradientes de temperatura de aproximadamente 1 por $20 \mathrm{~km}$, promovendo fluxos de energia diferentes para a atmosfera, acarretando em gradientes de pressão em níveis acima da superfície, fator que impulsiona o movimento. A brisa marítima é caracterizada pelo aumento na intensidade do vento, na mudança de sua direção e no aumento da umidade. Como a brisa marítima é, geralmente, mais intensa do que a terrestre, esperam-se eventos extremos na zona consteira associados a ela. As linhas de instabilidade, por sua vez, também podem contribuir com eventos altamente energéticos nas zonas costeiras. Sua formação, associada à circulação de brisas (COHEN et al., 2009), é favorecida nas zonas costeiras, principalmente na região norte/nordeste da costa brasileira. Complexos Convectivos de Mesoescala também responsabilizam-se por ventos bastante intensos em seu desenvolvimento. No entanto, como seu desenvolvimento é preferencialmente continental, não são esperados extremos de retorno nos campos de ventos associados à sua atuação.

Já na região mais ao sul do domínio, a estabilidade gerada pela presença da ASAS é quebrada por feições associadas ao fluxo de oeste presente na circulação geral dessa região. Nota-se a presença de zonas baroclínicas, intensas e estreitas denominadas zonas frontais. As regiões mais baroclínicas dessas zonas são denominadas frentes. E sua passagem pela zona costeira dessa porção do domínio garante a inversão dos ventos do quadrante norte/nordeste para ventos de direção sul. O fluxo em altitude a oeste dessa zona frontal caracteriza-se por uma grande instabilidade, responsável pela intensificação das ondulações nesse escoamento zonal e na geração de vórtices ciclônicos. Muitos trabalhos buscaram construir uma climatologia desses ciclones para a região da América do Sul, com especial atenção para os esforços de Gan e Rao (1991). 
Em seu trabalho, através da utilização de cartas de superfície e estações de radiossondagem, verificaram uma variabilidade sazonal nas ocorrências da ciclogênese, bem como as regiões favoráveis ao seu desenvolvimento. Uma dessas regiões localiza-se em aproximadamente $42.5^{\circ} \mathrm{S}$ e $62.5^{\circ} \mathrm{W}$ (Golfo de São Matias); e outra em cerca de $31.5^{\circ} \mathrm{S}$ e $55^{\circ} \mathrm{W}$ (sobre a região do Uruguai). A figura 1.3, presente no trabalho supracitado, ilustra essas regiões.

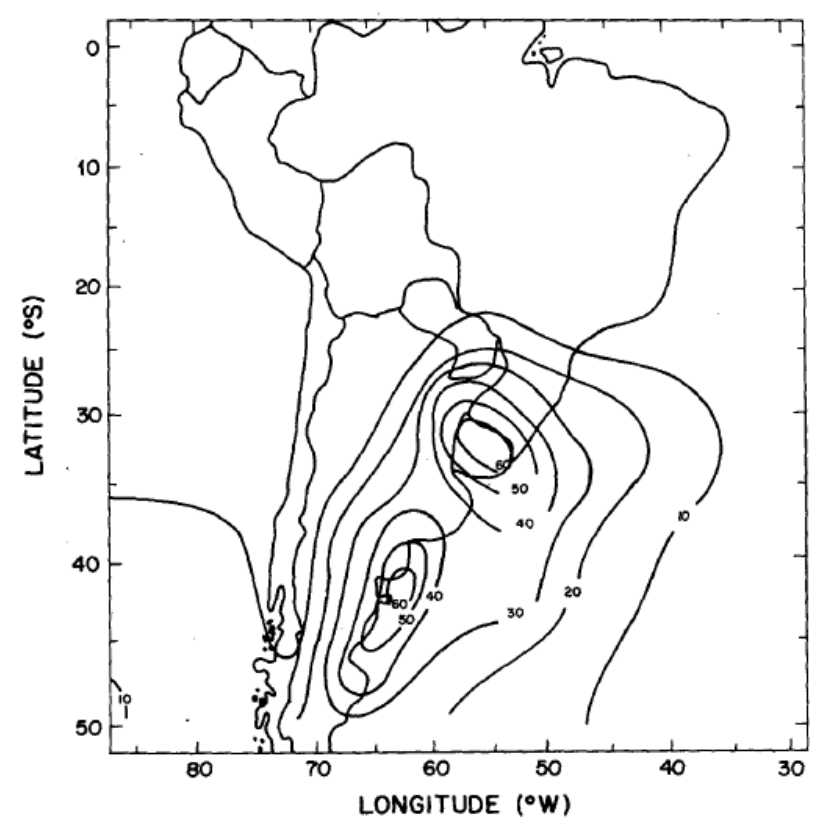

Figura 1.3: Mapa de distribuição anual da frequência de ocorrência de ciclones América do Sul. Extraído de Gan e Rao (1991)

O trabalho de Gan e Rao (1991) foi aprimorado pelos esforços de Sinclair (1994), que elaborou uma nova climatologia de ciclones extratropicais para as estações de inverno e verão em todo o Hemisfério Sul, para o período de 1980 a 1986. Através da metodologia adotada em seu trabalho, foram verificadas maiores ocorrências de ciclones em torno da Antártica e nas proximidades dos continentes em latitudes médias, com maior frequência para a estação de inverno devido à influência das correntes oceânicas adjacentes. Seus resultados também indicam uma maior ocorrência de ciclogênese no leste da América do Sul para latitudes ao norte de $40^{\circ} \mathrm{S}$ em zonas próximas à regiões baroclínicas resultantes da influência de correntes de jato em altos níveis. Ainda de acordo com Sinclair (1994), há uma segunda região preferencial à elevada densidade ciclogenética em cerca de $30^{\circ} \mathrm{S}$. 
Mais recentemente, Reboita (2008), através da análise comparativa entre os resultados de uma simulação com o modelo RegCM3 e das reanálises do NCEP/NCAR, elaborou uma climatologia para a ocorrência de ciclogênese sobre o Oceano Atlântico Sul. Em seu trabalho, Reboita (2008) identificou três regiões de grande importância na incidência de ciclones: a primeira, nas vizinhanças da região sul/sudeste do Brasil entre $25^{\circ} \mathrm{S}$ e $30^{\circ} \mathrm{S}$; a segunda, na desembocadura do Rio da Prata (divisa entre Uruguai e Argentina) em $35^{\circ} \mathrm{S}$; e, finalmente, uma região posicionada ao sul da Argentina, em cerca de $48^{\circ} \mathrm{S}$. Essas regiões estão ilustradas na figura 1.4.
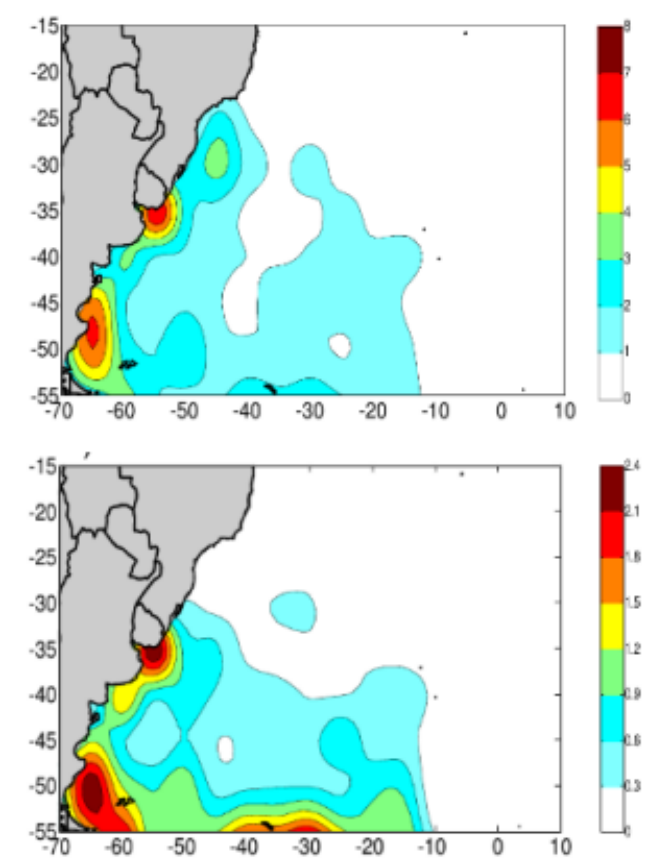

Figura 1.4: Densidade de ciclogêneses, menos intensos (acima) e mais intensos (abaixo). Extraído de Reboita (2008).

A identificação de regiões favoráveis à ocorrência de ciclones é de grande valia para a avaliação do comportamento dos ventos extremos nas seções seguintes. 


\section{Material e Métodos}

\subsection{Conjuntos de Dados}

\subsubsection{Dados de Reanálise NCEP/NCAR I}

Será utilizada uma base de dados de vento a 10m de altura, nas direções zonal e meridional, do projeto de reanálise NCEP/NCAR I. Segundo Kalnay et al. (1996), o resultado desse projeto foi obtido através de técnicas estáveis para análise em modelos de circulação geral somados à dados assimilados provenientes de estações em superfície, aeronaves, navios, balões piloto, boias, derivados de satélites, radiossondas, etc. Esses dados são assimilados ao modelo apenas após um prévio controle de qualidade. De tal procedimento resulta um conjunto de variáveis climáticas com ampla cobertura espacial, disponibilizado a partir do mês de janeiro de 1948 até o presente. A principal vantagem desta base de dados está em sua consistência física e dinâmica e grande regularidade espaço-temporal. As principais características desse conjunto são:

- Horários por dia: 00Z, 06Z, 12Z e 18Z;

- Malha de dados global com 144x73 pontos: de 0E a 357.5E de longitude e de 90N a 90S de latitude;

- Resolução zonal: $2.5^{\circ}$;

- Resolução meridional: $2.5^{\circ}$;

Esse processo de reanálise, que consiste basicamente na assimilação de dados observacionais a um modelo numérico para a obtenção de uma interpolação física de qualidade, garante uma boa referência tridimensional para o estado da atmosfera. A resolução horizontal de 2.5 graus 
somada a informações a cada 6 horas permitem uma boa representação de variáveis em escala sinótica, em que fenômenos meteorológicos possuem ampla extensão espacial e tempo de evolução mais lento. Essa baixa resolução não admite a representação explícita de fenômenos locais nos pontos de grade do modelo e isso deve ser levado em consideração durante as análises dos valores extremos de retorno obtidos.

\subsubsection{Simulação com o Modelo BRAMS}

Além dos dados de reanálise descritos anteriormente, foi utilizado nesse trabalho uma simulação numérica integrada como um das etapas do projeto Impactos, Vulnerabilidades e Adaptação as Mudanças Climáticas para o Oceano Atlântico Sul (IVAM-OAS), financiado pelo Centro de Pesquisas Leopoldo Américo Miguez de Mello (CENPES), da Petrobras. Tal simulação foi realizada com o intuito de atuar como referência e condição inicial e de contorno para projeções climáticas e outros modelos locais de circulação atmosférica e oceânica. O período de simulação total contempla o intervalo entre 1982 - 2011. Maiores detalhes quanto à configuração das simulações encontram-se no relatório técnico Wainer et al. (2013).

O refinamento espaço-temporal concedido por esse downscaling oferece um maior detalhamento ao comportamento dos extremos associados à fenômenos transientes.

O modelo utilizado foi o BRAMS, Brazilian Regional Atmospheric Modeling System, derivado do Regional Atmospheric Modeling System (COTTON et al., 2003), e desenvolvido para um aprimoramento das simulações nos trópicos, através da inclusão de uma série de sub-modelos e parametrizações. Seu desenvolvimento esteve vinculado com algumas instituições brasileiras, como o Instituto de Astronomia, Geofísica e Ciências Atmosféricas da Universidade de São Paulo - IAG/USP e o Centro de Previsão de Tempo e Estudos Climáticos/Instituto Nacional de Pesquisas Espaciais - CPTEC/INPE. O BRAMS é um modelo bastante versátil, que conta com a capacidade de simular circulações em variadas escalas espaciais, sendo frequentemente aplicado para a representação de fenômenos com escalas de centenas de quilômetros, ou fenômenos de mesoescala. O desenvolvimento da sua integração numérica baseia-se nas equações da dinâmica e termodinâmica da atmosfera, adicionada a parametrizações de vários outros processos, como difusão turbulenta, radiação, processos úmidos incluindo a formação e a interação de nu- 
vens, água líquida e gelo, calor sensível e latente, camadas de solo, vegetação, entre outros. A versão utilizada para o desenvolvimento da simulação estudada no presente trabalho é a 4.2. Um downscaling consistente, com resultados que apresentem melhorias notáveis com relação ao dado original de entrada, deve possuir um ponto de equilíbrio entre refinamento, ajuste e estabilidade da simulação, uma vez que o maior detalhamento dos campos simulados contribui com o aumento da complexidade e possibilidade de erros na representação de padrões atmosféricos, cujas aproximações numéricas dependem da escala em que é feita a simulação. Como o domínio de estudo do presente trabalho está na região do Oceano Atlântico Sudoeste, a grade do modelo atmosférico foi construída de tal forma a ser suficientemente grande para a formação de uma pista de vento sobre o oceano. E uma ampla região continental foi mantida para que os efeitos de interação com o continente e oceano adjacente fossem considerados nos resultados. Duas grades foram utilizadas para a configuração da simulação, representadas na figura 2.1, com configurações gerais dadas pela tabela 2.1 . 


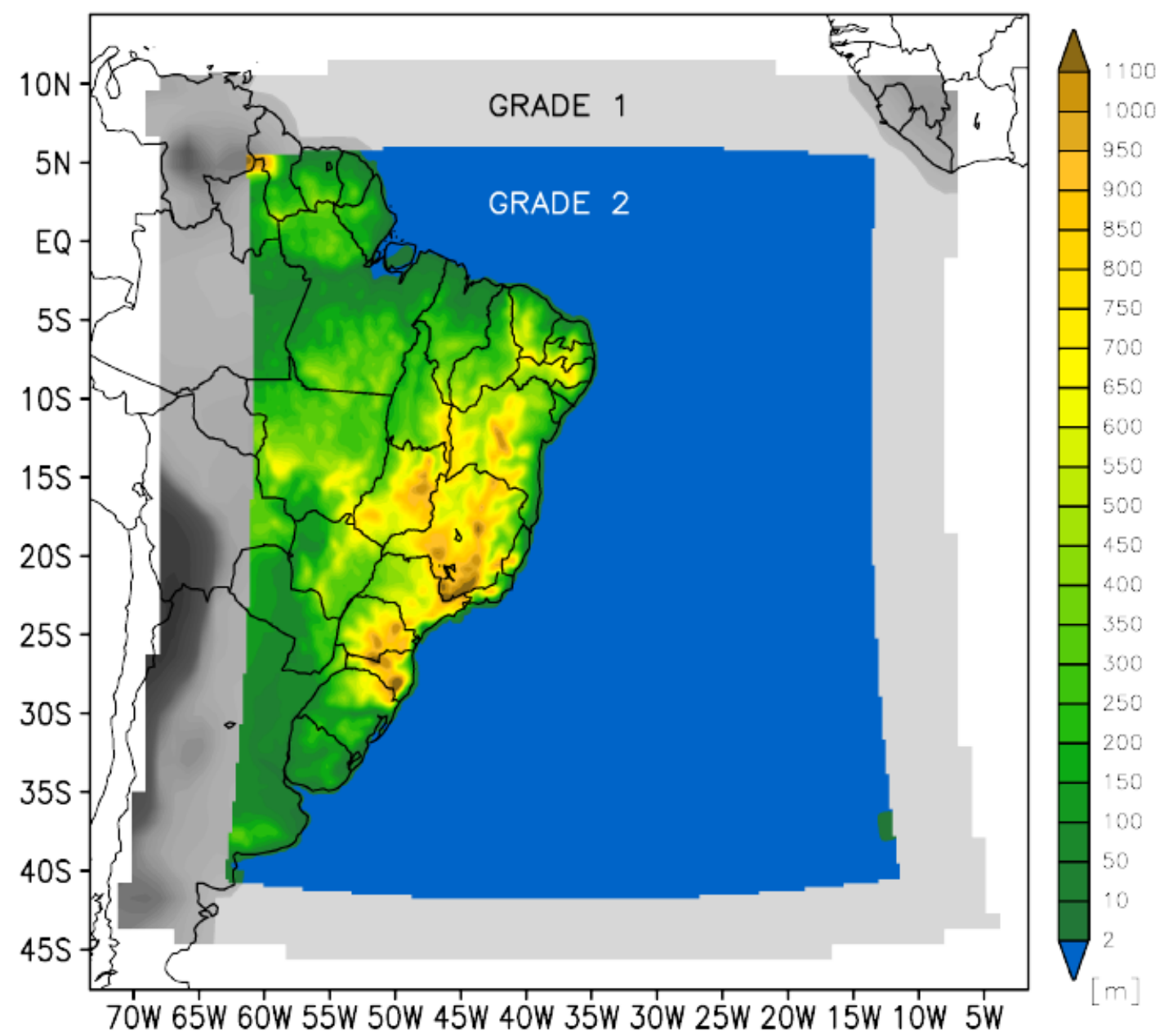

Figura 2.1: Grades utilizadas para o downscaling atmosférico.

Tabela 2.1: Características dimensionais das grades da simulação utilizada

\begin{tabular}{lcccccc} 
Grade & Longitude & Latitude & Resolução & $\mathrm{Nx}$ & $\mathrm{Ny}$ & $\mathrm{Nz}$ \\
\hline \hline 1 & $73.33 \mathrm{~W}$ a $1.65 \mathrm{~W}$ & $47.57 \mathrm{~S}$ a $14.41 \mathrm{~N}$ & $1^{\circ} \times 1^{\circ}$ & 68 & 65 & 37 \\
2 & $63.50 \mathrm{~W}$ a $10.68 \mathrm{~W}$ & $42.25 \mathrm{~S}$ a $6.73 \mathrm{~N}$ & $0.25^{\circ} \times 0.25^{\circ}$ & 198 & 200 & 37 \\
\hline
\end{tabular}

A utilização dessas duas grades para a simulação é justificada pela grande diferença entre as escalas espaciais da condição de contorno dada pela reanálise do NCEP 1 e do downscaling, $2.5^{\circ}$ no primeiro e $0.25^{\circ}$ no segundo. Trata-se de um contraste muito grande para uma operação de downscaling desse tipo, com uma ordem de grandeza de diferença entre os conjuntos. A utilização das duas grades contribuiu para a formação de um setor intermediário, com resolução de $1^{\circ}$, suavizando a transição entre os conjuntos com diferentes resoluções. As análises, porém, foram feitas apenas na grade 2 , interna. 
A condição de contorno dada pela reanálise do NCEP sobre as grades 1 e 2 do downscaling foi configurada de tal forma a oferecer grande influência nas simulações, tanto em suas bordas como em suas zonas centrais e de topo, uma vez que buscou-se uma melhoria de resolução sem negligência aos campos de larga escala provenientes do NCEP.

$\mathrm{Na}$ listagem abaixo, seguem as principais configurações para a integração:

- Grade espacial: de 63.497W a $10.675 \mathrm{~W}$ em longitude e $42.255 \mathrm{~S}$ a $6.733 \mathrm{~N}$ em latitude;

- Resolução aproximada: 0.25 graus em x e y (aproximadamente $30 \mathrm{~km}$ de espaçamento horizontal);

- Resolução temporal: 1 hora. Com dados gravados a cada 3 horas, suficientes para descrever adequadamente o ciclo diurno, com simulações de sistemas de mesoescala e de escala local, como brisas marítimas e frentes frias;

- 37 níveis na vertical, sendo o primeiro em 15 metros e o topo em 22.101 metros;

- Foi utilizada uma parametrização de cumulus Grell com fechamento Ensemble, microfísica nível 2;

- A simulação foi inicializada com umidade do solo homogênea;

- As condições iniciais e de contorno são dadas pela reanálise do NCEP/NCAR 1;

- A topografia de 200 metros derivada do Shuttle Radar Topography Mission (SRTM);

- Para a definição da temperatura da superfície do mar (TSM), foi utilizado um conjunto semanal de dados da NOAA Optimum Interpolation (OI) Sea Surface Temperature (OISST);

- O tipo de vegetação da iniciativa U.S. Geological Survey (USGS) e do MODIS Normalized Difference Vegetation Index (NDVI/MODIS);

- E os dados de utilização do solo dados pela FAO. 


\subsection{Método Peaks Over Threshold - POT}

\subsubsection{Descrição Geral e Critérios de Independência}

Essa técnica consiste, basicamente, no ajuste dos excessos acima de um dado limiar extraídos de uma série temporal à Distribuição Generalizada de Pareto (Generalized Pareto Distribution - GPD).

De acordo com a descrição técnica do método oferecida por Embrechts et al. (1997) e Mendes (2004), os excessos extraídos das séries devem ser estatisticamente independentes e constituir um processo de Poisson, i.e., devem ser aleatórios e possuir mesma probabilidade de ocorrência. Tal condição de independência estatística e identidade de distribuição (iid) é de difícil definição para dados de intensidade do vento, que resultam da ação de diversos fenômenos em escalas temporais variadas. Portanto, o critério de independência no presente trabalho foi dado pelo cálculo de uma janela temporal mínima para a garantia de independência entre os picos para cada uma das séries temporais do domínio. A construção dessa janela foi feita da seguinte maneira:

1. Divisão das séries em intervalos de 24 horas

2. Cálculo da autocorrelação entre os valores máximos a cada 24 horas

3. Detecção do valor mínimo de autocorrelação

4. Estabelecimento da janela temporal para o valor de mínima autocorrelação

A partir disso, apenas picos espaçados por essa janela temporal foram utilizados para o cálculo dos excessos e aplicação na análise. Isso garante a utilização de extremos com origens fenomenológicas distintas para compor o conjunto de excessos aos quais será aplicada a POT. Como a duração da janela temporal é individual a cada série (uma vez que leva em conta suas próprias características de autocorrelação), seus valores são variáveis no espaço. A aplicação desse cálculo para a determinação do espaçamento mínimo entre picos parece um tanto rigorosa com relação aos métodos adotados em alguns trabalhos anteriores, cujos critérios estão representados na tabela 2.2. Porém, a inclusão de extremos provenientes de um mesmo fenômeno 
meteorológico pode implicar em uma distorção nos parâmetros obtidos pelo ajuste e inflar a quantidade de excessos acima do limiar, comprometendo a extrapolação dos extremos de retorno (BRABSON; PALUTIKOF, 2000).

Tabela 2.2: Critérios de independência utilizados em trabalhos anteriores

\begin{tabular}{lc} 
Trabalho & Critério \\
\hline \hline Cook (1982) & $48 \mathrm{~h}$ \\
Gusclla (1991) & $48 \mathrm{~h}$ \\
Coles e Walshaw (1994) & $60 \mathrm{~h}$ \\
Caires e Sterl (2005) & $48 \mathrm{~h}$ \\
\hline
\end{tabular}

\subsubsection{Teoria Básica}

Considerando uma série de eventos iid $x_{1}, x_{2}, \ldots, x_{N}$ com distribuição comum $F_{X}$. O limiar $u$ é considerado um valor alto próximo do limite superior da distribuição, $x_{\text {sup }}$. Os excessos acima desse limiar $y_{1}, y_{2}, \ldots, y_{N_{u}}$ são os valores $x_{i}-u$, sendo $N_{u}$ o número de excessos acima do limiar $u$. Tal como pode ser observado na figura 2.2.

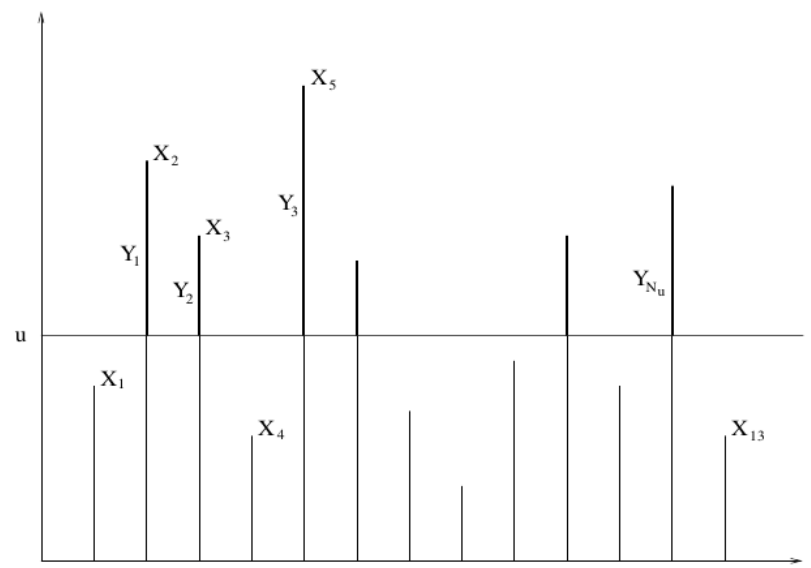

Figura 2.2: Exemplo hipotético de uma série de eventos iid. Extraído de Embrechts et al. (1997).

A GPD pode ser matematicamente descrita através da seguinte função de distribuição (EMBRECHTS et al., 1997; MENDES, 2004; BELITSKY; MOREIRA, 2007): 


$$
G_{\xi, \beta}(y)=\left\{\begin{array}{cc}
1-\left(1+\frac{\xi y}{\beta}\right)^{\frac{-1}{\xi}}, & \xi \neq 0 \\
1-e^{\frac{-y}{\beta}}, & \xi=0
\end{array}\right.
$$

Onde $y \geqslant 0$ para $\xi \geqslant 0$ e $-1 \leqslant y \leqslant 0$ para $\xi<0$, sendo $\xi$ o parâmetro de forma e $\beta$ o parâmetro de escala. Tais parâmetros podem ser calculados através de vários estimadores, sendo os principais deles: Maximum Likelihood Method (ML), Moment Method (MOM), Pickand's Estimator (PKD) e o Probability Weithed Moments (PWM). Campos (2009), em sua análise para altura de ondas, ofereceu uma exploração detalhada da estabilidade de cada um desses estimadores, concluindo que o MOM e o PWM ofereciam melhor qualidade no ajuste. Em trabalhos que tratam da análise da intensidade do vento, muitos autores efetuaram o cálculo dos parâmetros de forma e escala através do PWM e ML, como pode ser visto na tabela 2.3. O estimador utilizado no presente trabalho foi o PWM, tendo em vista sua utilização por outras referências que trataram da análise dos extremos de vento espacialmente e com alguma atenção para o Oceano Atlântico Sul. A descrição detalhada do estimador pode ser encontrada em Hosking e Wallis (1987, p 341).

Tabela 2.3: Estimadores utilizados em trabalhos anteriores

\begin{tabular}{lc} 
Trabalho & Estimador \\
\hline \hline Caires e Sterl (2005) & PWM \\
Oliveira et al. (2010) & ML \\
Vinoth e Young (2011) & PWM/ML \\
\hline
\end{tabular}

Mendes (2004, p. 77) e Embrechts et al. (1997, p. 162) descrevem detalhadamente como as distribuições condicionais para a ocorrência de um excesso acima de um limiar $u\left(F_{u}(y)\right)$ definido convergem para a GPD descrita $G_{(x i, \beta(u)}(y)$ dado um limiar suficientemente alto.

$$
\lim _{u \rightarrow x_{\text {sup }}}\left|F_{u}(y)-G_{\xi, \beta(u)}(y)\right|=0
$$

Assim como para a GEV, a função de distribuição da GPD, dada por 2.1, pode ser representara 
por um dos três seguintes submodelos de distribuição, de acordo com o valor do parâmetro de forma $\xi$ (EMBRECHTS et al., 1997; MENDES, 2004; BELITSKY; MOREIRA, 2007):

- Para $\xi>0$ : distribuições do modelo de Pareto (Tipo II);

- Para $\xi=0$ : a distribuição exponencial (Tipo I);

- Para $\xi<0$ : distribuição beta (Tipo III).

Como pode ser observado na figura 2.3:

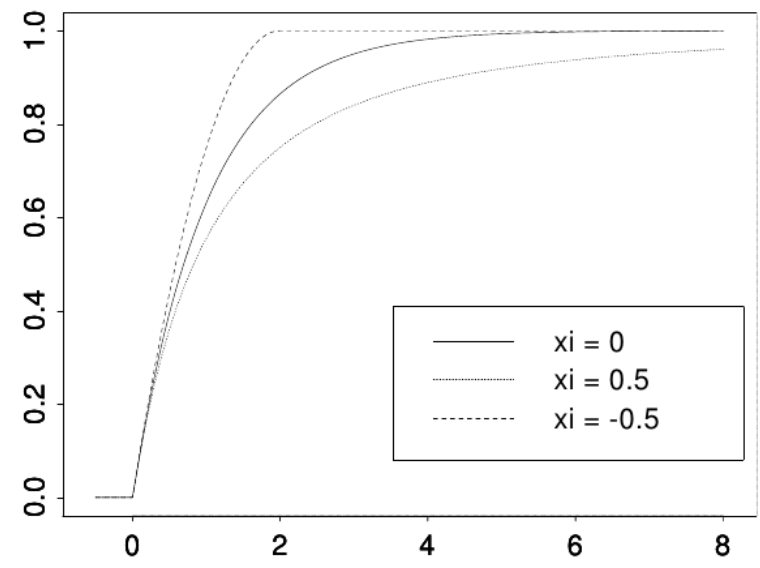

Figura 2.3: Formas da função de distribuição de uma GPD, extraído de Embrechts et al. (1997). O eixo $\mathrm{x}$ apresenta os valores para o limiar (u) e o eixo y a função de distribuição cumulativa.

\subsubsection{Determinação do Limiar}

A escolha do limiar para a aplicação da POT é um dos passos mais importantes do método e um dos mais discutidos na bibliografia. Segundo Embrechts et al. (1997), Mendes (2004), Belitsky e Moreira (2007), o limiar deve ser alto o suficiente para que a consideração dada pela equação 2.2 seja válida. No entanto, um limiar muito alto pode acarretar em um valor muito baixo para $N_{u}$. Dessa forma, deve-se buscar o equilíbrio entre os valores adequados de $N_{u}$ e $u$, para que a análise tenha um número suficientemente grande de dados e ainda assim possa satisfazer as suposições teóricas do método. Belitsky e Moreira (2007, p. 56) apresenta uma lista de procedimentos gráficos para a escolha do chamado limiar ótimo $u_{o p t}$, sendo o principal dele a análise do gráfico da média de excessos acima do limiar pelo limiar. Campos (2009), ao analisar séries 
individuais de altura de onda, fez uso desses procedimentos e descreve detalhadamente as etapas de escolha do $u_{o p t}$. No entanto, para uma análise de múltiplas séries distribuídas no espaço, como é o proposto no presente trabalho, tal procedimento torna-se inviável devido ao elevado número de séries a serem analisadas. Caires e Sterl (2005), Vinoth e Young (2011), em análises espaciais similares, fixaram o limiar em um determinado percentil da série de intensidade do vento total, sendo $97 \%$ no primeiro e $90 \%$ no último. Para esse trabalho o limiar foi fixado em 95\% de cada uma das séries temporais em cada um dos pontos de grade.

No trabalho de Caires e Sterl (2005), além da fixação do limiar como um dos passos do processo de aplicação da análise, os autores sugerem que o ajuste dos excessos acima desse limiar

sejam feitos com o quadrado da intensidade do vento $\left(U_{10}^{2}\right)$ para maior rapidez na convergência do cálculo dos parâmetros de forma e escala. Depois disso, a raiz quadrada dos extremos de retorno obtidos pode ser efetuada para análise dos resultados. Tal procedimento foi adotado no presente trabalho.

\subsubsection{Cálculo dos Valores Extremos de Retorno}

A partir do ajuste dos excessos acima do limiar à função de distribuição GPD pode-se determinar o vento extremo para períodos de retorno específicos. Os valores extremos de retorno $x_{r}$ resultam da extrapolação da GPD para os períodos requeridos. A equação utilizada no presente trabalho, também utilizada por Silva (2008), Campos (2009), para o cálculo de $x_{r}$ é dada por:

$$
x_{r}=u+\frac{\beta}{\xi}\left[\left(\frac{n}{N_{u}}(1-p)\right)^{-\xi}-1\right]
$$

Sendo,

- $x_{r}$ : extremo de retorno

- $n$ : número total de dados nas séries 
- $p$ : probabilidade de não-excedência

A probabilidade de não-excedência é dada por:

$$
p=1-\frac{1}{N_{e}}
$$

Sendo $N_{e}$ o número de excessos esperado para o um dado período de retorno $p_{r}$ e dado por:

$$
N_{e}=p_{r} \frac{N_{u}}{N_{\text {anos }}}
$$

Onde $N_{a n o s}$ é o número de anos contemplado na análise. Tal formulação para $N_{e}$ assume uma quantidade de excedentes ao limiar constante ao longo dos anos. Portanto, esse cálculo da probabilidade de não-excedência garante legitimidade para os extremos de retorno $x_{r}$ apenas para extrapolações curtas de $p_{r}$. Como as séries a serem estudadas possuem 30 anos de duração (1982-2011), os extremos de retorno serão calculados para períodos de retorno de até $p_{r}=50$. Para análises de $x_{r}$ para $p_{r}$ de 100 anos ou mais, uma análise mais rigorosa deve ser feita, levando-se em conta as flutuações nos valores de $N_{u}$ ao longo dos anos.

Os intervalos de confiança dos extremos de retorno foram calculados de acordo:

$$
i c=c e n t r o \pm 1.96 \frac{\sqrt{v a r}}{\sqrt{n_{\text {dados }}}}
$$

Sendo,

- ic: intervalo de confiança 
- centro: valor central

- var: variância

- $n_{\text {dados }}:$ número de dados

\subsubsection{Critério de Estabilidade}

Para cada série temporal estudada, foram calculados os valores extremos de retorno para até 50 anos. O valor extremo de retorno foi considerado instável quando a diferença entre os intervalos de confiança e a reta original excediam dois desvios padrões para $p_{r}=10$ e quando excediam três desvios padrões para $p_{r}=50$.

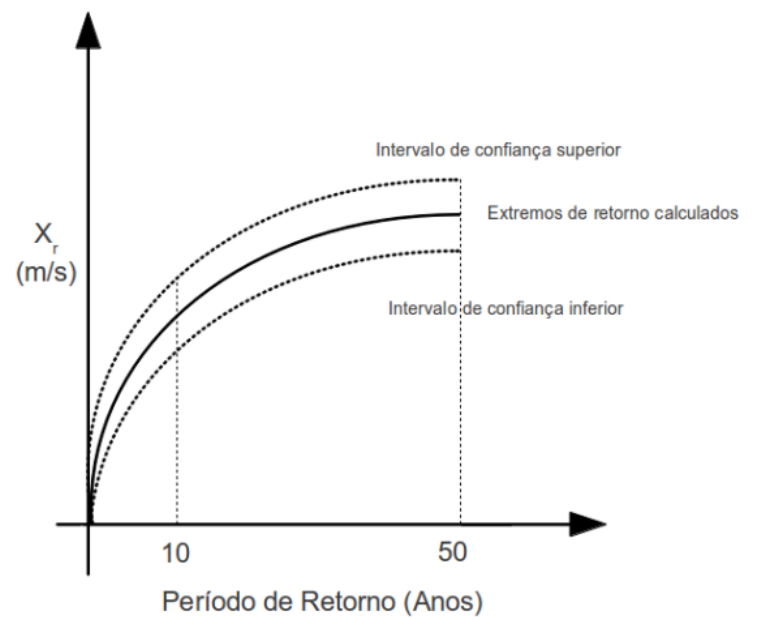

Figura 2.4: Esquematização de uma curva para valores extremos de retorno e seus intervalos de confiança

Outro ponto relevante a ser discutido é o valor final obtido, que não reflete o valor extremo absoluto a ser encontrado em um determinado período de retorno. Mas sim, indica que para $p_{r}$ anos, e partindo de $95 \%$ de confiança, a intensidade do vento na dada direção não irá exceder $x_{r} \mathrm{~m} / \mathrm{s}$.

\subsubsection{Separação Direcional das Séries}

Após a separação dos eventos independentes em cada uma das séries, tais valores iid foram separados de acordo com a direção do vento de acordo com a figura 2.5. Os intervalos, em 
graus, que constituem ventos dos quadrantes norte, sul, leste e oeste são de $30^{\circ}$. Ao passo que, para os quadrantes nordeste, noroeste, sudeste e sudoeste, tal intervalo contempla $60^{\circ}$.

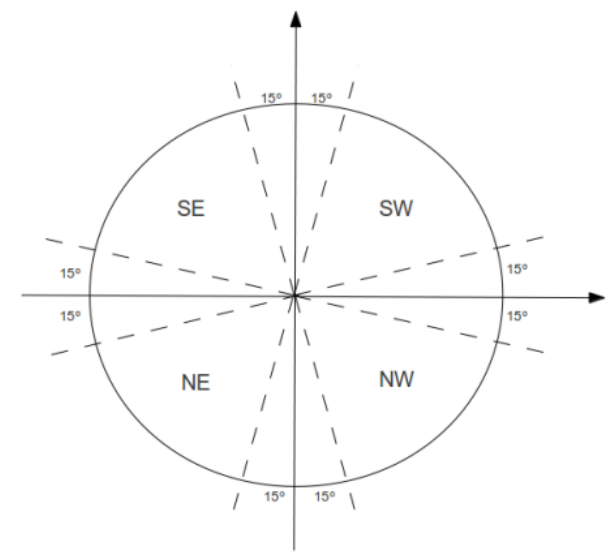

Figura 2.5: Diagrama de representação da separação direcional dos dados de intensidade do vento.

\subsubsection{Metodologia}

A metodologia do presente trabalho consiste na aplicação da técnica descrita anteriormente nos conjuntos do NCEP e BRAMS, e posterior análise dos gráficos resultantes. Todos os cálculos descritos para os ajustes das séries de excessos à GPD foram efetuados através de um pacote de programas de livre acesso em linguagem MATLAB denominado Wave Analysis fot Fatigue and Oceanography (WAFO).

A sequência de aplicação pode ser enumerada por:

1. Separação de eventos independentes;

2. Separação direcional pelas componentes do vento;

3. Geração dos mapas de $N_{u}$;

4. Ajuste dos excessos acima do limiar à GPD para obtenção dos parâmetros de forma e escala;

5. Cálculo dos extremos de retorno para até 50 anos; 


\section{$3 \quad$ Resultados e Discussão}

A apresentação dos resultados será regionalizada visando maior clareza na explanação dos mesmos. A subdivisão inclui um setor tropical, compreendido entre $20^{\circ} \mathrm{S}$ e $5 \mathrm{~N}$, e uma região ao sul do domínio estudado, entre $40^{\circ} \mathrm{S}$ e $20^{\circ} \mathrm{S}$.

Dados os principais fenômenos atmosféricos incidentes em cada uma dessas regiões, a quantidade de eventos independentes acima do limiar para a região sul é significativa para o estudo dos valores extremos de retorno provenientes de todos os quadrantes do vento. Já para a região tropical, onde predominam ventos dos setores leste, valores extremos de retorno serão abordados para as direções norte, nordeste e sudeste.

As figuras que representam os mapas de distribuição dos valores extremos de retorno $\left(x_{r}\right)$ para 10, 25 e 50 anos, para ambos os conjuntos (NCEP e BRAMS), foram posicionadas de tal forma a facilitar as comparações entre os campos. E as escalas de cores nas figuras são as mesmas para cada período de retorno. A manutenção de uma escala única para todas as figuras poderia comprometer o detalhamento de estruturas para cada período estudado.

\subsection{Limiares}

Os limiares calculados a partir do percentil de $95 \%$ das séries temporais completas em cada ponto de grade encontram-se representados na figura 3.1. Neles, é possível observar valores mais elevados de $u$ nas regiões subtropicais, o que indica um aumento na intensidade do vento extremo para a região subtropical em detrimento da tropical. O limiar indica o valor mínimo dos extremos selecionados para cada ponto de grade. 


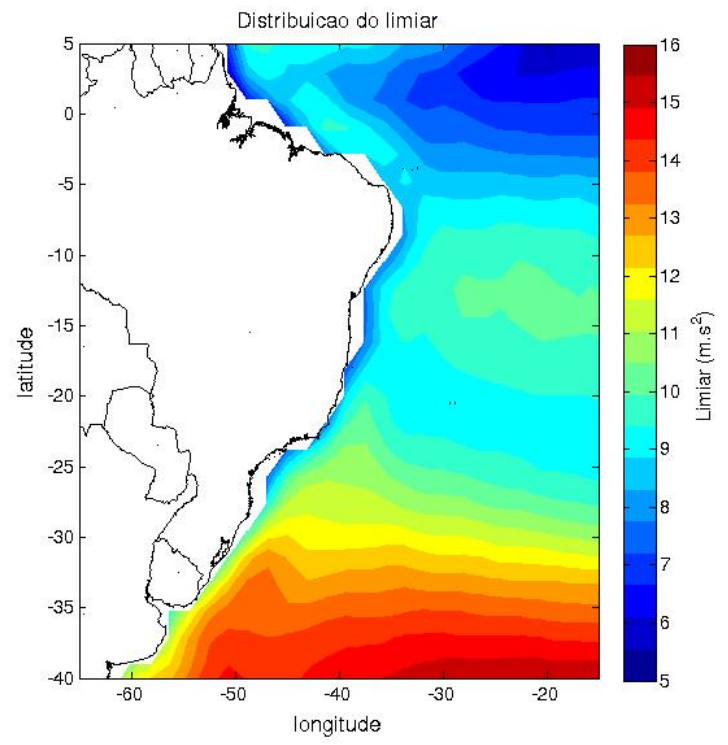

(a) NCEP

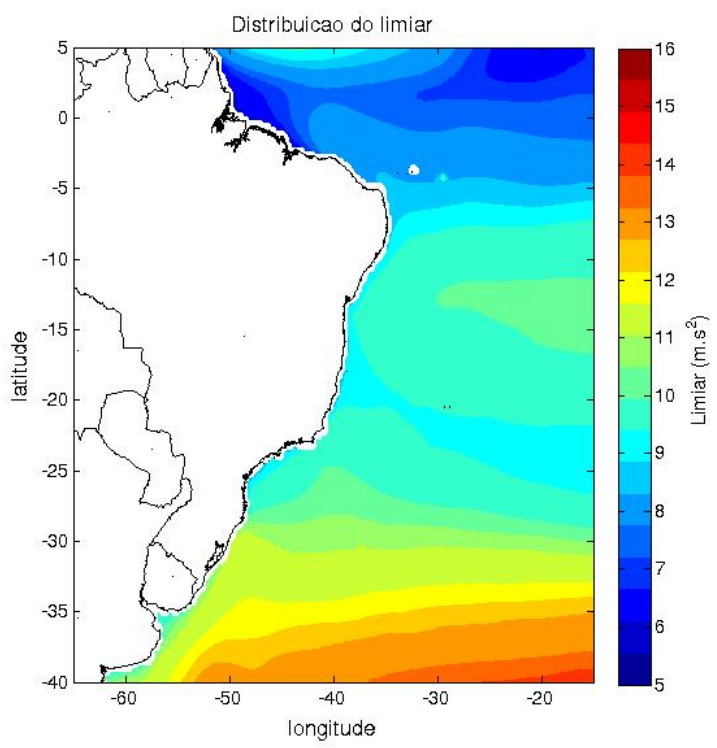

(b) BRAMS

Figura 3.1: Limiares $u$ (percentil de $95 \%$ das séries completas) calculados para os conjuntos NCEP e BRAMS.

\subsection{Região Tropical}

Os ventos nessa região do domínio, entre $20^{\circ} \mathrm{S}$ e $5^{\circ} \mathrm{N}$ de latitude, respondem à influência da variabilidade no posicionamento da ASAS e, consequentemente, ao posicionamento da ZCIT. Predominam os ventos dos quadrantes leste, nordeste e sudeste. E isso reflete diretamente no comportamento dos extremos de retorno na zona costeira, como será visto a seguir.

Os mapas com os valores de $N_{u}$ para ventos de leste encontram-se na figura 3.2. Nota-se que há um maior número de eventos extremos acima do limiar representados pela reanálise do NCEP, principalmente na zona costeira nordeste/norte. No entanto, o BRAMS apresenta um maior espalhamento espacial de eventos em todo o domínio. Por se tratar da zona de encontro dos ventos alíseos e da ação da ASAS, ventos desse quadrante são esperados em praticamente todo o domínio. E o aumento na resolução com o downscaling do BRAMS pode explicar o maior espalhamento dos eventos pela região, devido ao seu grau de detalhamento e maior qualidade na representação de fenômenos locais. 


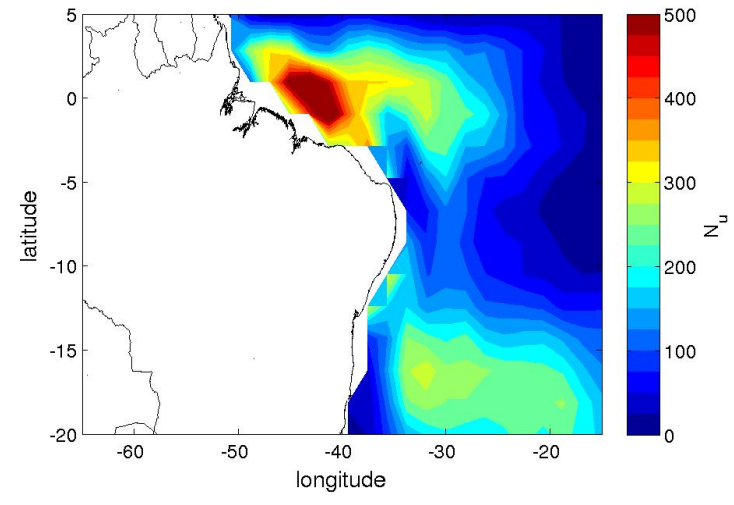

(a) NCEP

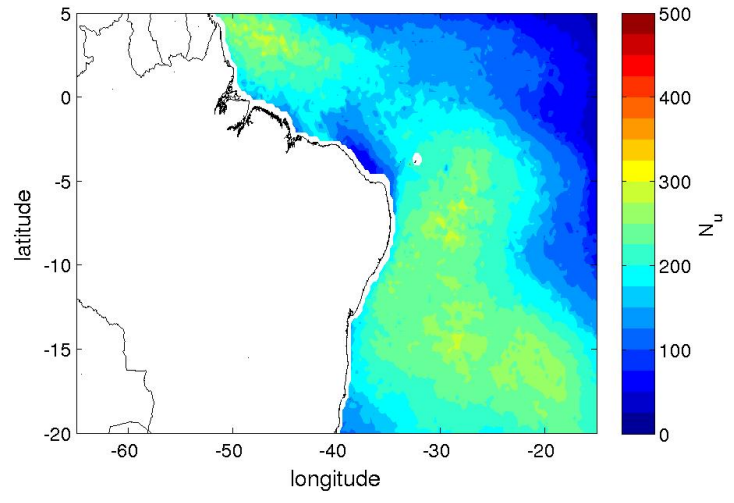

(b) BRAMS

Figura 3.2: Quantidade de eventos acima do limiar $\left(N_{u}\right)$ para ventos de leste. Região Tropical.

Tal característica é refletida nos extremos de retorno $x_{r}$, que encontram-se na figura 3.3. Nos mapas do NCEP nota-se a presença de um núcleo único e extenso de valores extremos de retorno estáveis (sem divergência dos intervalos de confiança) nas vizinhanças da zona costeira norte/nordeste do Brasil. Para períodos de retorno de 50 anos os valores atingem até $30 \mathrm{~m} / \mathrm{s}$. Esse núcleo pode estar relacionado com a representação da zona de encontro dos alíseos nessa região. Já os mapas de $x_{r}$ do BRAMS apresentam vários núcleos estáveis em todo o domínio, com intensidades similares às encontradas com o NCEP. Na zona costeira, destaca-se um núcleo na região nordeste, em aproximadamente $42^{\circ} \mathrm{W}$ longitude e $2^{\circ} \mathrm{S}$ latitude, com valores $x_{r}$ para 50 anos atingindo também $30 \mathrm{~m} / \mathrm{s}$, que podem ser resultantes não apenas dos extremos associados aos ventos alíseos mas também à brisa marítima e até mesmo a formação de linhas de instabilidade, representadas mais adequadamente pela simulação. Também na zona costeira, em cerca de $35^{\circ} \mathrm{W}$ e $14^{\circ} \mathrm{S}$, há um núcleo não representado pelo NCEP com extremos de retorno para 50 anos atingindo cerca de $24 \mathrm{~m} / \mathrm{s}$. Na região oceânica. A presença desses núcleos distintos da representação dada pelo NCEP pode ser explicada pela representação das ondas de leste na região através do downscaling do BRAMS. A distribuição em pulsos desses valores extremos indica tal fenômeno como gerador desses núcleos extremos. 


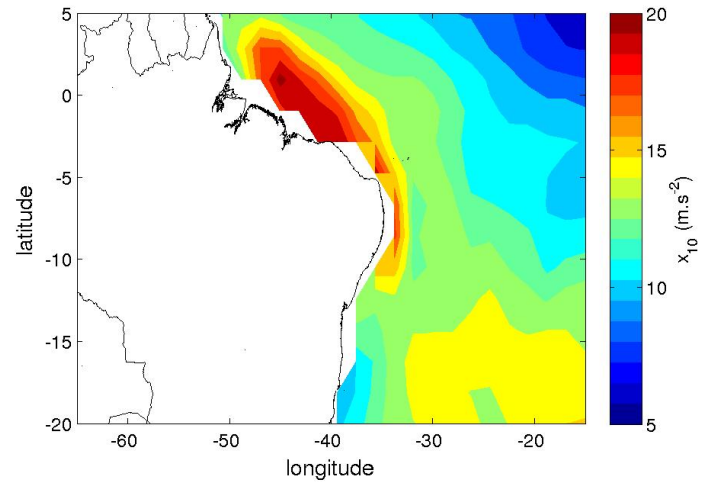

(a) NCEP - 10 anos

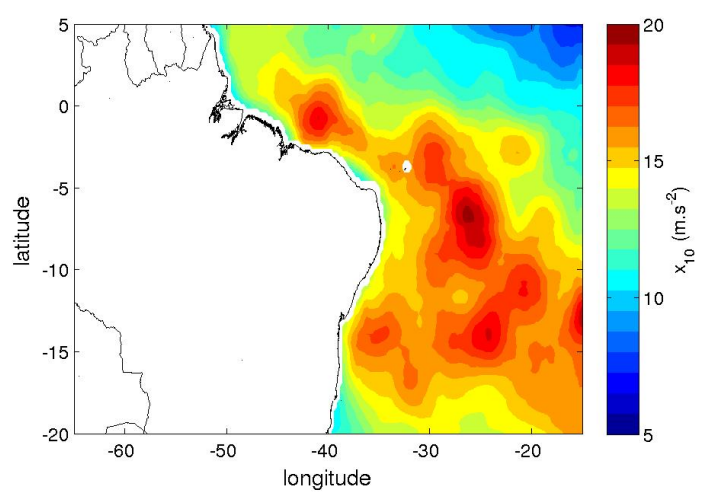

(d) BRAMS - 10 anos

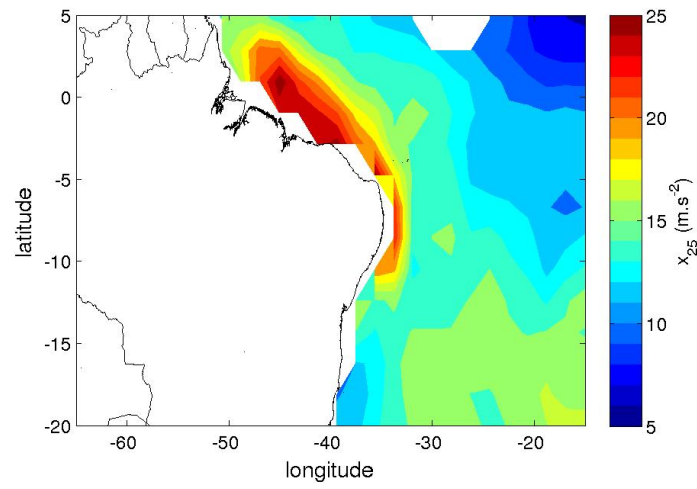

(b) NCEP - 25 anos

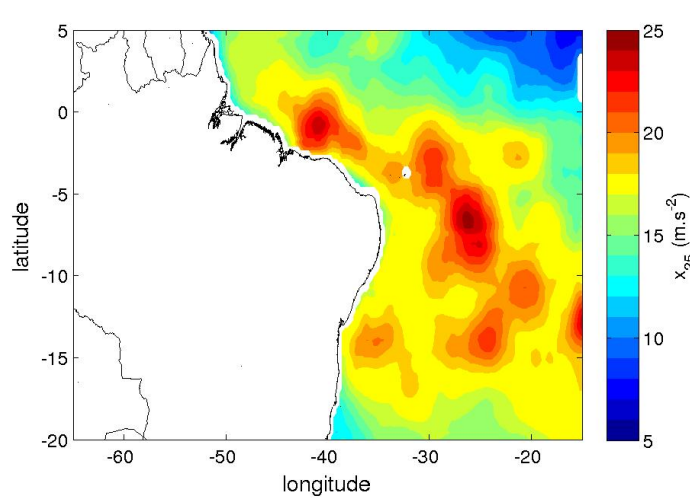

(e) BRAMS - 25 anos

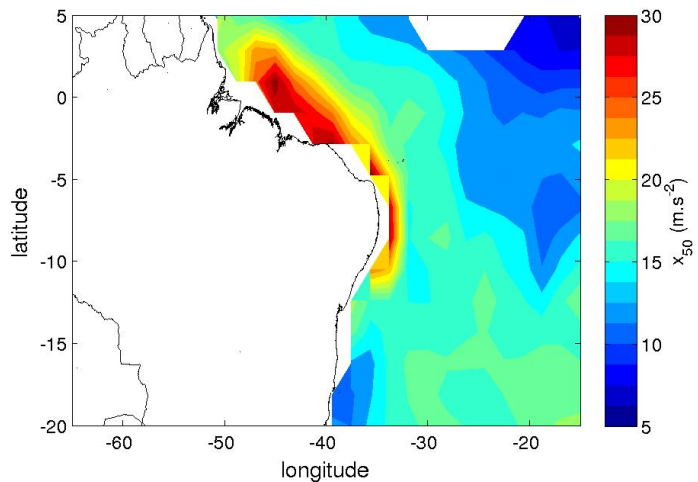

(c) NCEP - 50 anos

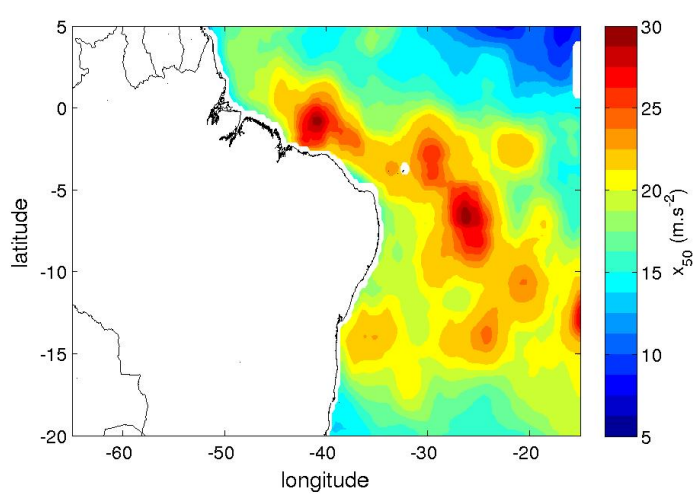

(f) BRAMS - 50 anos

Figura 3.3: Valores extremos de retorno para ventos de leste. Região Tropical. 
Já os mapas de distribuição de $N_{u}$ para ventos de nordeste encontram-se na figura 3.4. Há uma grande quantidade de eventos extremos com intensidades acima do limiar escolhido no extremo norte do domínio, em ambos os conjuntos, ligados à presença dos ventos alíseos de nordeste na região. Nota-se, porém, uma quantidade muito maior de extremos no conjunto NCEP com relação ao BRAMS, isso indica que, muito embora o downscalling do BRAMS contemple um maior número de fenômenos geradores de eventos extremos, a intensidade dos mesmos pode ter sido menor. Sendo assim, menos eventos excedem o limiar estabelecido. O núcleo presente na zona costeira sudeste, evidente no mapa do NCEP, será discutido na seção adiante que trata dos resultados na porção sul do domínio.

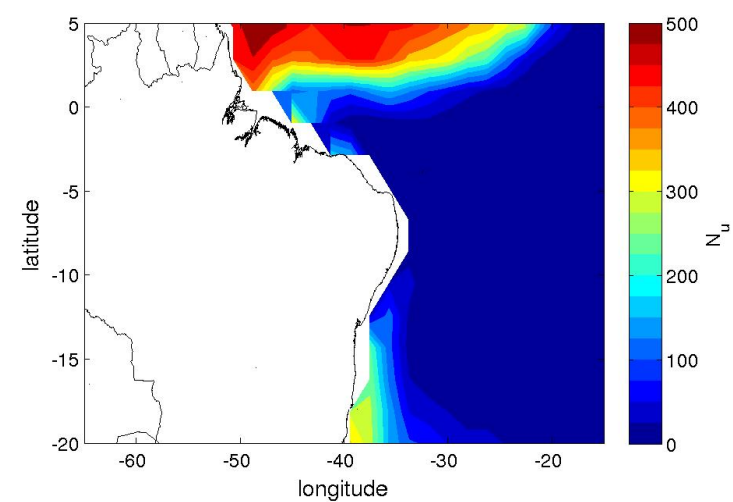

(a) NCEP

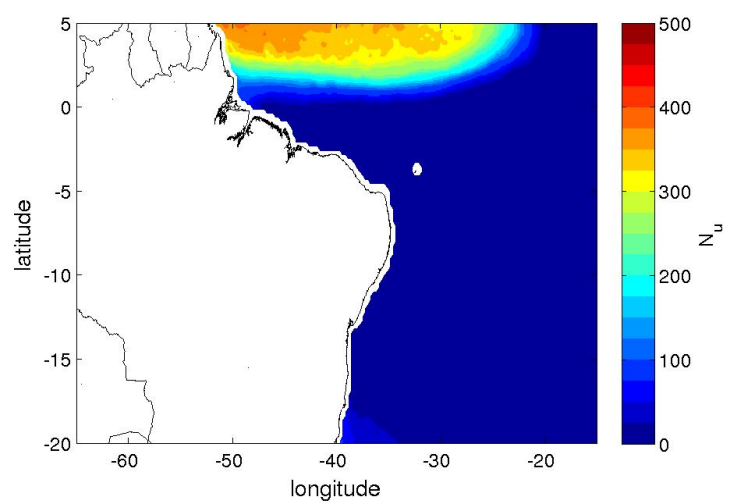

(b) BRAMS

Figura 3.4: Quantidade de eventos acima do limiar $\left(N_{u}\right)$ para ventos de nordeste. Região Tropical.

Os mapas de distribuição de $x_{r}$ para ventos de nordeste e períodos de retorno de 10,25 e 50 anos encontram-se na figura 3.5. A primeira característica notável é a extensão da instabilidade dos valores extremos de retorno, ocasionada por baixos valores de $N_{u}$. Os valores estáveis encontram-se no extremo norte do domínio, para ambos os conjuntos de dados, sendo ligeiramente mais intensos para o BRAMS (atingindo cerca de $35 \mathrm{~m} / \mathrm{s}$ para 50 anos de retorno) do que para o NCEP (que atingem aproximadamente $30 \mathrm{~m} / \mathrm{s}$ para 50 anos de retorno). Tais valores relacionam-se com os ventos alíseos de nordeste persistentes na região. Além disso, nos mapas do NCEP, nota-se a presença de um núcleo costeiro com valores extremos de retorno para ventos de nordeste bastante elevados, atingindo até $40 \mathrm{~m} / \mathrm{s}$ para períodos de retorno de 50 anos. Tal 
núcleo não encontra-se presente nos mapas de representação do BRAMS. 


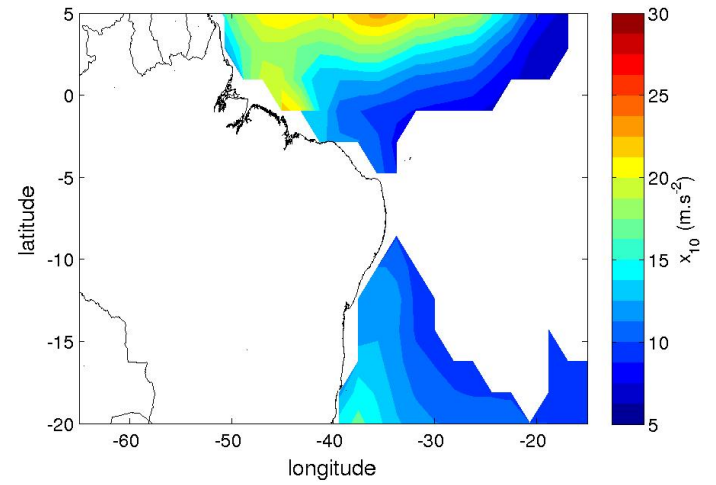

(a) NCEP - 10 anos

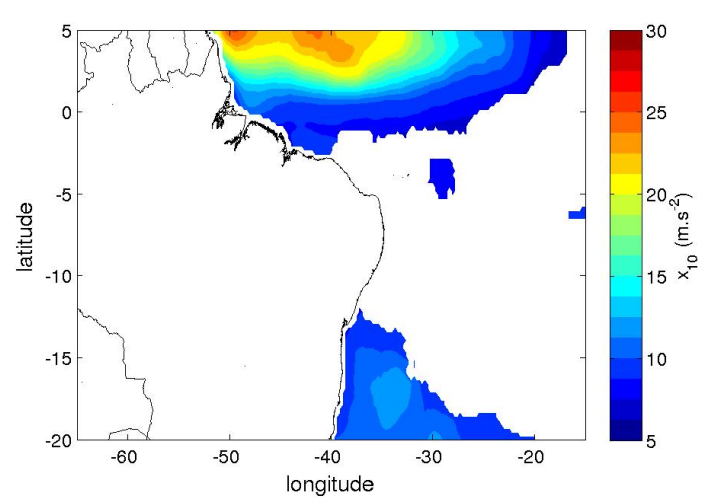

(d) BRAMS - 10 anos

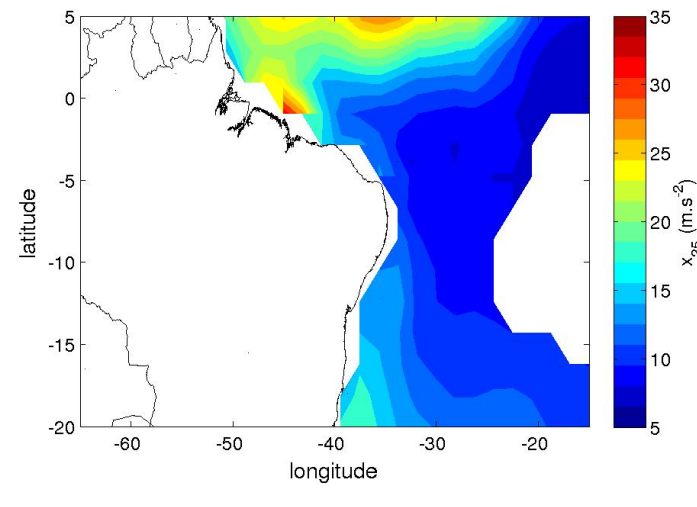

(b) NCEP - 25 anos

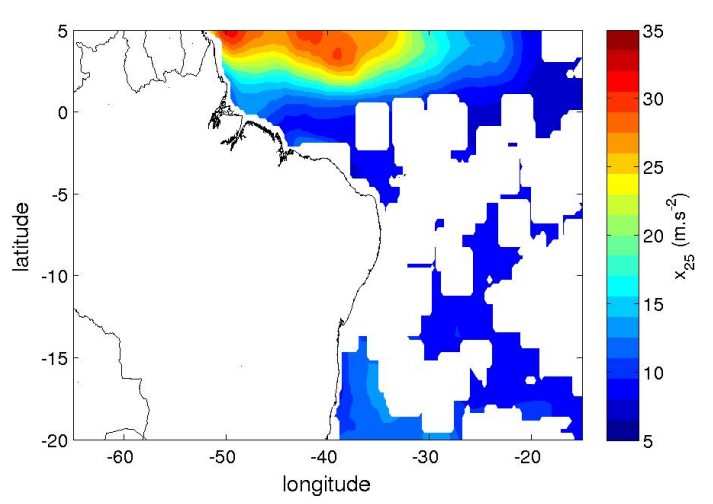

(e) BRAMS - 25 anos

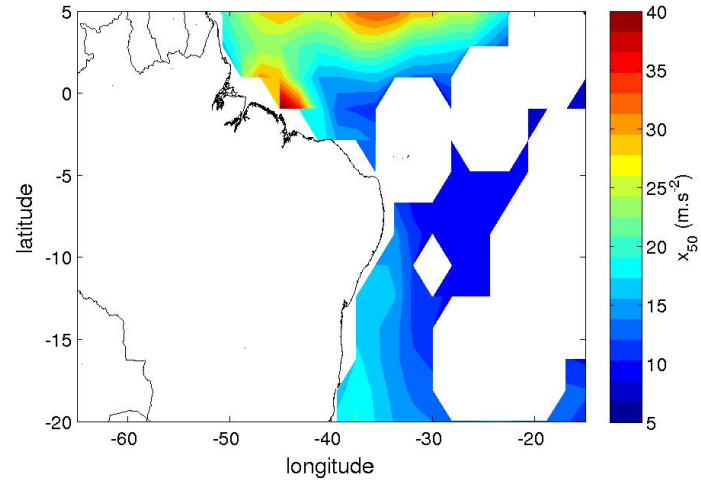

(c) NCEP - 50 anos

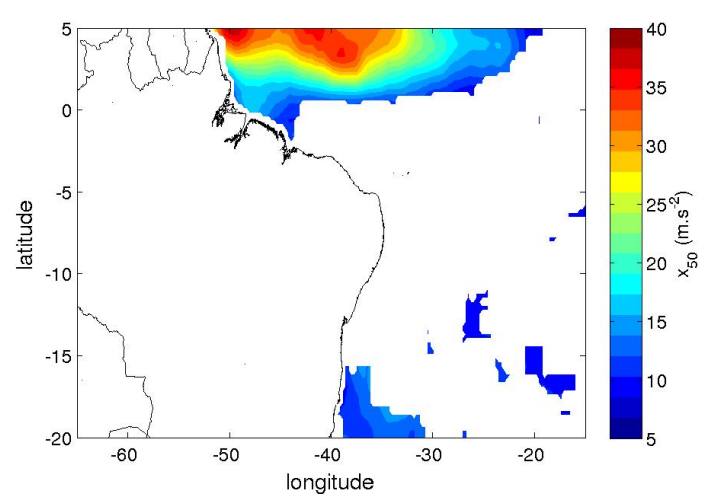

(f) BRAMS - 50 anos

Figura 3.5: Valores extremos de retorno para ventos de nordeste. Região Tropical. 
Os mapas representando os valores de $N_{u}$ para os ventos de sudeste no domínio tropical encontramse na figura 3.6. Neles, é possível observar a alta incidência de valores extremos acima do limiar na região de atuação da ASAS, quando encontra-se em sua posição mais ao sul e próxima ao continente. Tais valores são bastante elevados nos dados do NCEP, principalmente na região costeira, ao passo que para o BRAMS, as maiores ocorrências de valores extremos independentes encontram-se nas zonas costeira e oceânica. O efeito da representação da circulação de brisa pode favorecer a presença desses valores extremos costeiros em cerca de $37^{\circ} \mathrm{W}$ e $13^{\circ} \mathrm{S}$. Ao passo que os núcleos de $x_{r}$ elevados na zona oceânica podem associar-se tanto com a atuação da ASAS como com distúrbios de leste na região.

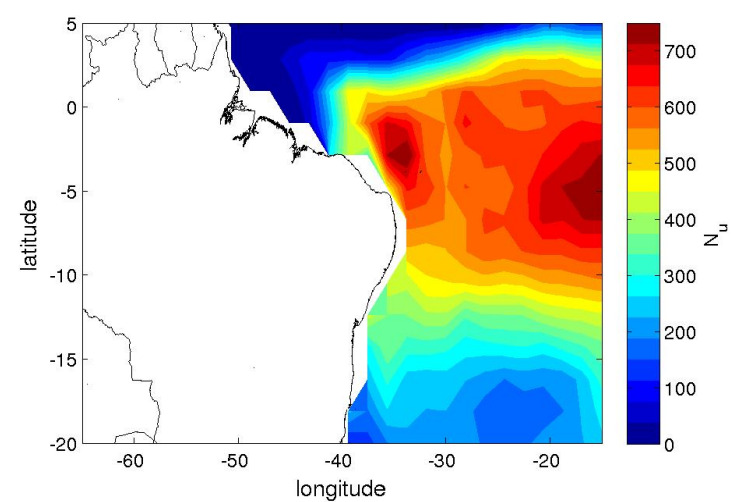

(a) NCEP

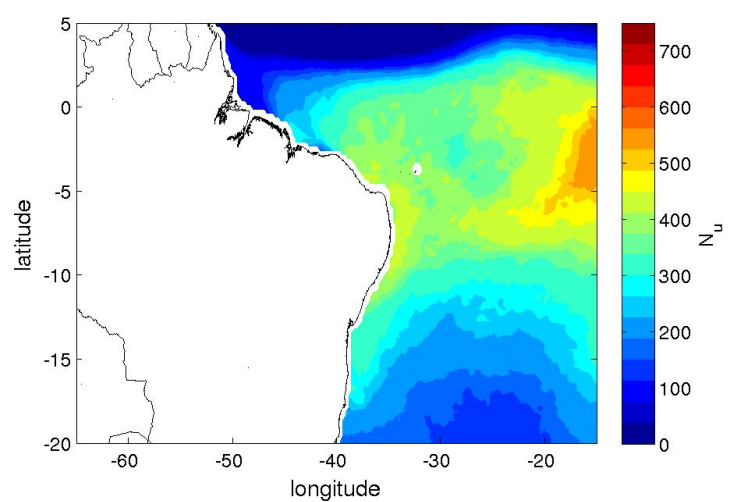

(b) BRAMS

Figura 3.6: Quantidade de eventos acima do limiar $\left(N_{u}\right)$ para ventos de sudeste. Região Tropical.

Os valores extremos de retorno de ventos de sudeste para tais conjuntos, representados na figura ??, refletem tal característica. Nota-se a presença de núcleos estáveis na zona oceânica para os dados do BRAMS. Para o NCEP, no entanto, os núcleos de valores extremos de retorno concentram-se na zona costeira, principalmente na região nordeste, em que valores estáveis de $x_{r}$ para 50 anos atingem até $35 \mathrm{~m} / \mathrm{s}$ em cerca de $41^{\circ} \mathrm{W}$ e $1^{\circ} \mathrm{S}$, e $27 \mathrm{~m} / \mathrm{s} \mathrm{em} 34^{\circ} \mathrm{W}$ e $8.5^{\circ} \mathrm{S}$. Para os BRAMS, notam-se núcleos estáveis na região oceânica e núcleos bem definidos na zona costeira. Um deles, com valores de $x_{r}$ que atingem também $35 \mathrm{~m} / \mathrm{s}$, ocupam uma região em que os valores encontrados pelo NCEP apresentaram instabilidade e não puderam ser representados para períodos de retorno de 50 anos, em aproximadamente $34^{\circ} \mathrm{W}$ e $0^{\circ}$. Outro, também pre- 
sente nos mapas do NCEP, encontra-se em aproximadamente $36^{\circ} \mathrm{W}$ e $12^{\circ} \mathrm{S}$ e seus valores de $x_{r}$ atingem cerca de $28 \mathrm{~m} / \mathrm{s}$. Em ambos os casos, é notável a presença de tais valores extremos ocasionados pela presença da Zona de Convergência Intertropical (ZCIT) e variabilidade da ASAS na região. A brisa marítima também Os núcleos encontrados nas zonas costeiras e oceânicas da região sudeste serão abordados adiante. 


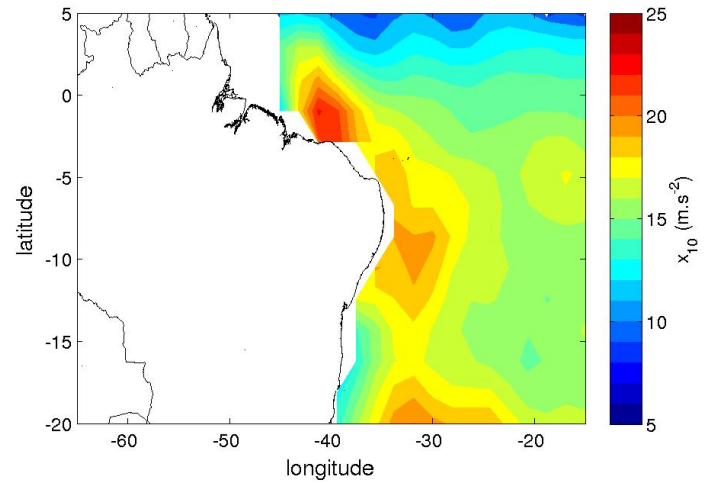

(a) NCEP - 10 anos

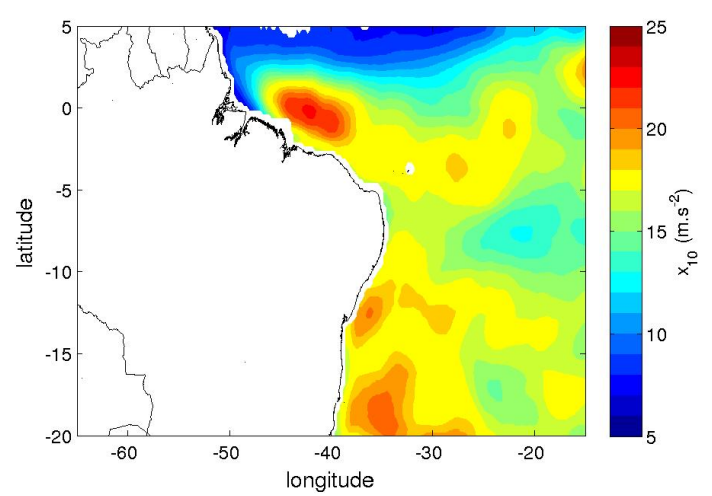

(d) BRAMS - 10 anos

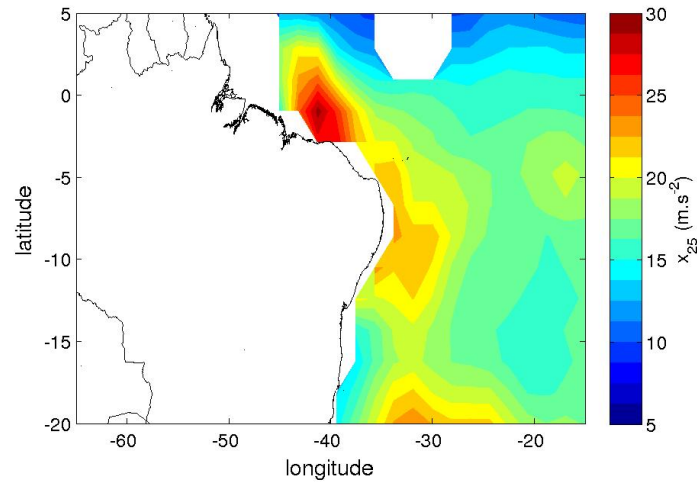

(b) NCEP - 25 anos

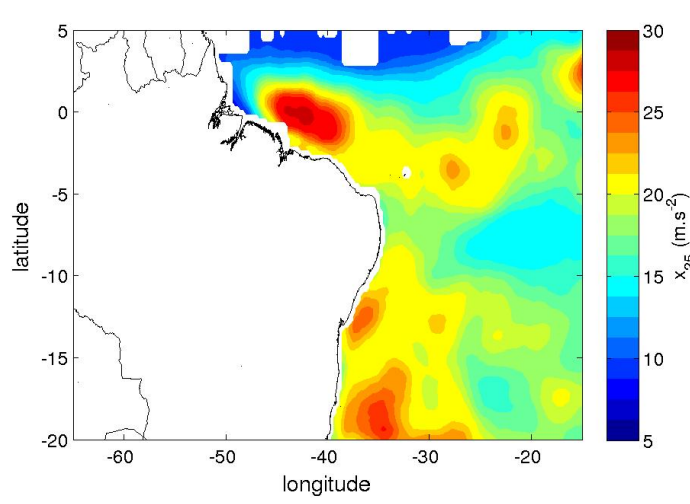

(e) BRAMS - 25 anos

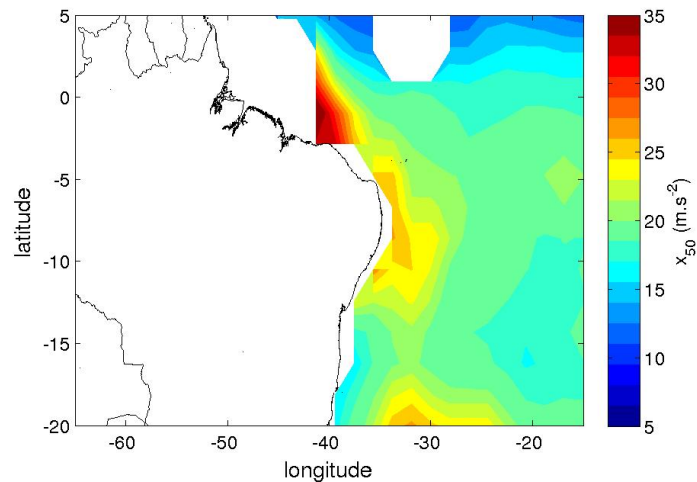

(c) NCEP - 50 anos

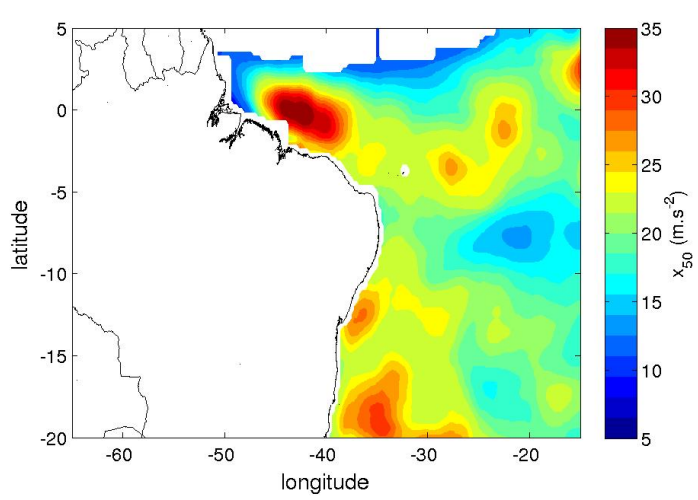

(f) BRAMS - 50 anos

Figura 3.7: Valores extremos de retorno para ventos de sudeste. Região Tropical. 


\subsection{Região Sudeste/Sul}

Nessa parcela do domínio, que contempla a região contida entre $40^{\circ} \mathrm{S}$ e $20^{\circ} \mathrm{S}$ de latitude, os ventos são influenciados por sistemas instáveis, pela passagem de sistemas frontais, pela formação de ciclones e por bloqueios no escoamento de grande escala. A presença de todas essas feições garante regiões com extremos de retorno significativos em todas as direções ao longo da zona costeira dessa porção do domínio.

Os mapas de distribuição dos valores de $N_{u}$ para ventos do quadrante norte encontram-se na figura 3.8. No mapa do NCEP, nota-se uma zona de grande incidência para valores extremos de ventos de norte na zona costeira e oceânica sudeste do Brasil. Uma quantidade significativa estende-se nessa região oceânica até o extremo sul do domínio. O núcleo de maior ocorrência localiza-se em uma região favorável à formação de ventos desse quadrante pela atuação do braço oeste da ASAS. No mapa do BRAMS, porém, não é possível distinguir uma região mais favorável à ocorrência. Valores significativos espalham-se por todo o domínio, tanto costeiro quanto oceânico, exceto em uma pequena parcela da costa sudeste/sul do Brasil. O maior detalhamento das feições pelo downscaling, além da resolução de fenômenos em escala subsinótica, garantiu um maior número de eventos desse quadrante na zona costeira.

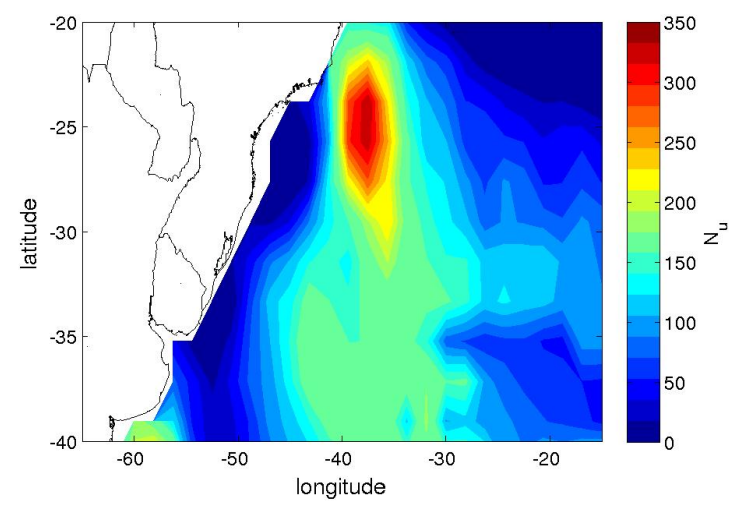

(a) NCEP

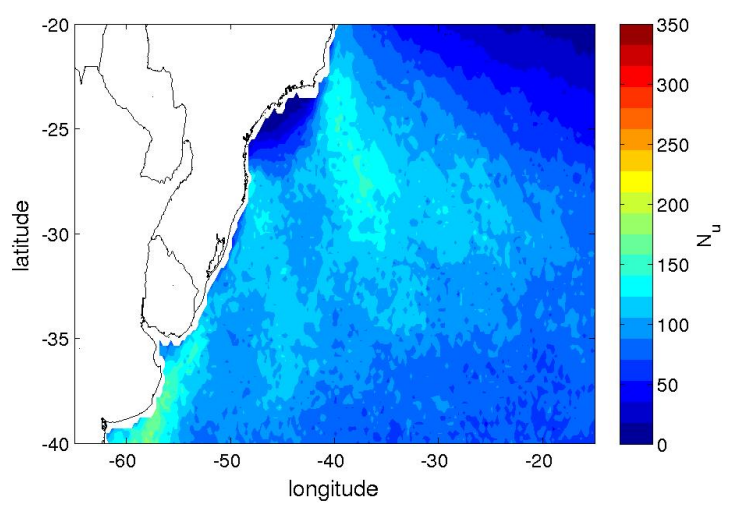

(b) BRAMS

Figura 3.8: Quantidade de eventos acima do limiar $\left(N_{u}\right)$ para ventos de norte. Região Sudeste/Sul. 
Essa distribuição diferenciada dos valores de $N_{u}$ refletiu diretamente na distribuição dos extremos de retorno. Para o NCEP nota-se um núcleo com extremos intensos de aproximadamente 40m/s para períodos de retorno de 50 anos na zona costeira sudeste, justamente na região de maior $N_{u}$. Para os mapas do BRAMS, no entanto, esse núcleo não é verificado. O núcleo estável mais evidente para esse conjunto encontra-se nas proximidades da zona costeira do Rio Grande do Sul, com valores que atingem cerca de $43 \mathrm{~m} / \mathrm{s}$ para períodos de retorno de 50 anos. Tendo em vista que a simulação com o BRAMS foi desenvolvida de tal forma a manter os principais fenômenos do conjunto NCEP e resolver os demais possíveis pelo aumento na resolução, esse núcleo de extremos de retorno na região sudeste pode ter sido mascarado pela influência de outros fenômenos resolvidos pelo modelo. 


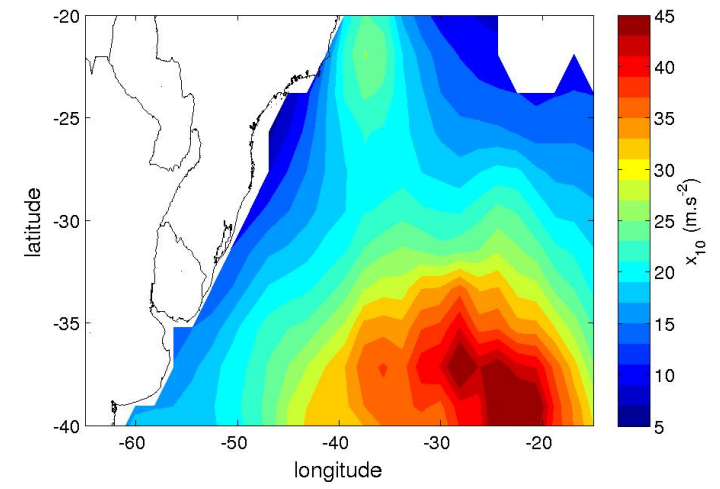

(a) NCEP - 10 anos

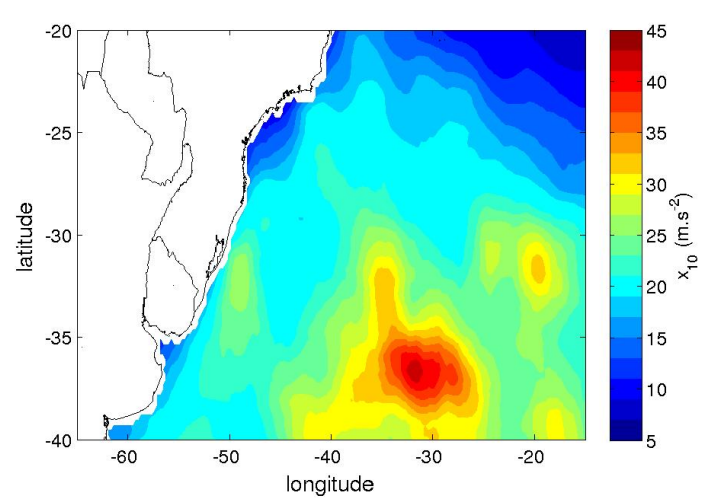

(d) BRAMS - 10 anos

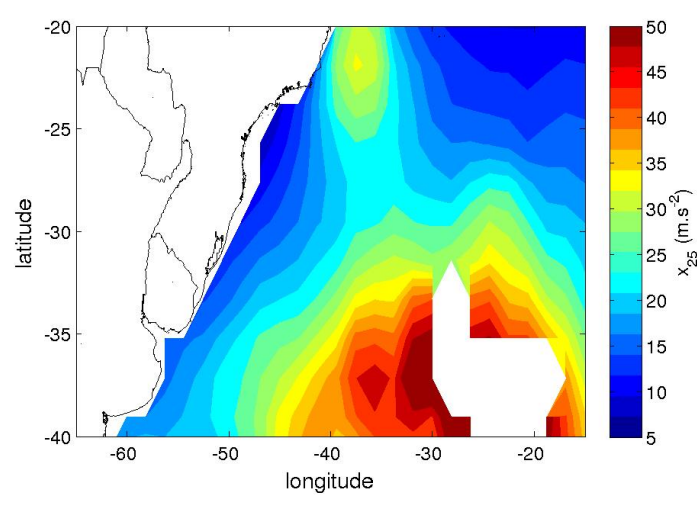

(b) NCEP - 25 anos

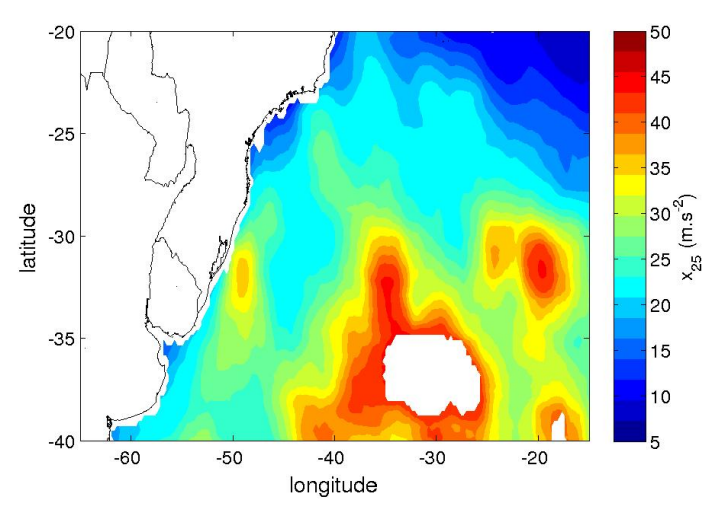

(e) BRAMS - 25 anos

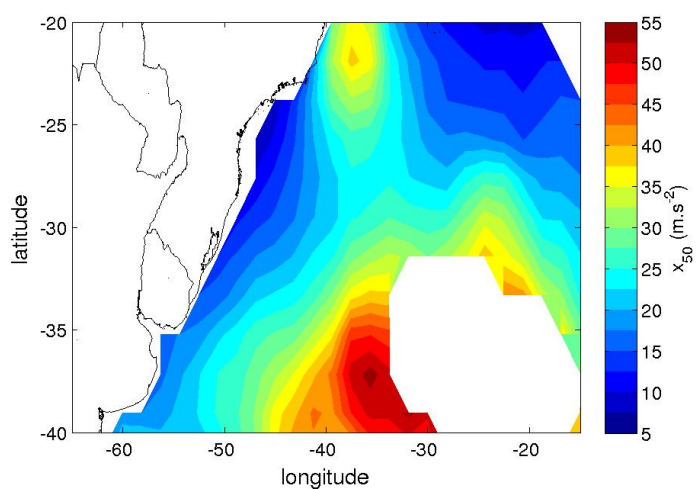

(c) NCEP - 50 anos

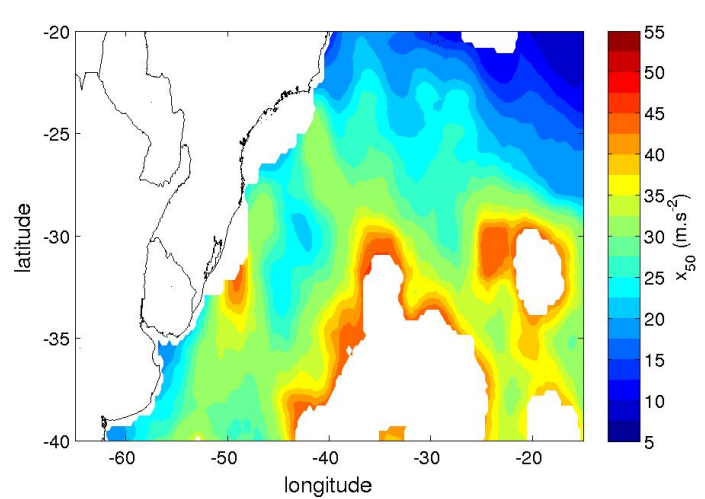

(f) BRAMS - 50 anos

Figura 3.9: Valores extremos de retorno para ventos de norte. Região Sudeste/Sul. 
Na figura 3.10 encontram-se os mapas de distribuição de $N_{u}$ para ventos de nordeste. Nelas, pode-se observar a elevada incidência de eventos extremos na zona costeira do domínio, com dois núcleos mais evidentes na costa sudeste (ao redor da região de Cabo Frio/RJ) e sul (costa do Rio Grande do Sul). Nos mapas do BRAMS, esses núcleos são mais evidentes. E, diferentemente do que foi observado para outras direções, os valores não se distanciam tanto entre os dois conjuntos. Com exceção do núcleo na costa do Rio Grande do Sul, que conta com maior incidência de eventos extremos para o BRAMS. Em ambos os casos, a elevada quantidade de eventos extremos acima do limiar para esse quadrante nessas duas regiões relaciona-se com a presença da ASAS e com o favorecimento na incidência de ventos de nordeste dada pela orientação da linha de costa.

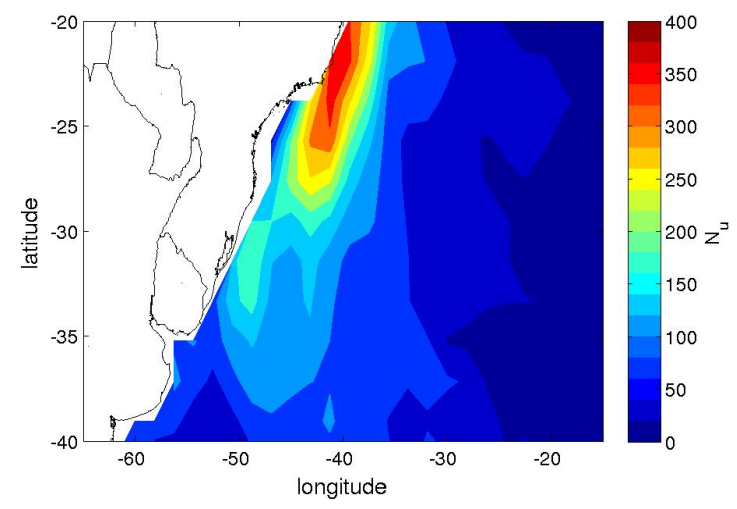

(a) NCEP

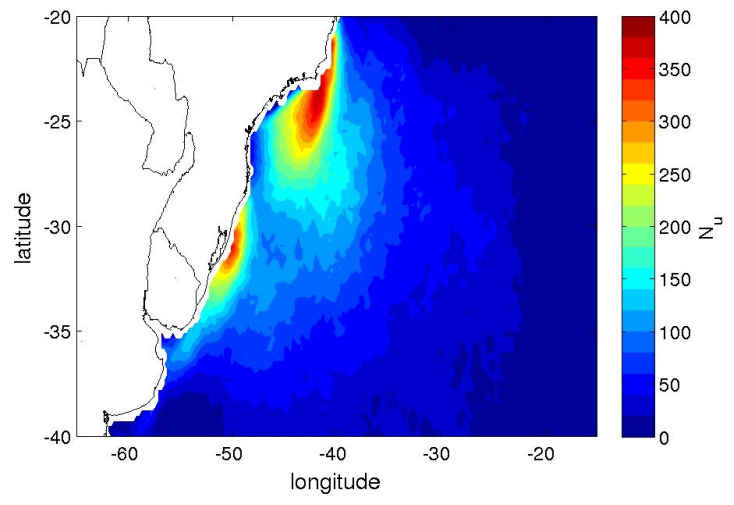

(b) BRAMS

Figura 3.10: Quantidade de eventos acima do $\operatorname{limiar}\left(N_{u}\right)$ para ventos de nordeste. Região Sudeste/Sul.

Nos mapas de extremos de retorno, representados na figura 3.11, nota-se uma ampla zona de instabilidade da aplicação da metodologia para o extremo sul do domínio oceânico devido à escassez de picos excedentes ao limiar oriundos de nordeste nessas áreas. Nos mapas do NCEP, muito embora haja uma quantidade significativa de valores extremos na zona costeira, apenas um núcleo de extremos de retorno estáveis significativo pode ser visualizado em cerca de $40^{\circ} \mathrm{W}$ e $25^{\circ} \mathrm{S}$ com valores $x_{r}$ atingindo $25 \mathrm{~m} / \mathrm{s}$ para períodos de retorno de 50 anos. Já para o BRAMS, as duas regiões com elevada incidência de extremos indicada nos mapas de $N_{u}$ apresentam extremos de retorno elevados, com dois núcleos estáveis razoavelmente definidos. Em cerca de 
$41^{\circ} \mathrm{W}$ e $25^{\circ} \mathrm{S}$, os valores de $x_{r}$ atingem $28 \mathrm{~m} / \mathrm{s}$ para períodos de retorno de 50 anos. Já na costa do Rio Grande do sul, nota-se um núcleo de $x_{r}$ com valores atingindo $30 \mathrm{~m} / \mathrm{s}$ para períodos de retorno de 50 anos.

A ausência de núcleos estáveis significativos na zona costeira dos mapas do NCEP pode ser explicada também pela ausência de detalhamento nos fenômenos resolvidos pelo modelo de reanálise. Ao passo que para o BRAMS, o aumento na resolução do downscaling foi responsável pelo detalhamento de fenômenos responsáveis pela incidência de ventos de nordeste intensos, além da influência da ASAS, como a incidência de centros de alta pressão na retaguarda dos sistemas frontais. 


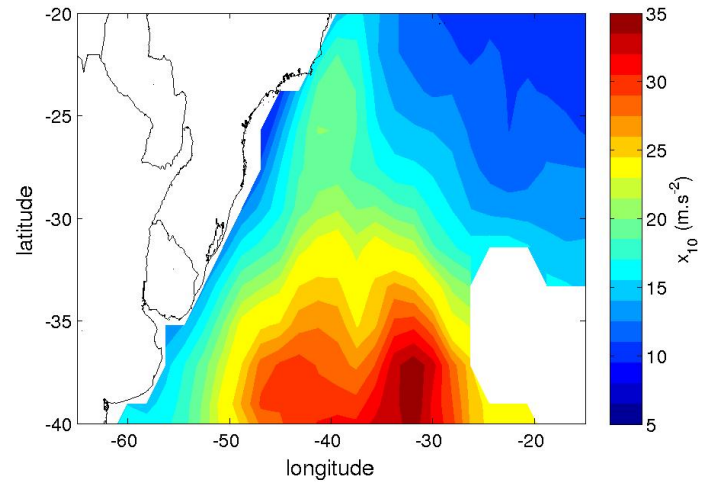

(a) NCEP - 10 anos

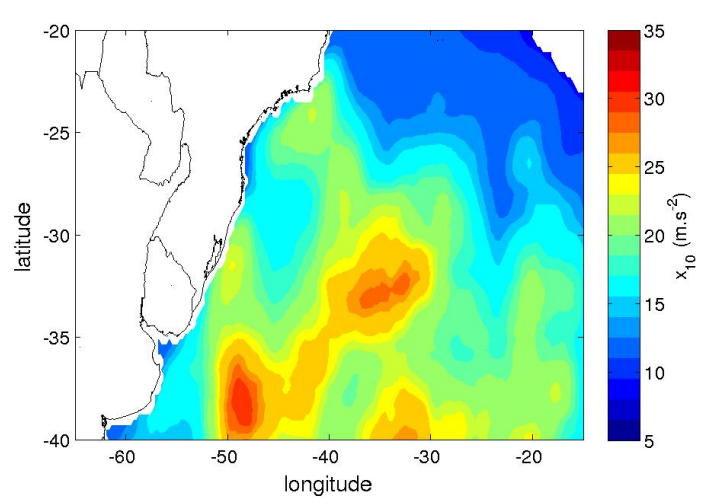

(d) BRAMS - 10 anos

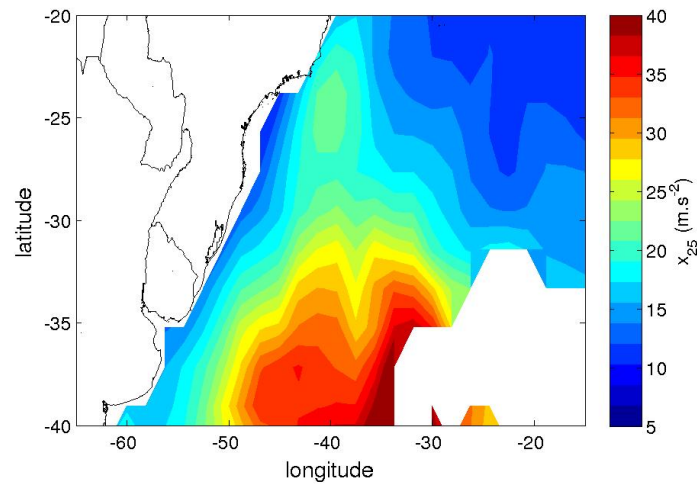

(b) NCEP - 25 anos

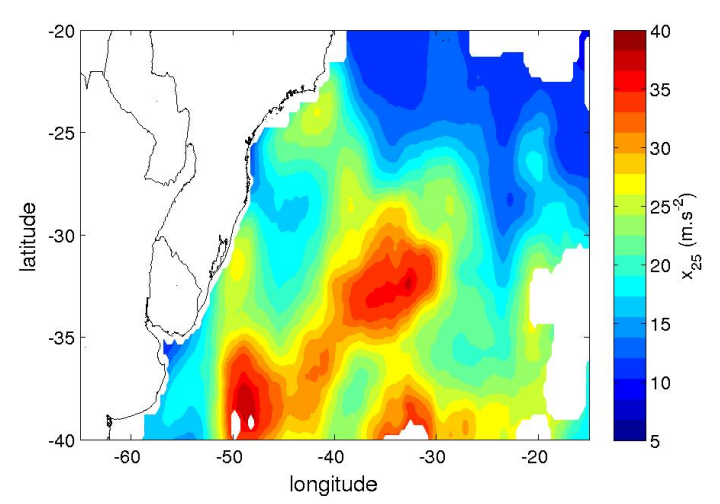

(e) BRAMS - 25 anos

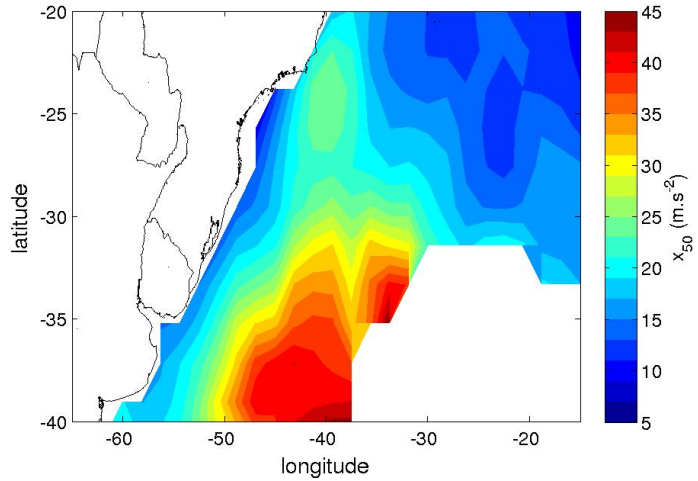

(c) NCEP - 50 anos

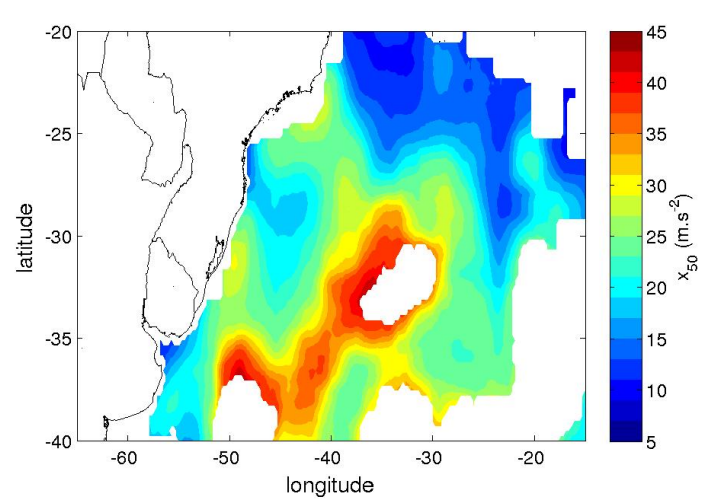

(f) BRAMS - 50 anos

Figura 3.11: Valores extremos de retorno para ventos de nordeste. Região Sudeste/Sul. 
Os mapas com os valores de $N_{u}$ para ventos de leste encontra-se na figura 3.12. No mapa do BRAMS, é notável a presença de uma grande quantidade de eventos com ventos de leste excedentes ao limiar. Para o NCEP tal característica não foi verificada. O maior número de eventos extremos independentes encontrados pelo resultado da simulação com o BRAMS com relação ao NCEP pode ser justificado pelo maior detalhamento na transição entre continente e oceano dada pelo downscaling, acarretando em uma melhor representação da circulação local. Sendo assim, as brisas marítimas foram melhor representadas e podem ter contribuído para um número maior de eventos extremos de leste na região.

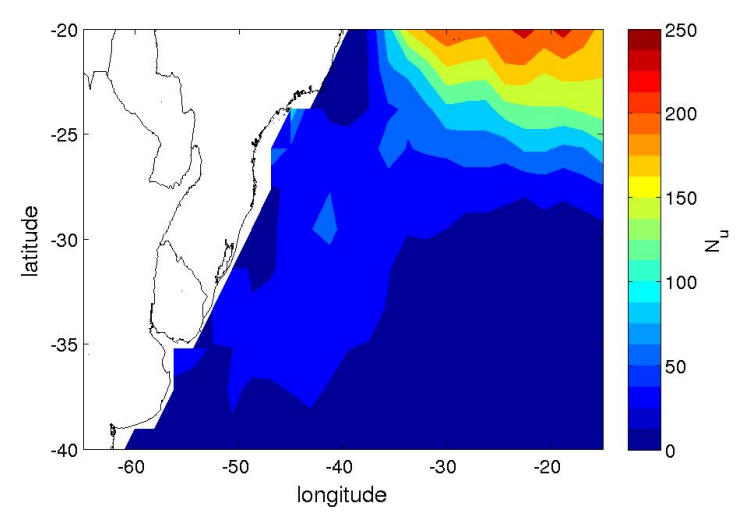

(a) NCEP

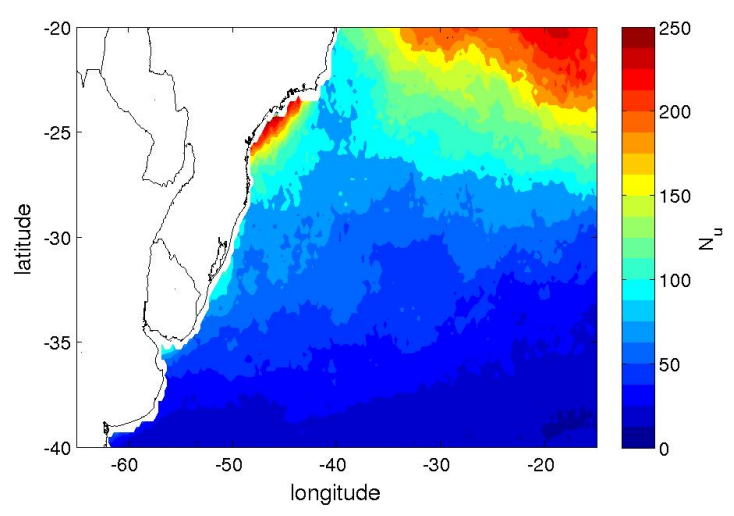

(b) BRAMS

Figura 3.12: Quantidade de eventos acima do limiar $\left(N_{u}\right)$ para ventos de leste. Região Sudeste/Sul.

Nos mapas de representação dos valores extremos de retorno (figura 3.13), porém, essa região não apresentou extremos de retorno significativos. Um núcleo estável pode ser visualizado na região costeira sul, em cerca de $46^{\circ} \mathrm{W}$ e $27^{\circ} \mathrm{S}$, com valores de $x_{r}$ atingindo $25 \mathrm{~m} / \mathrm{s}$ para períodos de retorno de 50 anos. Esse núcleo encontra-se ligeiramente deslocado da zona costeira. Isso indica que a grande quantidade de eventos na zona costeira associados à brisa não constituíram valores de retorno elevados. O posicionamento desse núcleo sugere a atuação da rotação do vento dos quadrantes norte/nordeste para sul/sudoeste com a passagem de sistemas frontais pela região. 


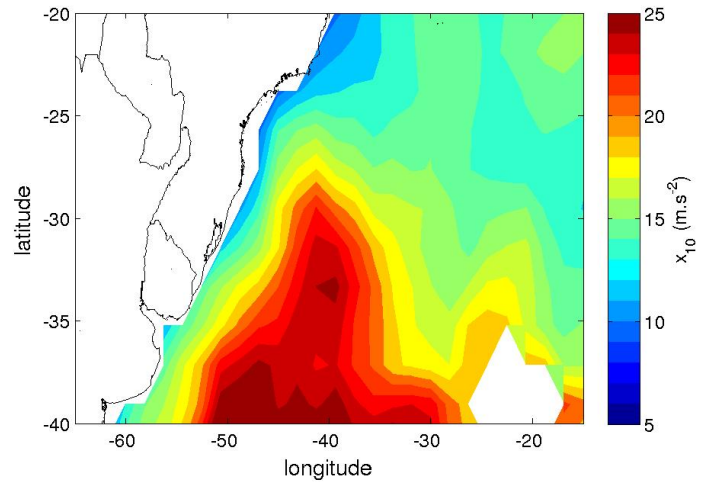

(a) NCEP - 10 anos

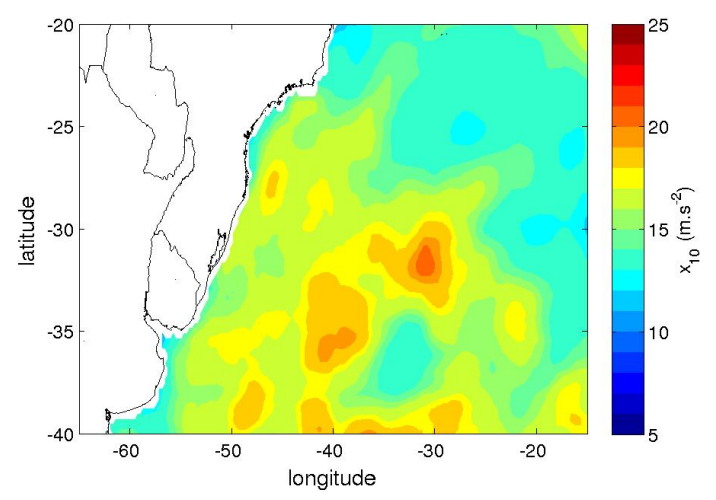

(d) BRAMS - 10 anos

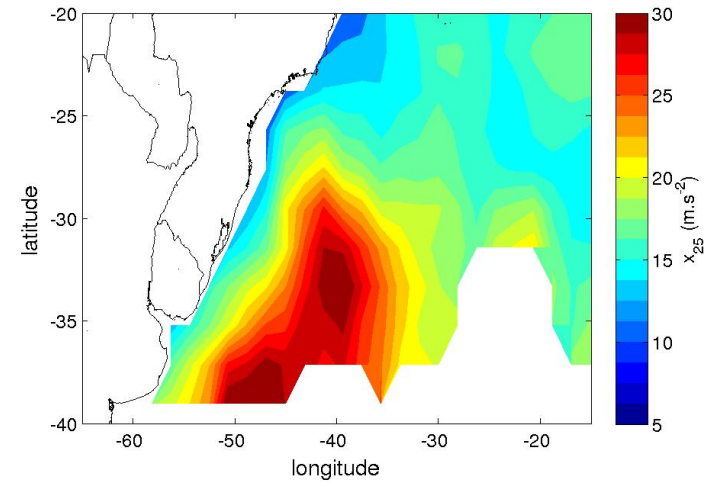

(b) NCEP - 25 anos

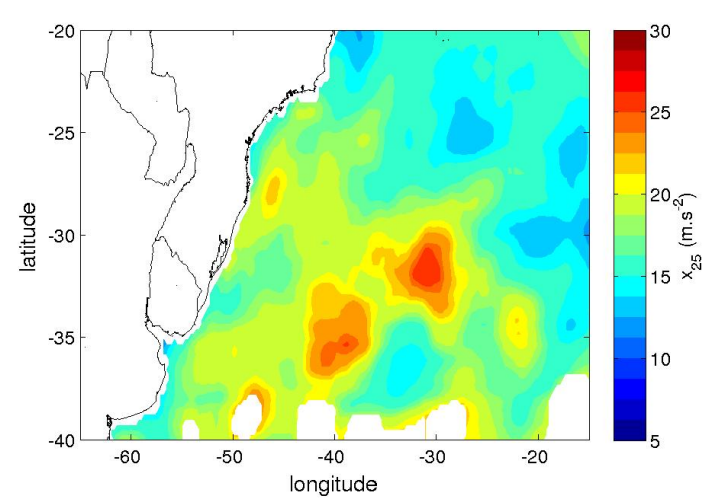

(e) BRAMS - 25 anos

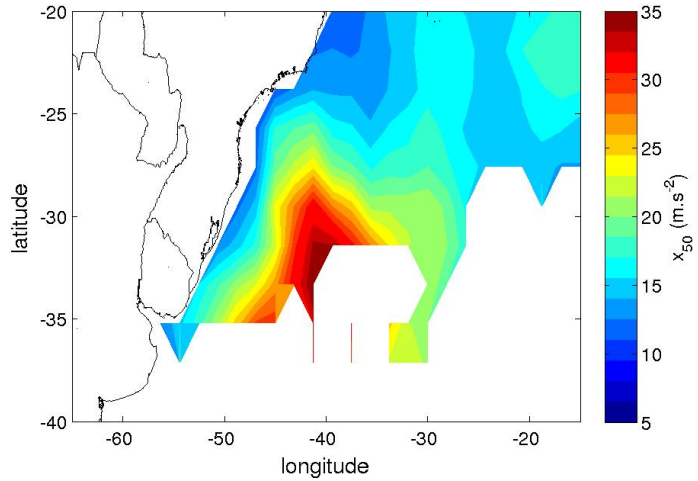

(c) NCEP - 50 anos

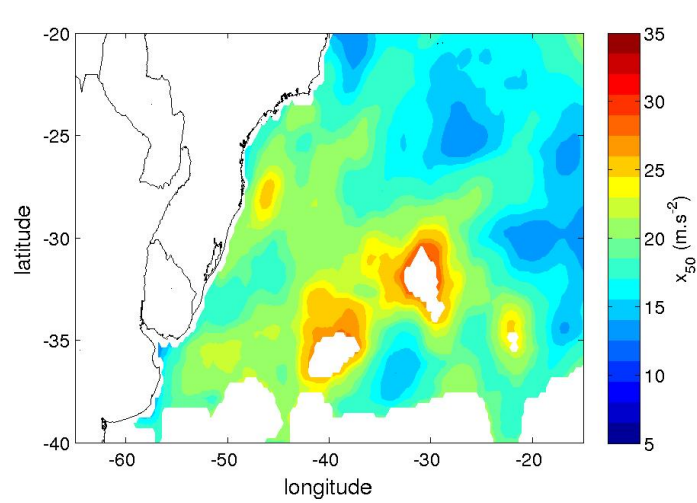

(f) BRAMS - 50 anos

Figura 3.13: Valores extremos de retorno para ventos de leste. Região Sudeste/Sul. 
Algo similar ao verificado para ventos de leste foi notado para ventos de sudeste. Há uma quantidade considerável de eventos extremos acima do limiar para esse quadrante na zona costeira sudeste/sul, através da análise com o BRAMS. Como para o NCEP não há um devido detalhamento da zona costeira, tais valores não foram significativos. Na região oceânica do extremo norte desse domínio, em ambos os conjuntos, nota-se uma incidência considerável de eventos extremos, dados os elevados valores de $N_{u}$. Tais feições podem ser verificadas na figura 3.14. Mais uma vez, a melhor representação do contraste entre áreas continentais e oceânicas desempenhou um importante papel na quantidade de eventos extremos independentes disponíveis para análise.

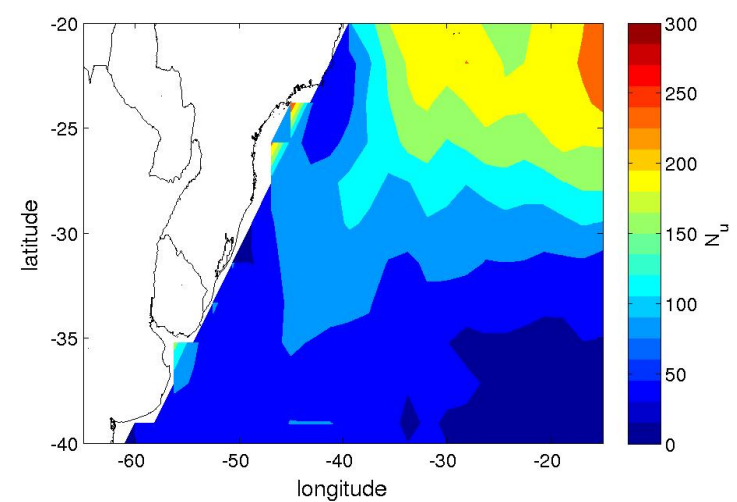

(a) NCEP

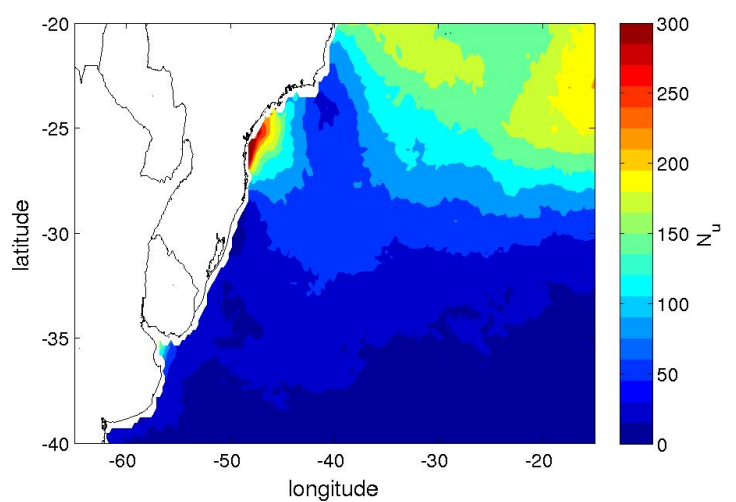

(b) BRAMS

Figura 3.14: Quantidade de eventos acima do limiar $\left(N_{u}\right)$ para ventos de sudeste. Região Sudeste/Sul.

Nos mapas de extremos de retorno (figura 3.15), nota-se uma associação direta das regiões com elevada incidência de eventos com maiores intensidades nos extremos de retorno. Para o NCEP, nota-se um núcleo estável de $x_{r}$ na região oceânica sudeste, com extremos de retorno atingindo aproximadamente $30 \mathrm{~m} / \mathrm{s}$, provavelmente associados à rotação do vento com a passagem de sistemas frontais. Já para o BRAMS, além da presença de valores elevados de $x_{r}$ nessa mesma região, nota-se um núcleo estável na zona costeira sudeste sul, com valores atingindo cerca de $26 \mathrm{~m} / \mathrm{s}$. Esse núcleo costeiro também pode associar-se com a melhor resolução da brisa na zona costeira. 


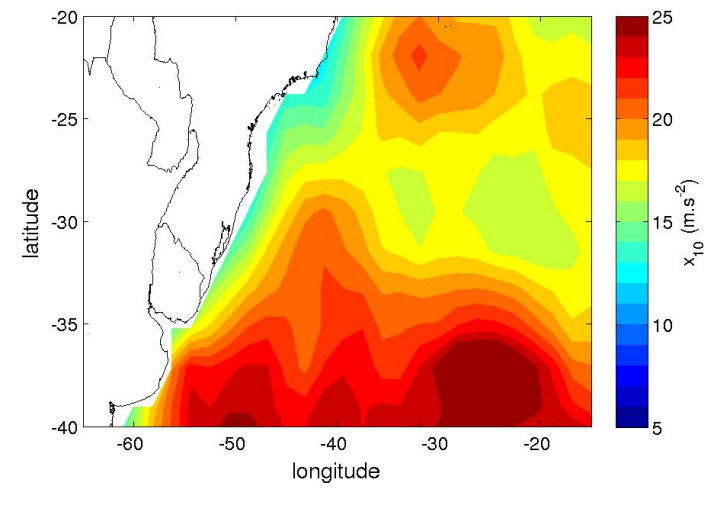

(a) NCEP - 10 anos

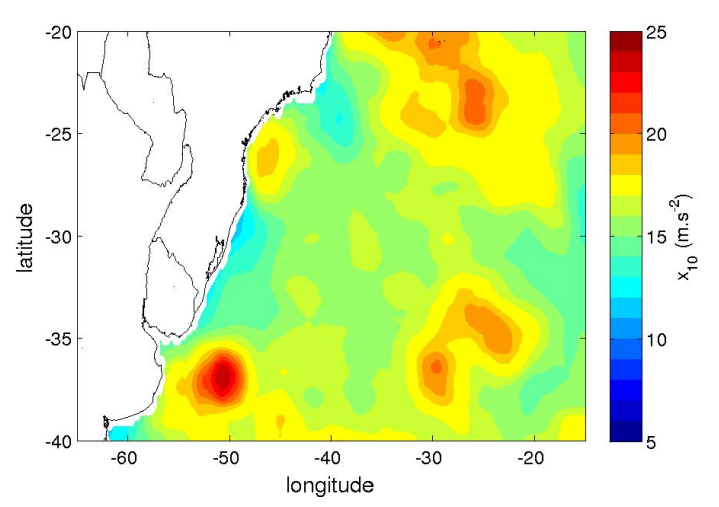

(d) BRAMS - 10 anos

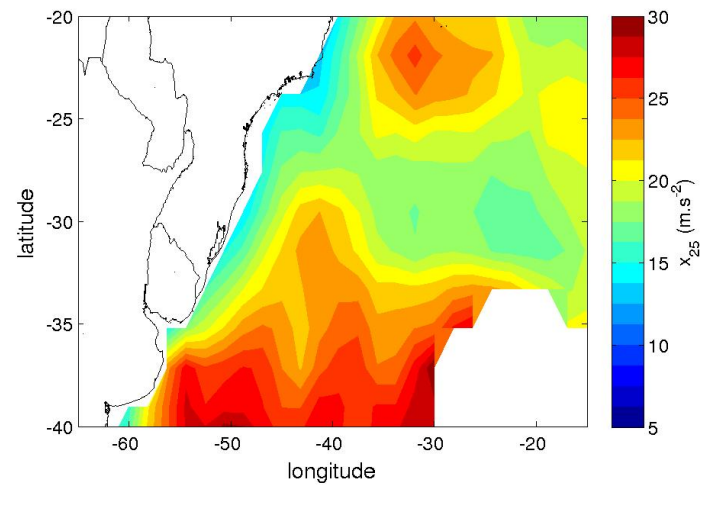

(b) NCEP - 25 anos

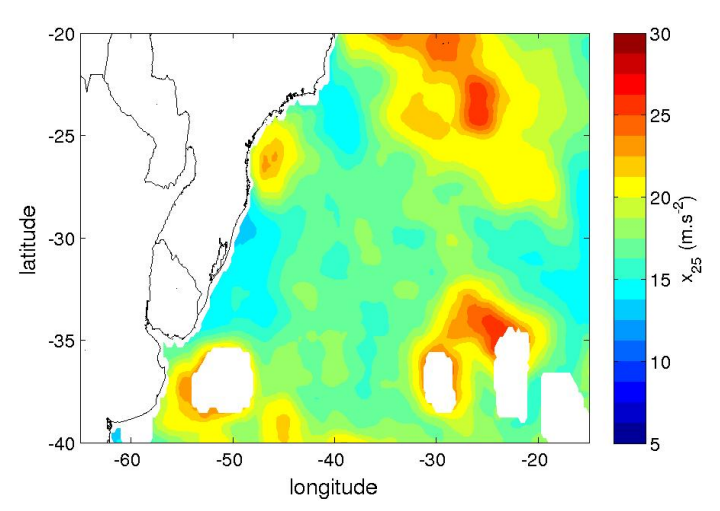

(e) BRAMS - 25 anos

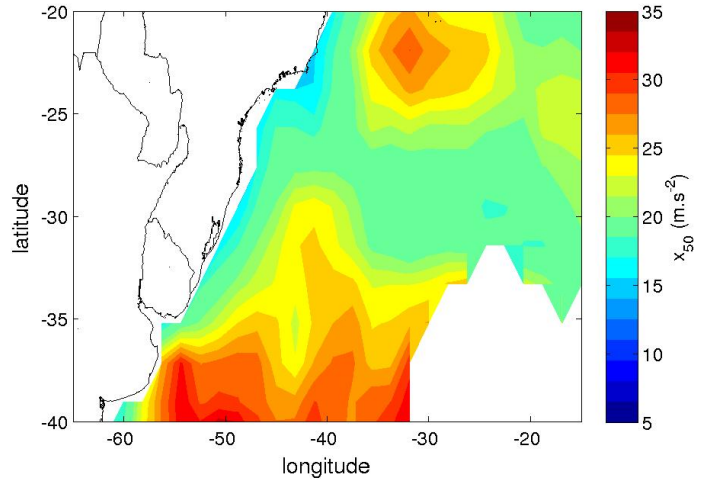

(c) NCEP - 50 anos

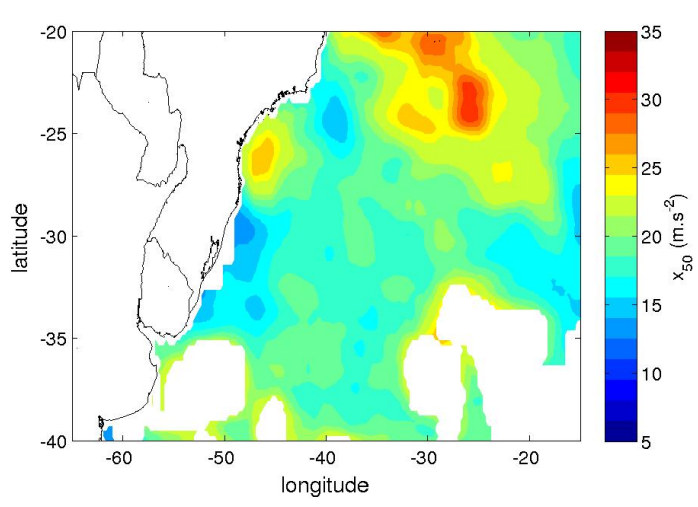

(f) BRAMS - 50 anos

Figura 3.15: Valores extremos de retorno para ventos de sudeste. Região Sudeste/Sul. 
Os mapas de distribuição das ocorrências de eventos extremos acima do limiar para ventos da direção sul podem ser vistos na figura 3.16. Para o NCEP, dois núcleos de ocorrência destacam-se na zona costeira sudeste/sul e extremo sul do domínio. Já para o BRAMS, há um espalhamento de regiões com ocorrências significativas de extremos desse quadrante por toda a zona costeira sudeste/sul do domínio. A melhor representação dos eventos em escala subsinótica, feita pelo downscalling, pode ter contribuído para uma maior dispersão da quantidade de picos independentes acima do limiar.

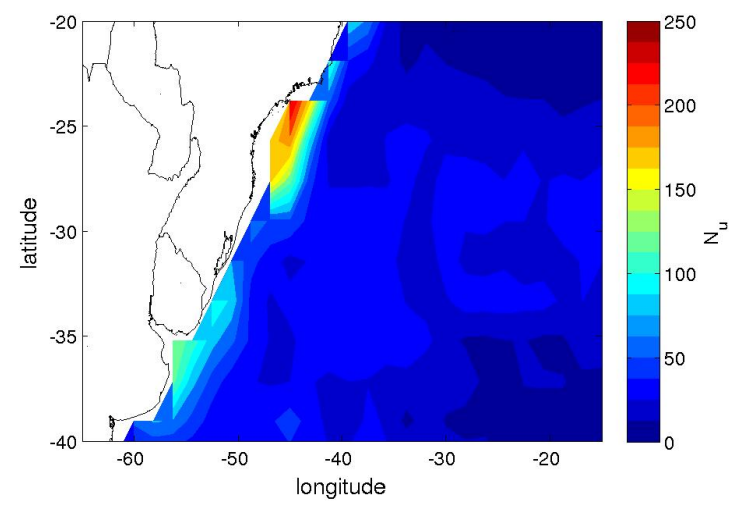

(a) NCEP

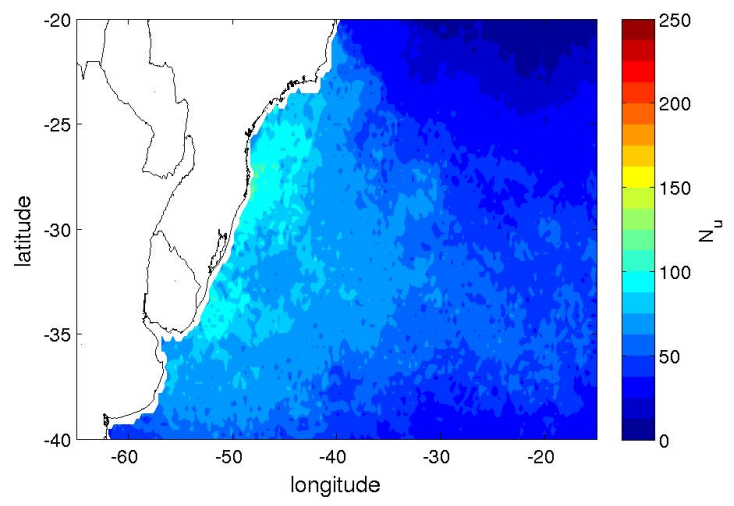

(b) BRAMS

Figura 3.16: Quantidade de eventos acima do limiar $\left(N_{u}\right)$ para ventos de sul. Região Sudeste/Sul.

Já os mapas de distribuição dos extremos de retorno encontram-se na figura 3.17. Para o NCEP nota-se amplas áreas de instabilidade do método pelo domínio. E, levando-se em consideração a grande ocorrência de extremos na zona costeira representada pelo mapa de distribuição de $N_{u}$, apenas um núcleo se destaca na costa sudeste, com intensidades que chegam a $25 \mathrm{~m} / \mathrm{s}$ para 50 anos de retorno. Além desse, destaca-se um núcleo na zona oceânica sul do domínio. Porém, como trata-se de uma região com baixo $N_{u}$, seu valor estatístico pode estar comprometido.

Para o BRAMS, no entanto, há um grande detalhamento dos extremos de retorno na zona costeira, com três núcleos bem definidos e de elevada intensidade. O primeiro localiza-se na zona costeira do litoral sudeste/sul com valores de $x_{r}$ atingindo $35 \mathrm{~m} / \mathrm{s}$ para 50 anos de retorno. Há outro núcleo estável na zona costeira do Rio Grande do Sul, com intensidade dos extremos atingindo $31 \mathrm{~m} / \mathrm{s}$. Um terceiro núcleo na região de desembocadura do Rio da Prata com va- 
lores extremo de retorno para 50 anos de aproximadamente $33 \mathrm{~m} / \mathrm{s}$. Todos esses três núcleos associam-se à passagem de frentes e formação de ciclones pela região, que acarretam em intensos ventos de sul nessas regiões. Por tais sistemas serem melhor resolvidos pela simulação de alta resolução, a diferença entre os mapas é justificável. 


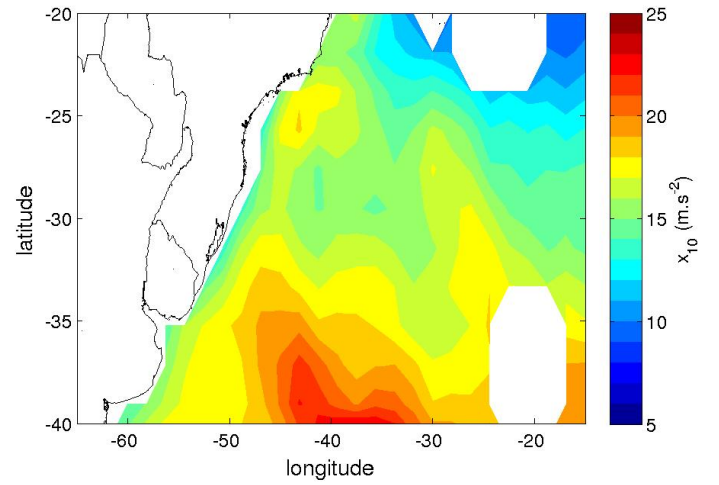

(a) NCEP - 10 anos

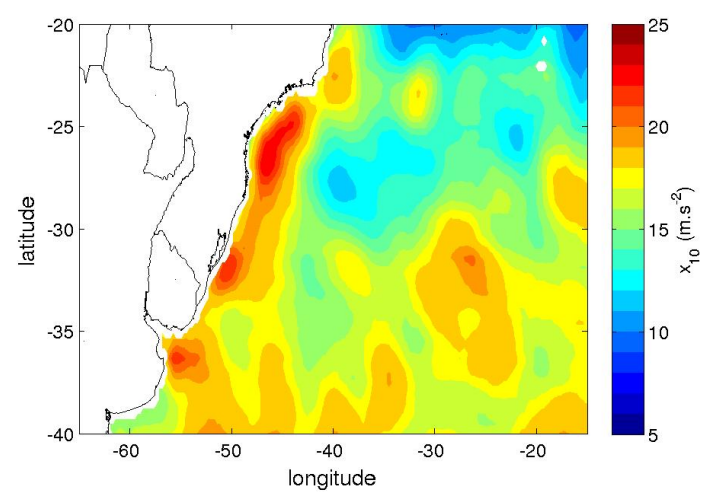

(d) BRAMS - 10 anos

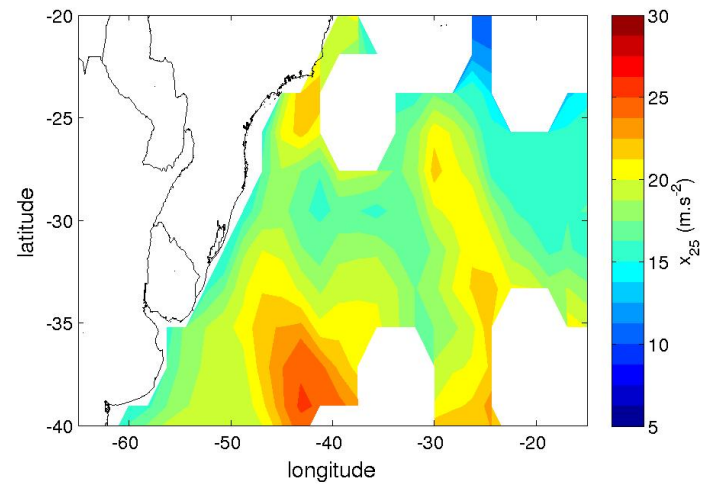

(b) NCEP - 25 anos

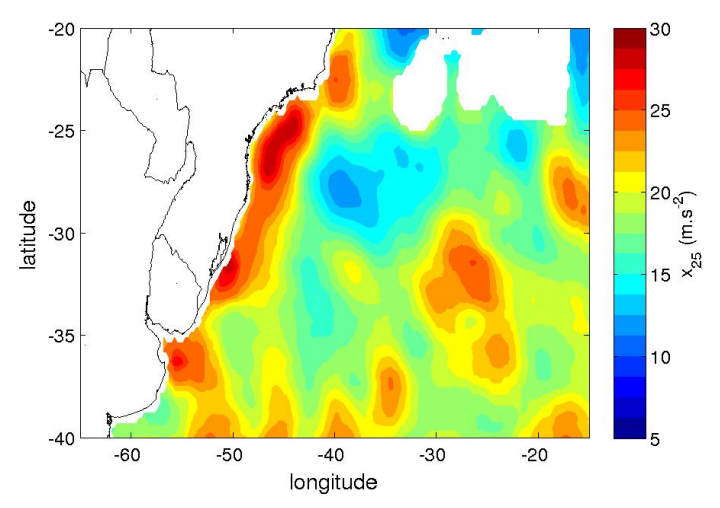

(e) BRAMS - 25 anos

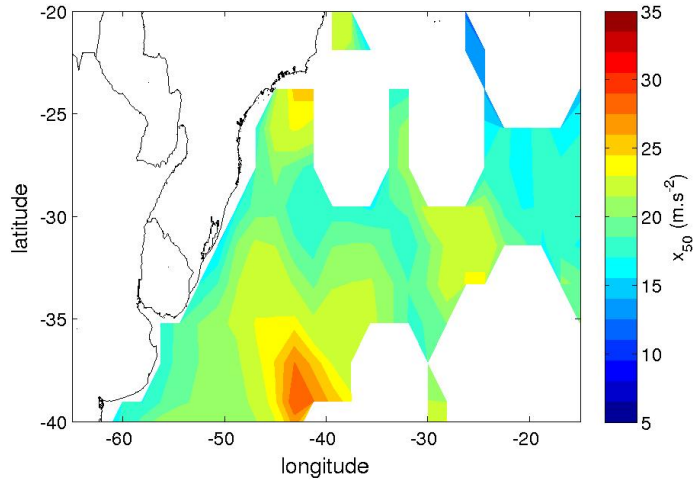

(c) NCEP - 50 anos

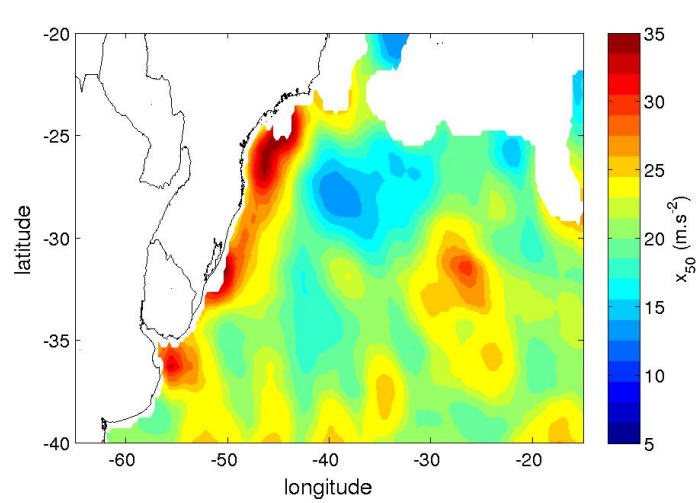

(f) BRAMS - 50 anos

Figura 3.17: Valores extremos de retorno para ventos de sul. Região Sudeste/Sul. 
Os eventos extremos de ventos de sudoeste, cuja distribuição encontra-se representada na figura 3.18, predominam na zona oceânica do extremo sul do domínio. Isso é verificado para ambos os conjuntos, sem grandes núcleos na zona costeira. Tais ocorrências relacionam-se com os ventos desse quadrante ligados ao escoamento de larga escala nessa zona do domínio.

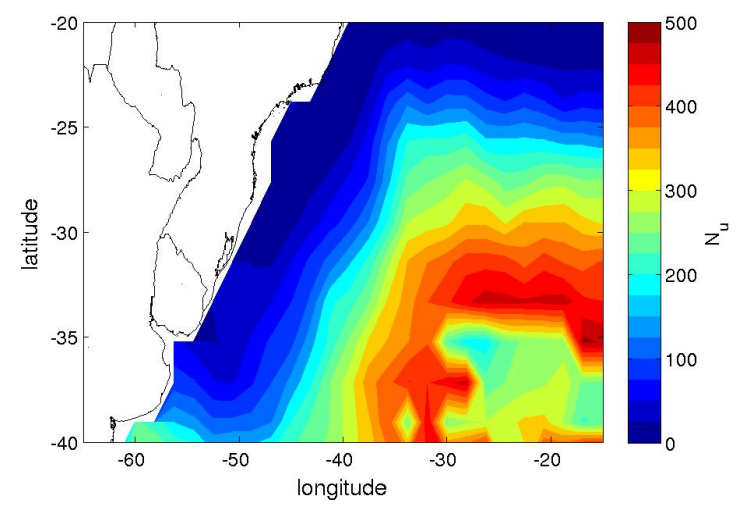

(a) NCEP

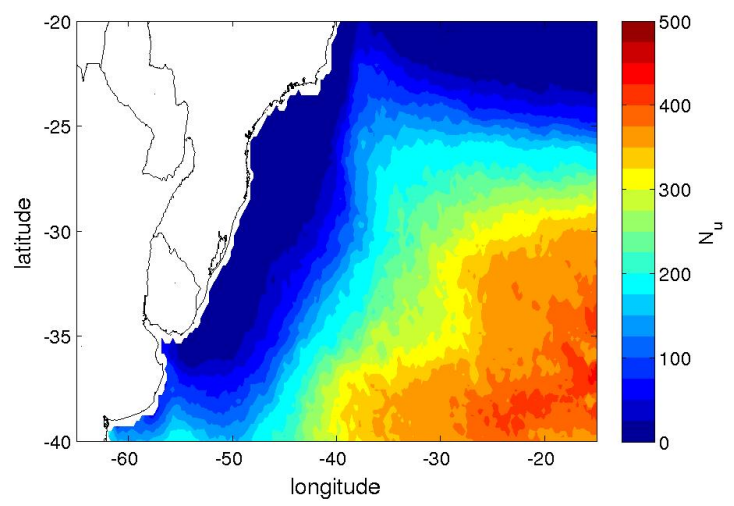

(b) BRAMS

Figura 3.18: Quantidade de eventos acima do limiar $\left(N_{u}\right)$ para ventos de sudoeste. Região Sudeste/Sul.

Os mapas extremos de retorno refletem o comportamento da distribuição de $N_{u}$ em ambos os conjuntos, com exceção de dois núcleos estáveis para o BRAMS mais próximos à zona costeira. O primeiro, em aproximadamente $35^{\circ} \mathrm{W}$ e $23^{\circ} \mathrm{S}$ com extremos de retorno atingindo $35 \mathrm{~m} / \mathrm{s}$ para 50 anos de retorno. Além dele, verifica-se outro núcleo no extremo sul da zona costeira do domínio em $51^{\circ} \mathrm{W}$ e $38^{\circ} \mathrm{S}$, com valores de $x_{r}$ atingindo $27 \mathrm{~m} / \mathrm{s}$. A quantidade de eventos acima do limiar disponível para análise nessas duas regiões é suficiente para maiores chances de sucesso na aplicação do método (aproximadamente 120 eventos em ambos os casos). Tais núcleos podem estar também associados aos ventos dos quadrantes sul/sudoeste ligados à passagem de sistemas frontais. 


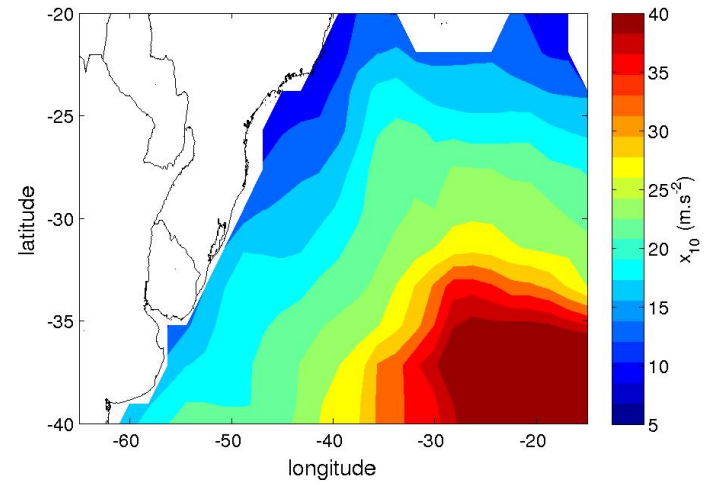

(a) NCEP - 10 anos

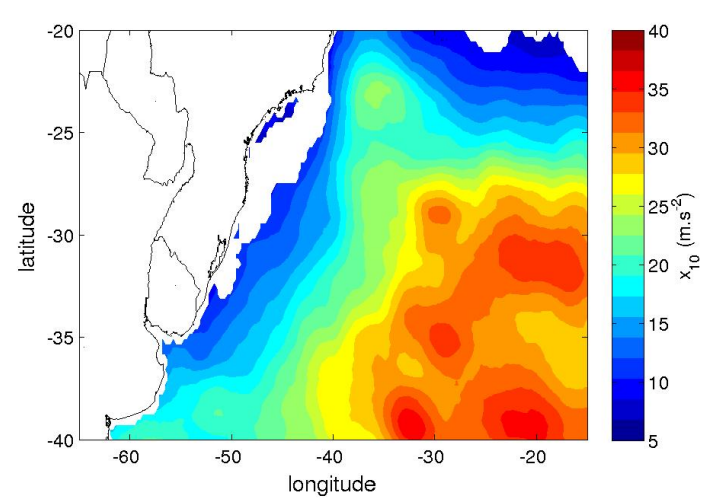

(d) BRAMS - 10 anos

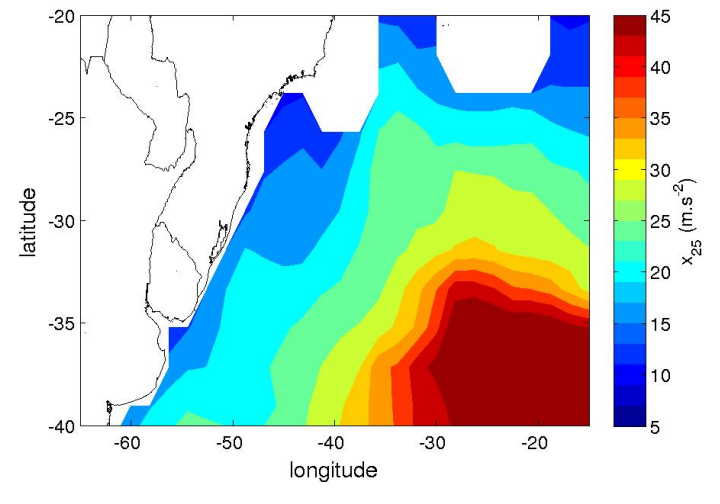

(b) NCEP - 25 anos

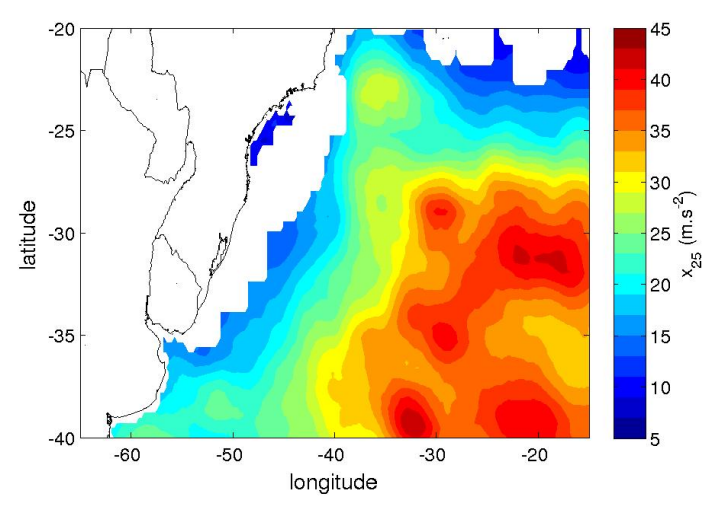

(e) BRAMS - 25 anos

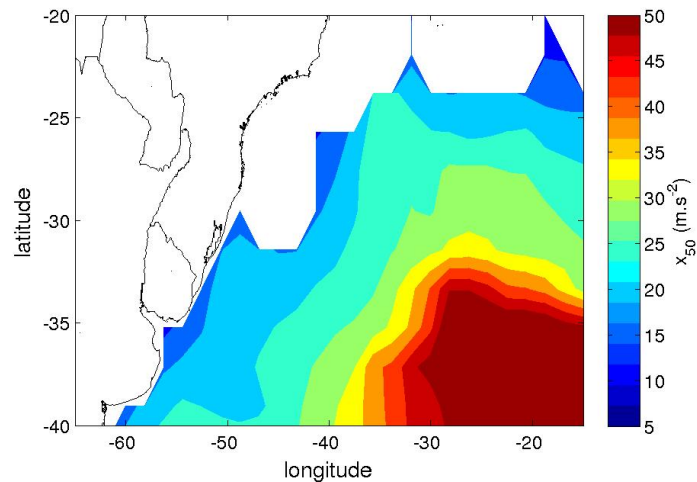

(c) NCEP - 50 anos

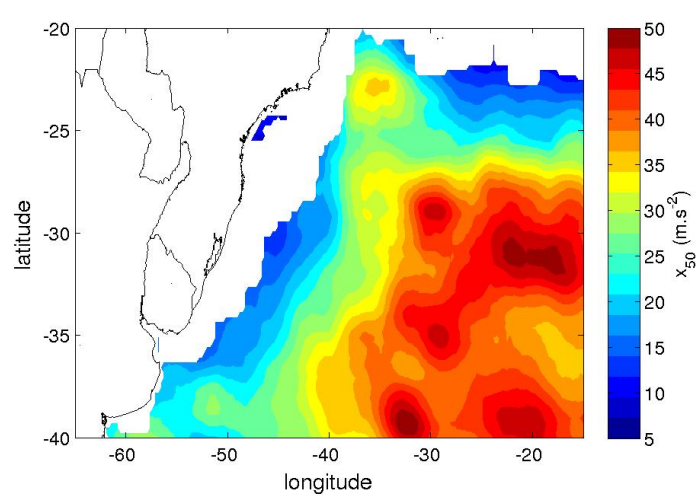

(f) BRAMS - 50 anos

Figura 3.19: Valores extremos de retorno para ventos de sudoeste. Região Sudeste/Sul. 
Eventos extremos de ventos de oeste são frequentes no extremo sul do domínio analisado, tendo em vista o escoamento de oeste em larga escala nessa região. Isso pode ser verificado pelos mapas de distribuição de $N_{u}$ presentes na figura 3.20. Diferentemente do que foi encontrado para outras direções, eventos na zona costeira predominam para o conjunto NCEP. No caso do BRAMS, a elevada quantidade de picos independentes acima do limiar no limite sul do domínio poderia estar envolvida com efeitos da borda do modelo.

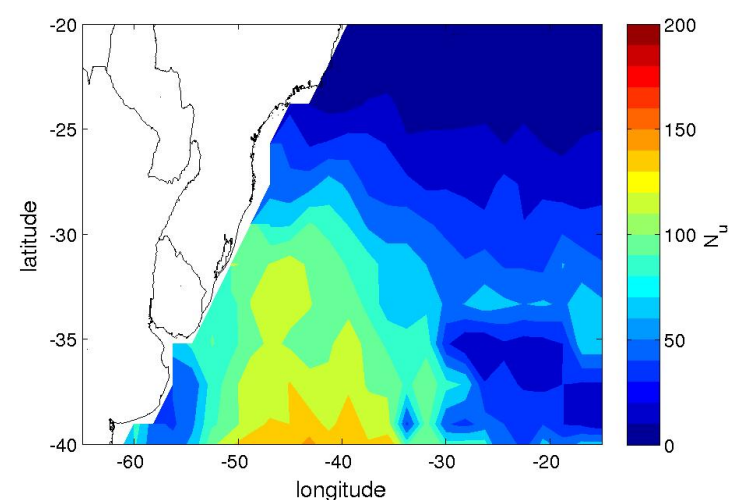

(a) NCEP

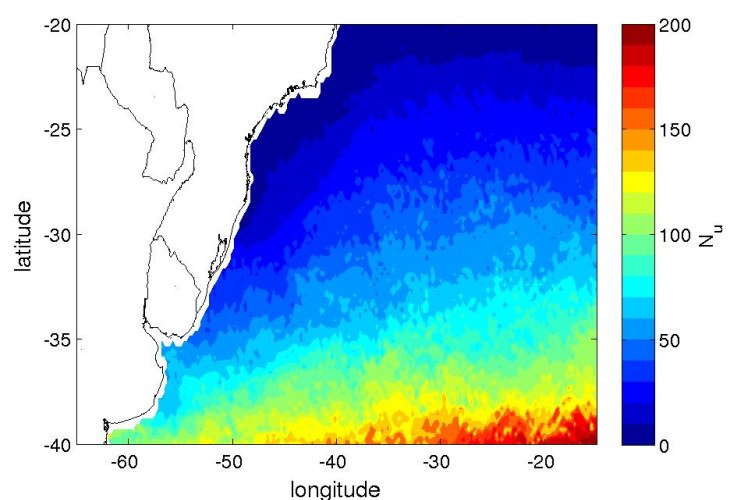

(b) BRAMS

Figura 3.20: Quantidade de eventos acima do limiar $\left(N_{u}\right)$ para ventos de oeste. Região Sudeste/Sul.

Os mapas de extremos de retorno para ventos de oeste encontram-se na figura 3.21. Como faltam quantidades adequadas de $N_{u}$ para análise em quase todo o domínio, muitas áreas de instabilidade estatística do método são verificadas nos mapas. Extremos de retorno muito intensos predominam na região próxima à costa quando são analisados os dados do NCEP. Já para o BRAMS, não são verificados núcleos estáveis próximos à costa, com os valores de retorno mais intensos presentes na porção oceânica ao extremo sul do domínio. Isso pode ser explicado pela representação do fluxo de oeste em larga escala sofrer poucas interferências de outras feições no caso do NCEP. Já para o BRAMS, uma série de outros fenômenos são resolvidos pelo modelo e carregados junto ao fluxo oeste de grande escala. 


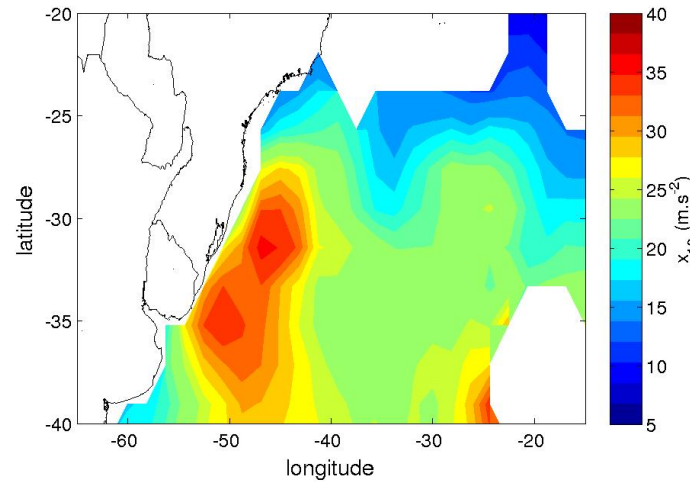

(a) NCEP - 10 anos

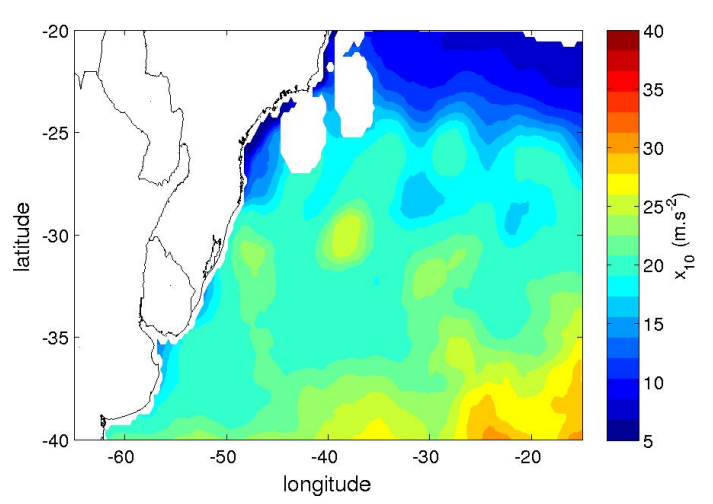

(d) BRAMS - 10 anos

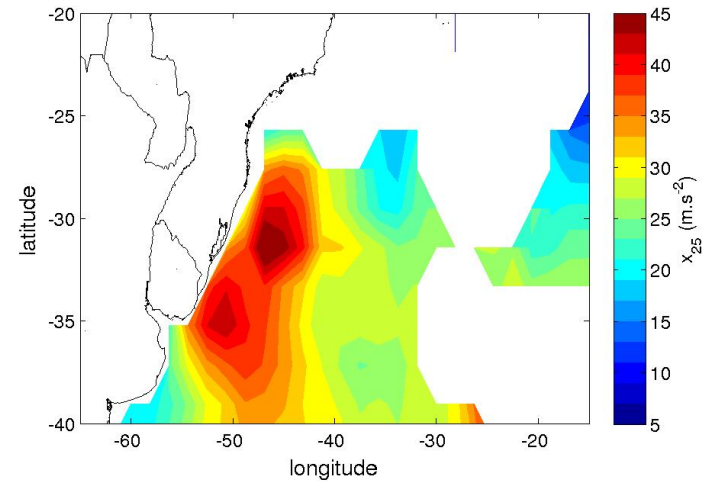

(b) NCEP - 25 anos

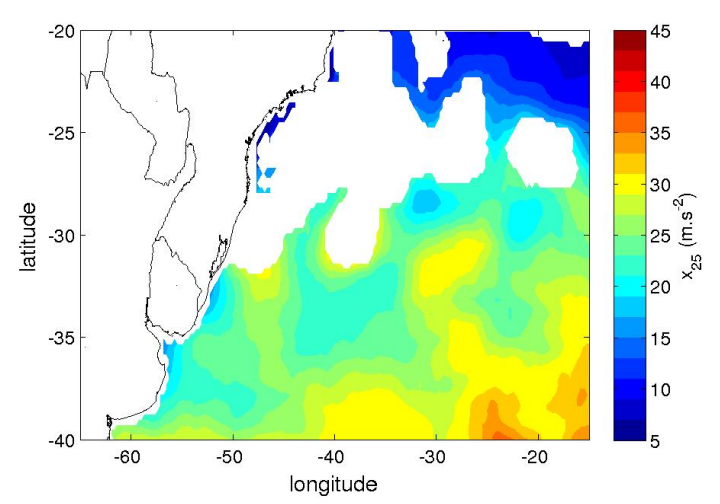

(e) BRAMS - 25 anos

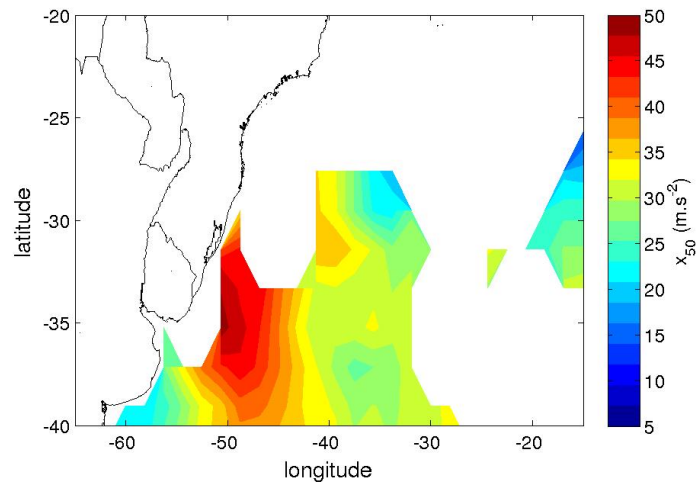

(c) NCEP - 50 anos

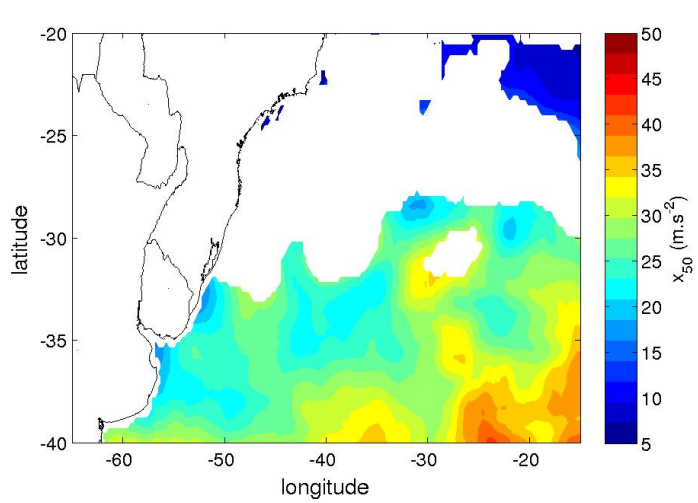

(f) BRAMS - 50 anos

Figura 3.21: Valores extremos de retorno para ventos de oeste. 
Por fim, têm-se os eventos extremos vinculados à ventos de noroeste. A distribuição de $N_{u}$ para esse quadrante encontra-se na figura 3.22. Os mapas são bastante similares para ambos os conjuntos e apresentam dois núcleos de ocorrência bem definidos na zona costeira do domínio. O primeiro na costa norte do Rio Grande do Sul e outro no extremo sul da zona costeira do domínio.

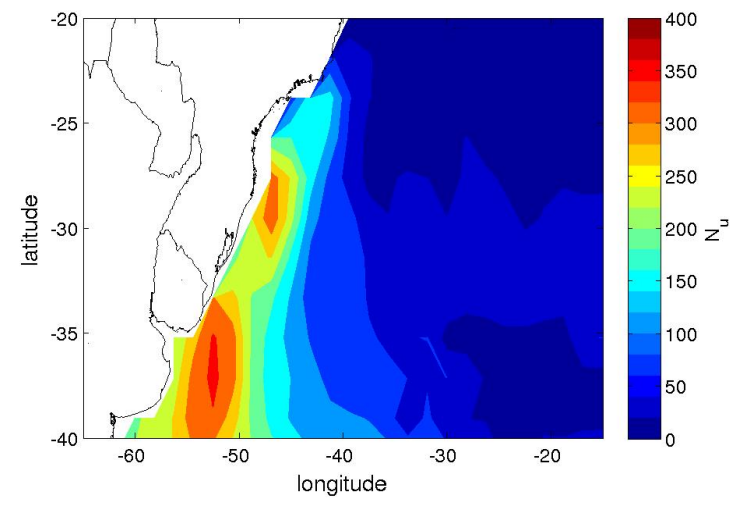

(a) NCEP

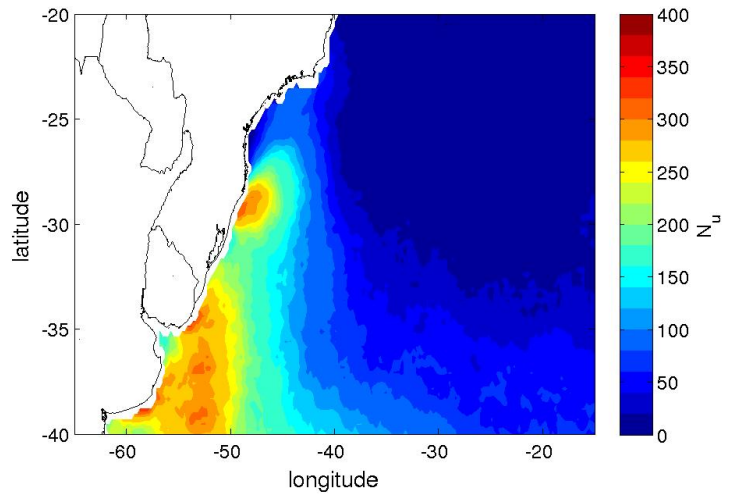

(b) BRAMS

Figura 3.22: Quantidade de eventos acima do limiar $\left(N_{u}\right)$ para ventos de noroeste. Região Sudeste/Sul.

Os extremos de retorno, visualizados na figura 3.23, coincidem com essas regiões de maior ocorrência. Nota-se que as intensidades no caso do BRAMS são significativamente maiores com relação ao NCEP, atingindo $45-50 \mathrm{~m} / \mathrm{s}$ para 50 anos de retorno no primeiro e $35-40 \mathrm{~m} / \mathrm{s}$ no segundo. Esses núcleos coincidem com a representação apresentada por Reboita (2008), que indicam tais regiões como favoráveis à ocorrência de ciclogênese. E ventos desse quadrante podem ser favorecidos por uma configuração composta por um centro de alta pressão ao norte e baixa pressão ao sul. Configuração esta, de frequente ocorrência na região. As maiores intensidades no caso do downscaling podem estar relacionadas também à maior ocorrência desses eventos no conjunto do BRAMS. 


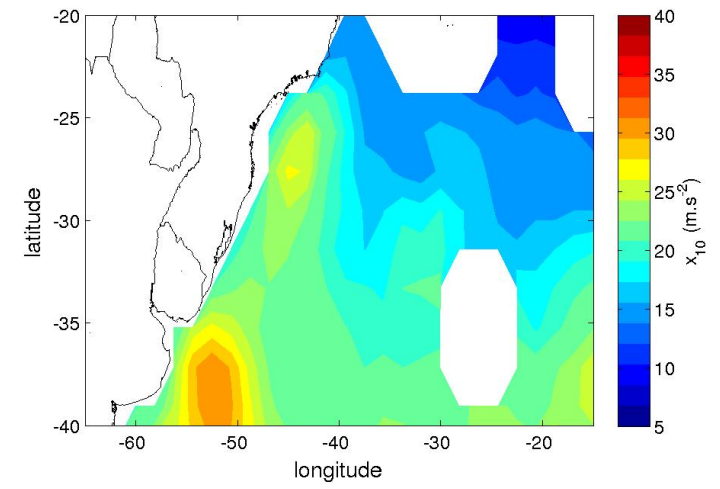

(a) NCEP - 10 anos

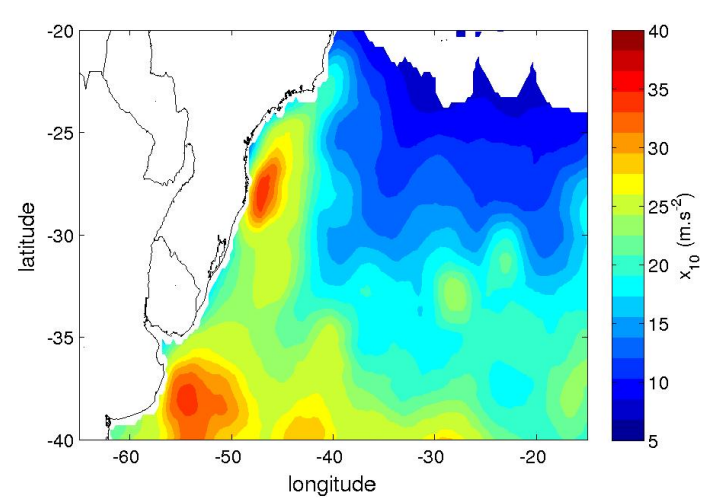

(d) BRAMS - 10 anos

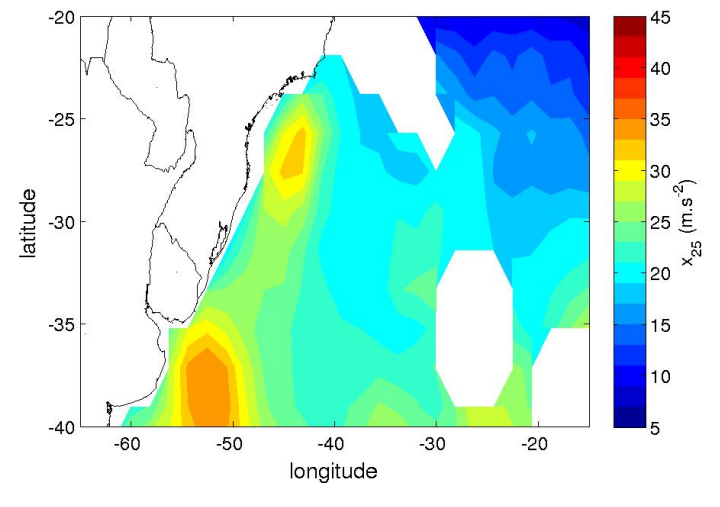

(b) NCEP - 25 anos

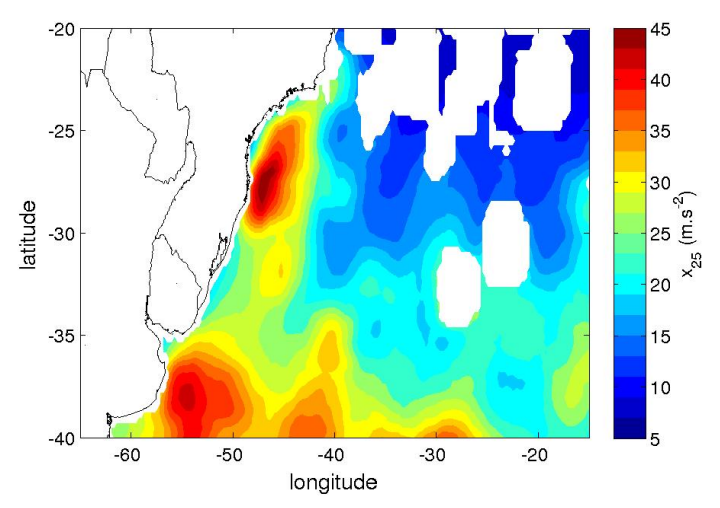

(e) BRAMS - 25 anos

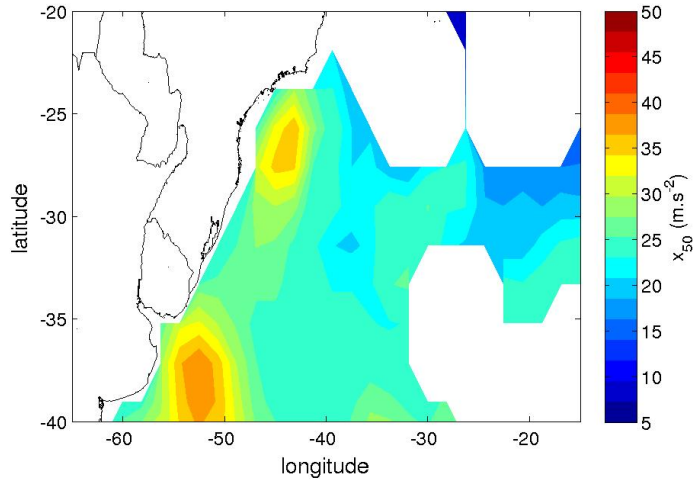

(c) NCEP - 50 anos

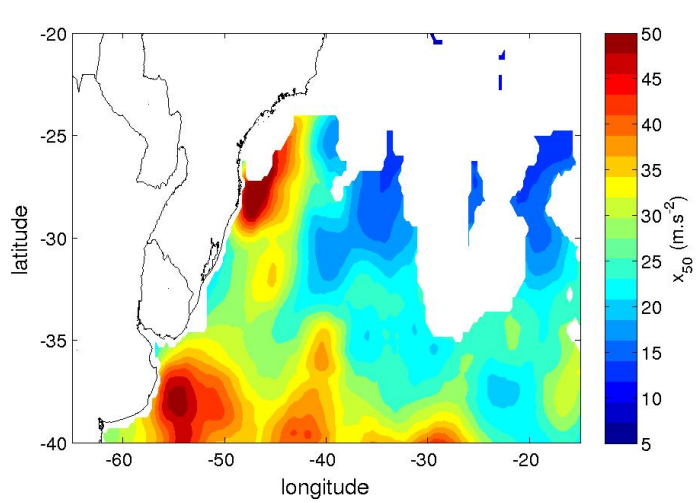

(f) BRAMS - 50 anos

Figura 3.23: Valores extremos de retorno para ventos de noroeste. Região Sudeste/Sul. 


\subsection{Comparação Qualitativa com Análise Feita a Partir de Dados Coletados}

A base de dados que fundamentou a análise de extremos exposta pelo relatório técnico CENPES/PDP/MCPETROBRAS (2005) provém de uma série de dados coletados in situ na região da Bacia de Campos. A localização exata e os períodos de coleta dos dados não encontram-se divulgados no documento. Os resultados para os extremos de intensidade do vento por quadrante são sumarizados na tabela 3.1 .

Tabela 3.1: Valores extremos para 50 anos de retorno para ventos de diferentes quadrantes na Bacia de Campos/RJ. Valores METOCEAN DATA extraídos de CENPES/PDP/MC-PETROBRAS (2005) e $x_{r}$ máximo aproximado na região da Bacia de Campos para NCEP e BRAMS

\begin{tabular}{lccc} 
Direção & METOCEAN & NCEP & BRAMS \\
\hline \hline $\mathrm{N}$ & 26.94 & 39 & 27 \\
$\mathrm{NE}$ & 27.55 & 24 & 28 \\
$\mathrm{E}$ & 24.02 & 15 & 20 \\
$\mathrm{SE}$ & 26.21 & 20 & 24 \\
$\mathrm{~S}$ & 29.19 & 22 & 28 \\
$\mathrm{SW}$ & 29.45 & instável & instável \\
W & 29.64 & instável & 30 \\
NW & 23.28 & 22 & instável \\
\hline
\end{tabular}

Esses valores calculados indicam que os ventos extremos de retorno na Bacia de Campos calculados a partir dos dados do METOCEAN DATA possuem maiores intensidades nas direções S, SW e W. E ventos com $x_{r}$ mais fracos pertencem aos quadrantes E e NW. Já as direções N, NE e SE encontram-se numa faixa intermediária com extremos de retorno de moderados a fortes. Tais valores, quando comparados com os resultados obtidos com o NCEP, são bastante divergentes de uma maneira geral. Já no caso do BRAMS, muito embora os valores encontrados para os extremos de retorno na região da Bacia de Campos sejam, em geral, menos intensos do que os descritos em CENPES/PDP/MC-PETROBRAS (2005), seu comportamento é similar. Sendo os extremos de retorno mais intensos para ventos provenientes dos quadrantes $\mathrm{S}$ e W e os menos intensos para o quadrante E, com as séries de eventos das demais direções garantindo valores de $x_{r}$ intermediários. Os valores de $x_{r}$ são instáveis para as direções $\mathrm{SW}$ e W.

Essa comparação é meramente qualitativa e as divergências entre os valores encontrados podem 
ser justificadas por quaisquer diferenças de aplicação do método, tais como escolha do limiar, estimador, coordenadas das séries, período e duração das séries estudadas e equação para cálculo de $x_{r}$. Uma comparação direta entre medições e séries do modelo nos mesmos pontos seria oportuna para a devida avaliação da maneira como o downscaling representa os extremos nessa importante área de atuação industrial. 


\section{Conclusões}

Para o estudo dos extremos de vento sobre o Oceano Atlântico Sul, a técnica de análise Peaks Over Threshold foi aplicada a dois conjuntos de dados: a base de reanálise NCEP/NCAR Reanalysis 1 e um downscaling com o modelo BRAMS, cujas condições iniciais foram oferecidas por esse mesmo conjunto de reanálise. A simulação foi construída e configurada de tal forma a oferecer um maior detalhamento dos fenômenos atmosféricos em escala sub-sinótica, influenciados diretamente pelas feições presentes no NCEP. Sendo assim, o downscaling buscou não negligenciar os campos de larga escala dados pelo NCEP, mas sim aprimorar seu detalhamento.

O estudo dos extremos de vento sobre os dois conjuntos levou em consideração as diferentes direções dos ventos intensos, algo apenas analisado em séries individuais medidas (CENPES/PDP/MCPETROBRAS, 2005).

Muito embora a técnica aplicada necessite de grande interatividade com o usuário, através da escolha dos limiares e estimadores, a fixação desses parâmetros não parece ter comprometido a análise estatística em pontos-chave para a elaboração da discussão entre o vínculo intensidade extrema-fenômeno gerador. Além disso, o cálculo dos valores extremos de retorno mostrou-se satisfatório para até 50 anos, uma vez que feições importantes foram destacadas nos resultados. Mesmo com a utilização de uma metodologia que leva em consideração um número de eventos independentes anuais constante ao longo dos anos.

Mapas de distribuição de valores de retorno de extremos do vento direcionalmente segregados não possuem registro na bibliografia. Trabalhos que trataram o mapeamento de $x_{r}$ para a intensidade do vento, porém sem distinção direcional, foram feitos por Caires e Sterl (2005), Vinoth e Young (2011). Nesse trabalho, algumas correspondências foram encontradas com 
os resultados dos trabalhos supracitados. Uma dessas correspondências está na intensidade dos extremos de retorno que, de uma maneira geral, não se distanciaram do encontrado anteriormente nesses trabalhos supracitados. Relembrando o mapa com os resultados obtidos por Vinoth e Young (2011), apresentado no capítulo 1, detalhado para a mesma região de estudo do presente trabalho na figura 4.1, nota-se algumas regiões com valores extremos de retorno bastante intensos com correspondências aos resultados encontrados no presente trabalho. $\mathrm{Na}$ figura de Vinoth e Young (2011), nota-se um núcleo com extremos de retorno elevados na região costeira norte/nordeste. No presente trabalho, os valores de $x_{r}$ elevados nessa região associam-se a ventos de leste e nordeste. Outro núcleo com alta intensidade encontra-se na região costeira nordeste/sudeste, cujas direções predominantes pertencem aos quadrantes sudeste e leste. Já no extremo sul, os esforços de Vinoth e Young (2011) acarretam na formação de núcleos com elevada intensidade na zona costeira do Rio Grande do Sul e na região de divisa Uruguai/Argentina.

Tais regiões foram vinculadas, pelos estudos direcionais do presente trabalho, à ventos de diferentes quadrantes associados a diferentes fenômenos: extremos de leste associados a ZCIT, ASAS e perturbações de leste. Ventos extremos de nordeste, na região norte do domínio, ligados à atividade da ZCIT e potenciais geradores de linhas de instabilidade, além de efeitos da circulação de brisa. Ainda na porção norte do domínio, extremos de sudeste mostram-se relacionados a atividade da ASAS e, em alguns núcleos extremos na zona costeira, suspeita-se da contribuição da circulação de brisa. Na porção sul do domínio, extremos de retorno para ventos da direção norte divergiram de acordo com o conjunto de dados, para o NCEP predomiram extremos na zona costeira sudeste, pela persistência do ramo oeste da ASAS, e para o BRAMS na zona costeira do extremos sul do Brasil, favorecidos pela pista de vento que essa região proporciona. Ventos extremos de nordeste na região sul do domínio mostram-se destacados na zona costeira do sul do Brasil, cuja persistência é favorecida pela pista de vento construída pela orientação da linha de costa. Extremos de retorno para ventos das direções leste e sudeste predominaram na zona costeira sudeste/sul do Brasil, especialmente para os resultados com a simulação do BRAMS, o que indica a atuação da circulação de brisa na região, além de eventos de 
rotação do vento pela passagem de um sistema frontal. Notaram-se extremos de retorno intensos para ventos de sul ao longo de toda a zona costeira sudeste/sul, em maior número no conjunto do BRAMS, ocasionados pela passagem de sistemas frontais e incidência de ciclones representados com maior detalhamento pelo downscalling. Extremos gerados por eventos de ventos de noroeste foram encontrados em ambos os conjuntos nas mesmas regiões, provavelmente ligados a configuração de centros de alta e baixa pressão favoráveis à formação de ventos dessa direção e a situações pré-frontais.

O downscaling obtido pela simulação com o modelo BRAMS ofereceu uma visão mais detalhada do comportamento dos extremos, tendo em vista a inclusão de fenômenos em escala sub-sinótica na análise. Em muitos casos, esse aumento na resolução acarretou em extremos menos intensos para o downscaling com relação ao NCEP, uma vez que os fluxos intensos de grande escala foram espalhados pela presença de novos fenômenos resolvidos, como foi verificado para ventos de norte, nordeste, sudeste e leste. Já em outros casos, os extremos de retorno calculados pela análise do conjunto do BRAMS foram mais intensos, muito provavelmente pela inclusão de estruturas atuantes na intensificação das feições geradoras dos extremos nas direções sul e noroeste.

Essas marcantes diferenças foram auxiliadas pelo maior detalhamento entre as zonas oceânicas e continentais dado pelo aumento na resolução pelo modelo BRAMS. No caso do NCEP, como os pontos vizinhos encontram-se a grandes distâncias entre si, a transição continente e oceano foi abrupta e sem grandes detalhamentos. Isso indica que, estudos voltados ao comportamento dos eventos extremos na zona costeira, cujo investimento vem crescendo nos últimos anos, carecem de conjuntos de dados com maior resolução para uma representação adequada dos extremos de retorno. 


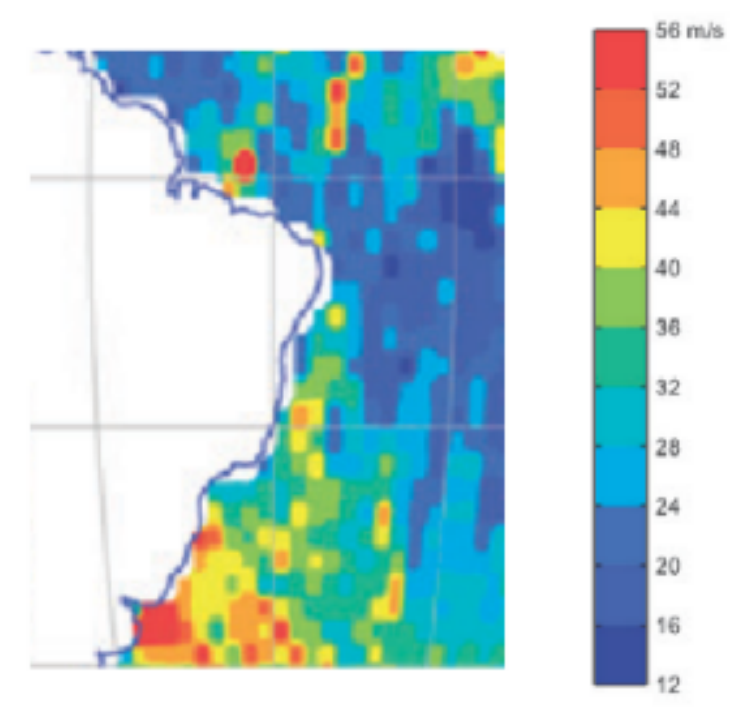

Figura 4.1: Valores extremos de retorno para 100 anos calculados por Vinoth e Young (2011). Adaptado para foco sobre o Oceano Atlântico Sul.

\subsubsection{Sugestões Para Trabalho Futuros}

As dificuldades encontradas na elaboração do presente trabalho permitem as seguintes inferências para aprimoramento de trabalhos futuros com o mesmo foco de análise:

Um aprimoramento nesse cálculo, que leve em consideração as oscilações anuais na quantidade de eventos independentes, pode oferecer estabilidade para cálculos de extremos de retorno para períodos mais longos.

1. A problemática para a escolha de um limiar ótimo para a efetuação dessa análise é conhecida e outros esforços devem ser levados em consideração para trabalhos futuros. Deve ser feito um aprimoramento para a escolha desse limiar e outros estimadores para a aplicação do método. Algumas ferramentas estatísticas que levem em consideração a homogeneidade espacial dos conjuntos de dados, como métodos da Regional Frequency Analysis, podem ser aplicados previamente à análise POT em si.

2. Outro fator que pode oferecer melhor insumo para análises aprofundadas é a modificação da equação de cálculo dos extremos de retorno de tal forma a incluir as oscilações anuais na quantidade de eventos extremos independentes, e não apenas considerá-los constantes 
ao longo dos anos.

3. Como a resolução do conjunto de dados mostrou-se de grande importância na análise da relação entre o fenômeno gerador e o extremo encontrado, o estudo de bases de reanálise com resolução mais refinada pode oferecer resultados mais sólidos.

4. O vínculo entre o valor extremo de retorno e seu fenômeno gerador pode ser objetivamente apontado com a elaboração de mapas para identificação dos sistemas atuantes no momento em que ocorreu o valor extremo.

5. A análise dos extremos em escala sazonal podem oferecer maior discernimento quanto às escalas temporais responsáveis pela maior incidência de eventos extremos. 


\section{Referências Bibliográficas}

ABILD, J.; ANDERSEN, E.; ROSBJERG, D. The climate of extreme winds at the great belt, Denmark. Journal of Wind Engineering and Industrial Aerodynamics, v. 41, n. 1-3, p. 521-532, out. 1992. ISSN 01676105. Disponível em: < http://linkinghub.elsevier.com/retrieve/pii/016761059290458M >.

ATKINSON, B. Meso-scale atmospheric circulations. [S.1.]: London Academic Press, 1981. 495 p., Chap. 5 \& 6. p.

BELITSKY, V.; MOREIRA, F. M. Emprego do Método "Peaks Over Threshold"na Estimação de Risco. In: Third Brazilian Conference on Statistical Modelling in Insurance and Finance. Maresias, São Paulo, Brasil: [s.n.], 2007. p. 116.

BRABSON, B. B.; PALUTIKOF, J. P. Tests of the Generalized Pareto Distribution for Predicting Extreme Wind Speeds. Journal of Applied Meteorology, v. 39, p. 1627-1640, 2000.

CAIRES, S.; STERL, A. 100-year return value estimates for ocean wind speed and significant wave height from the ERA-40 data. Journal of Climate, v. 18, p. 1032-1048, 2005. Disponível em: <http://journals.ametsoc.org/doi/abs/10.1175/JCLI-3312.1 >.

CAMPOS, R. M. Análise dos Extremos de Onda no Rio de Janeiro Associados a Ciclones Extratropicais no Atlântico Sul. 241 p. Dissertação (Mestrado) — Universidade Federal do Rio de Janeiro, Engenharia Oceânica. Universidade Federal do Rio de Janeiro, 2009.

CENPES/PDP/MC-PETROBRAS. Technical Specification "Metocean Data”, I-ET-3000.001000-941-PPC-001, Rev B. Rio de Janeiro, 2005. 85 p.

COHEN, J. et al. Linhas de Instabilidade na Costa N-NE da América do Sul. In: 2Tempo e Clima no Brasil. São Paulo: Oficina de Textos, 2009. cap. 5, p. 75 - 93.

COLES, S. G.; WALSHAW, D. Directional Modelling of Extreme Wind Speeds. Applied Statistics, v. 43, n. 1, p. 139, 1994. ISSN 00359254. Disponível em: <http://www.jstor.org/stable/2986118? origin $=$ crossref $>$.

COOK, N. Towards better estimation of extreme winds. Journal of Wind Engineering and Industrial Aerodynamics, v. 9, n. 3, p. 295-323, mar. 1982. ISSN 01676105. Disponível em: $<$ http://linkinghub.elsevier.com/retrieve/pii/0167610582900216>.

COTTON, W. R. et al. RAMS 2001: Current status and future directions. Meteorology and Atmospheric Physics, v. 82, n. 1-4, p. 5-29, jan. 2003. ISSN 0177-7971. Disponível em: $<$ http://www.springerlink.com/Index/10.1007/s00703-001-0584-9>.

EMBRECHTS, P.; KLüPPELBERG, C.; MIKOSCH, T. Modelling Extremal Events. Berlin, Heidelberg: Springer Berlin Heidelberg, 1997. (Stochastic Modelling and Applied Probability, v. 33). ISBN 978-3-540-60931-5. Disponível em: < http://www.springerlink.com/index/10$.1007 / 978-3-642-33483-2>$. 
FERREIRA, J.; Guedes Soares, C. Modelling distributions of significant wave height. Coastal Engineering, v. 40, n. 4, p. 361-374, jul. 2000. ISSN 03783839. Disponível em: $<$ http://linkinghub.elsevier.com/retrieve/pii/S0378383900000181>.

FERREIRA, J.; SOARES, C. An application of the peaks over threshold method to predict extremes of significant wave height. Journal of Offshore Mechanics and Arctic ..., v. 120, p. 165 - 176, 1998. Disponível em: <http://link.aip.org/link/?JMOEEX/120/165/1>.

FISHER, R. A.; TIPPETT, L. H. C. Limiting forms of the frequency distribution of the largest or smallest member of a sample. Mathematical Proceedings of the Cambridge Philosophical Society, v. 24, n. 02, p. 180, out. 1928. ISSN 0305-0041. Disponível em: $<$ http://www.journals.cambridge.org/abstractl_S0305004100015681>.

GAN, M. A.; RAO, V. B. Surface Cyclogenesis over South America. Monthly Weather Review, v. 119, n. 5, p. 1293-1302, maio 1991. ISSN 0027-0644. Disponível em: <http://journals.ametsoc.org/doi/abs/10.1175/1520-0493(1991)119<1293:SCOSA>2.0.CO;2>.

GUMBEL, E. J. Statistics of Extremes. New York: DOVER PUBLICATIONS, 1958. 400 p. ISBN 0486154483.

GUSCLLA, V. Estimation of Extreme Winds from ShortTerm Records. Journal of Structural Engineering, v. 117, n. 2, p. 375-390, fev. 1991. ISSN 0733-9445. Disponível em: $<$ http://ascelibrary.org/doi/abs/10.1061/(ASCE)0733-9445(1991)117:2(375)>.

HARRIS, I. Generalised Pareto methods for wind extremes. Useful tool or mathematical mirage? Journal of Wind Engineering and Industrial Aerodynamics, v. 93, n. 5, p. 341-360, maio 2005. ISSN 01676105. Disponível em: < http://linkinghub.elsevier.com/retrieve/pii/S0167610505000231>.

HOSKING, J. R.; WALLIS, J. R. Parameter and Quantile Estimation for the Generalized Pareto Distribution. Technometrics, v. 29, n. 3, p. 339-349, ago. 1987. ISSN 0040-1706. Disponível em: <http://www.tandfonline.com/doi/abs/10.1080/00401706.1987.10488243>.

KALNAY, E. et al. The NCEP/NCAR 40-Year Reanalysis Project. Bulletin of the American Meteorological Society, v. 77, n. 3, p. $437-471,1996$.

LEADBETTER, M. On a basis for 'Peaks over Threshold' modeling. Statistics \& Probability Letters, v. 12, n. 4, p. 357-362, out. 1991. ISSN 01677152. Disponível em: $<$ http://linkinghub.elsevier.com/retrieve/pii/0167715291901073>.

MACHADO, L. A. T. et al. Distúrbios Ondulatórios de Leste. In: Tempo e Clima no Brasil. São Paulo: Oficina de Textos, 2009. cap. 4, p. 61 - 74.

MENDES, B. V. d. M. Introdução à Análise de Eventos Extremos. Rio de Janeiro: E-papers Serviços Editoriais, 2004. 232 p.

MORIARTY, W.; TEMPLETON, J. On the estimation of extreme wind gusts by direction sector. Journal of Wind Engineering and Industrial Aerodynamics, v. 13, n. 1-3, p. 127-138, dez. 1983. ISSN 01676105. Disponível em: < http://linkinghub.elsevier.com/retrieve/pii/0167610583901356>.

NEELEMANI, S. Influence of Threshold Value on Peak over Threshold Method on the Predicted Extreme Significant Wave Heights in Kuwaiti Territorial Waters. Journal of Coastal Research, n. Special Issue 56, p. 564 - 568, 2009. 
OLIVEIRA, M. M. F. et al. Generalized extreme wind speed distributions in South America over the Atlantic Ocean region. Theoretical and Applied Climatology, v. 104, n. 3-4, p. 377-385, out. 2010. ISSN 0177-798X. Disponível em: < http://www.springerlink.com/index/10.1007/s00704-010-0350-3>.

PALUTIKOF, J. P. et al. A review of methods to calculate extreme wind speeds. Meteorological Applications, v. 6, n. 2, p. 119-132, 1999.

PARENTE, C. E. Uma Nova Técnica Espectral para Análise Direcional de Ondas. Tese (Doutorado) - Universidade Federal do Rio de Janeiro, 1999.

REBOITA, M. S. o. Ciclones Extratropicais sobre o Atlântico Sul: Simulação Climática e Experimentos de Sensibilidade. 316 p. Tese (Doutorado) - Universidade de São Paulo, 2008.

SILVA, F. L. C. da. Investigações Sobre a Chegada de Ondulações (Swell) em Situações de Bom Tempo na Bacia de Campos. 84 p. Dissertação (Mestrado) - Universidade Federal do Rio de Janeiro, 2008.

SIMIU, E. "Generalized Pareto methods for wind extremes. Useful tool or mathematical mirage?" by Ian Harris. Journal of Wind Engineering and Industrial Aerodynamics, v. 95, n. 2, p. 133-136, fev. 2007. ISSN 01676105. Disponível em: <http://linkinghub.elsevier.com/retrieve/pii/S0167610506000675>.

SIMIU, E.; HECKERT, N. A. Extreme Wind Distribution Tails: A "Peaks over Threshold" Approach. Journal of Structural Engineering, v. 122, n. 5, p. 539-547, maio 1996.

ISSN 0733-9445. Disponível em: <http://ascelibrary.org/doi/abs/10.1061/(ASCE)07339445(1996)122:5(539)>.

SINCLAIR, M. R. An Objective Cyclone Climatology for the Southern Hemisphere. Monthly Weather Review, v. 122, n. 10, p. 2239-2256, out. 1994. ISSN 0027-0644. Disponível em: $<$ http://journals.ametsoc.org/doi/abs/10.1175/1520-0493(1994)122<2239:AOCCFT>2.0. $\mathrm{CO} ; 2>$.

VINOTH, J.; YOUNG, I. R. Global Estimates of Extreme Wind Speed and Wave Height. Journal of Climate, v. 24, n. 6, p. 1647-1665, mar. 2011. ISSN 0894-8755. Disponível em: $<$ http://journals.ametsoc.org/doi/abs/10.1175/2010JCLI3680.1>.

WAINER, I. et al. A Mudança do Clima e as Operações Offshore no Oceano Atlântico Sul : IVAM-OAS - Downscaling Atmosférico. [S.1.], 2013. 